\title{
Hybrid Electric Vehicle Control Strategy Based on Power Loss Calculations
}

Steven J. Boyd

Virginia Polytechnic Institute and State University

Master of Science

Mechanical Engineering

Committee:

Dr. Douglas Nelson

Dr. Michael Ellis

Dr. Charles Reinholtz

August 28, 2006

Blacksburg, Virginia

Keywords: hybrid electric vehicle, control strategy, efficiency, split parallel architecture, E85

Copyright 2006, Steven J. Boyd 


\title{
Hybrid Electric Vehicle Control Strategy Based on Power Loss Calculations
}

Steven J. Boyd

\begin{abstract}
Defining an operation strategy for a Split Parallel Architecture (SPA) Hybrid Electric Vehicle $(\mathrm{HEV})$ is accomplished through calculating powertrain component losses. The results of these calculations define how the vehicle can decrease fuel consumption while maintaining low vehicle emissions. For a HEV, simply operating the vehicle's engine in its regions of high efficiency does not guarantee the most efficient vehicle operation. The results presented are meant only to define a literal strategy; that is, an understanding as to why the vehicle should operate in a certain way under the given conditions. The literature review gives a background of hybrid vehicle control publications, and without the SPA HEV addressed or a hybrid analysis based on loss calculations between engine only and hybrid modes, there is a need for this paper.

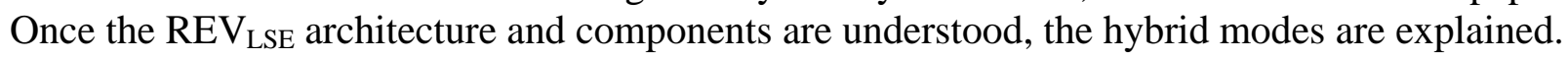
Then the losses for each hybrid mode are calculated, and both the conversion and assist efficiencies are detailed. The conversion efficiency represents the amount of additional fuel required to store a certain amount of energy in the battery, and this marginal efficiency can be higher than peak engine efficiency itself. This allows electric only propulsion to be evaluated against the engine only mode, and at low torques the electric motor is more efficient despite the roundtrip losses of the hybrid system.
\end{abstract}

\section{Acknowledgements}

I would like to acknowledge Dr. Doug Nelson and the students of the Hybrid Electric Vehicle Team of Virginia Tech for their contributions 


\section{Table of Contents}

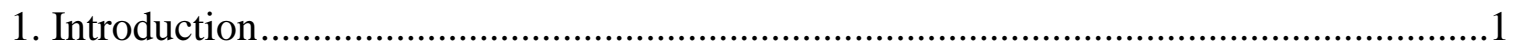

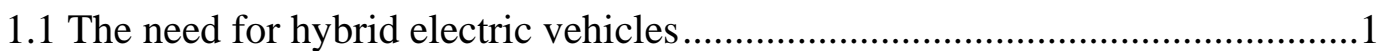

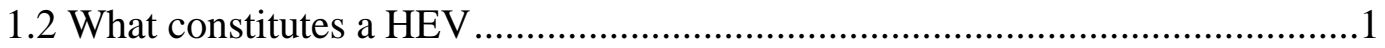

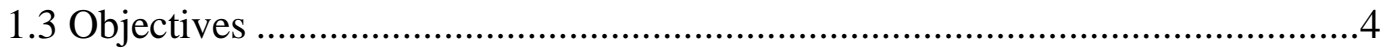

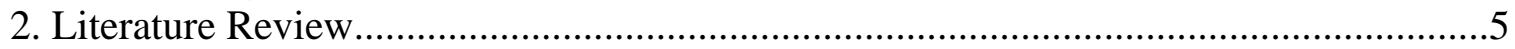

2.1 Toyota THS II paper ………………………..........................................

2.1.1 Fuel economy ……………………………………........................

2.1.2 Electrical accessories ......................................................................

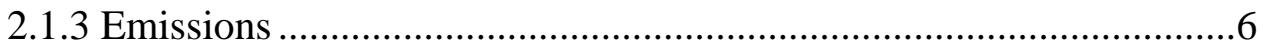

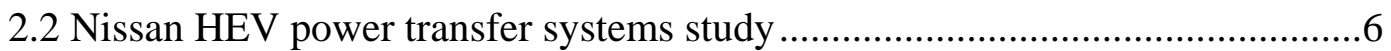

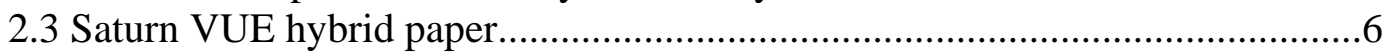

2.4 Saturn VUE hybrid model paper...........................................................................

2.5 NREL HEV control strategy paper ...............................................................

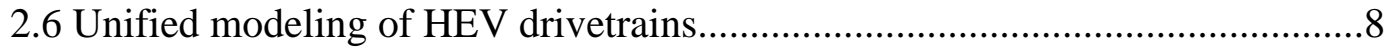

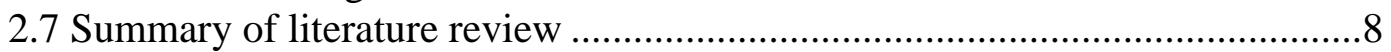

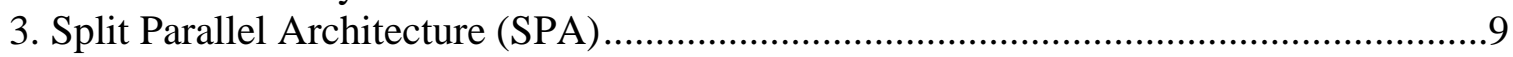

3.1 Introduction to the Challenge X competition......................................................

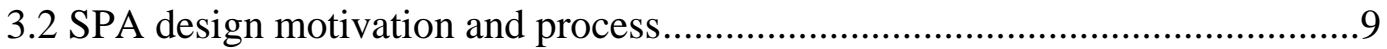

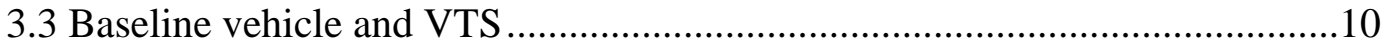

3.4 Fuel and powertrain selection ......................................................................11

3.5 Component sizing and selection ....................................................................12

3.6 Finalized component selection...........................................................................13

3.7 SPA hybrid vehicle design considerations.....................................................15

4. Relationship between Control Mode and Vehicle .........................................................17

4.1 Energy paths and hybrid modes ......................................................................17

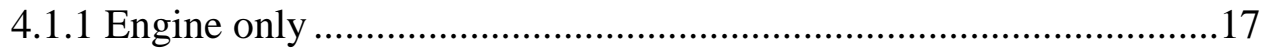

4.1.2 Engine generate ............................................................................17

4.1.3 Engine assist...............................................................................17

4.1.4 Electric only ................................................................................

4.1.5 Regenerative braking ......................................................................18

4.2 Meeting driver torque request .....................................................................19

4.2.1 Negative torque request .................................................................19

4.2.2 Positive torque request.....................................................................19

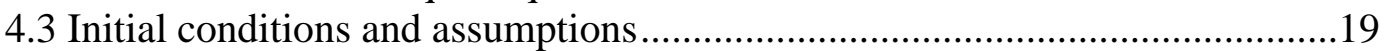

4.4 Specific component and vehicle considerations ……....................................20

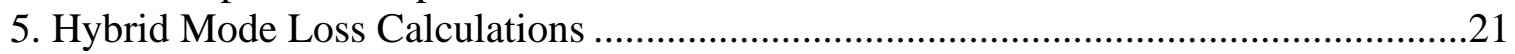

5.1 Engine only mode ....................................................................................21

5.1.1 Calculating fuel use..........................................................................21

5.2 Energy storage considerations and battery model ............................................23

5.2.1 Calculating battery losses ..............................................................23

5.2.2 Accounting for stored energy.........................................................24

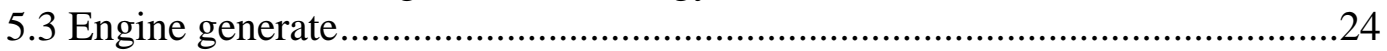

5.3.1 Calculating generate losses ..............................................................26 
5.3.2 Calculating conversion efficiency...................................................27

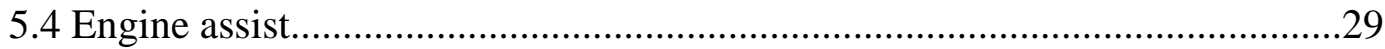

5.4.1 Calculating assist losses................................................................30

5.4.2 Calculating assist fuel and efficiency ................................................31

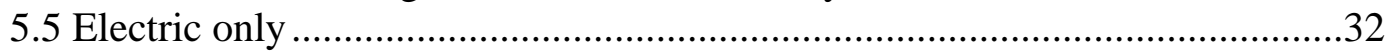

5.5.1 Calculating RTM losses....................................................................33

5.5.2 Calculating assist fuel and efficiency ……………............................34

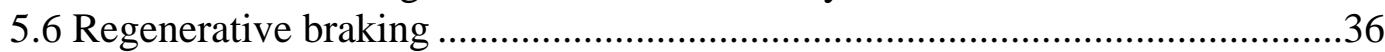

5.6.1 Calculating regenerative braking losses...........................................36

6. Practical Considerations for Analysis .............................................................................39

6.1 Defining the areas of normal engine operation.................................................39

6.2 Calculation of average conversion efficiency ...................................................40

6.3 Regenerative braking contributions to conversion efficiency ............................41

6.4 Impact of average conversion efficiency on assist efficiency ..........................42

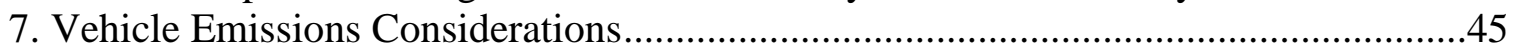

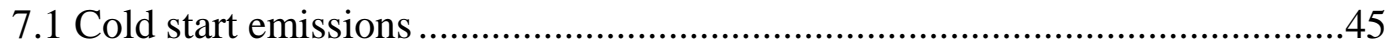

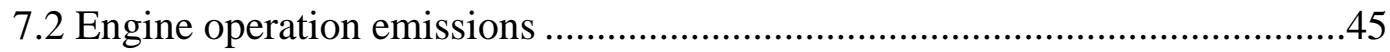

8. Overall Control Strategy ………………….............................................................47

8.1 Control strategy and operational areas..............................................................47

8.2 Analysis of control strategy over the UDDS ...............................................48

8.3 Future control strategy development ...........................................................49

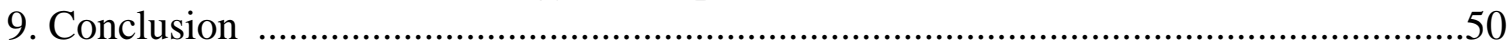

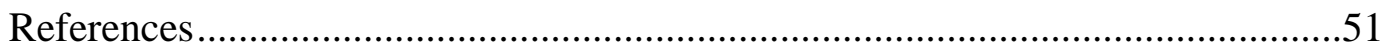

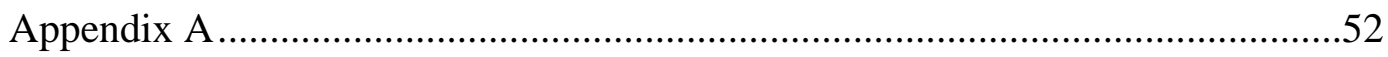

Vita 


\section{List of Multimedia Objects}

\section{Tables}

Table 1 Saturn VUE Hybrid modes ..............................................................................

Table 2 Stock Equinox general specifications .............................................................10

Table 3 Challenge X VTS ...........................................................................................11

Table $4 \quad$ Small displacement turbocharged engine comparison......................................13

Table 5 Equinox REV $_{\text {LSE }}$ design summary ................................................................15

Table 6 Available modes of operation ........................................................................19

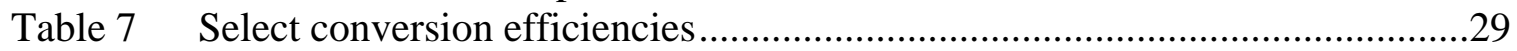

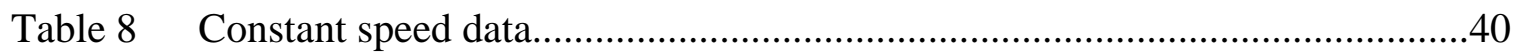

Table 9 Conversion efficiencies for specified torques and speeds ................................41

Table 10 Calculations for regenerative braking over the UDDS ....................................42

Table 11 Assist efficiencies with average conversion efficiency of 34\%.......................43

Table 12 Assist efficiencies with average conversion efficiency of 39\%.......................44

\section{Figures}

Figure 1 Typical engine fuel map............................................................................

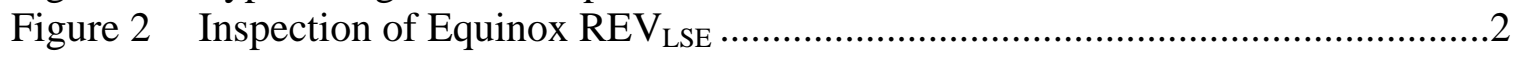

Figure 3 Example Hybrid Architectures …………….......................................................

Figure 4 Hydrogen storage in a 2002 Explorer ..............................................................12

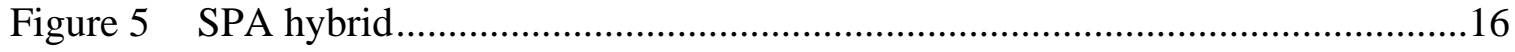

Figure 6 SPA energy flow diagram .......................................................................18

Figure 7 Engine only energy flow diagram.................................................................21

Figure 8 Engine only energy flow schematic.............................................................22

Figure 9 Engine efficiency contour plot........................................................................23

Figure 10 Comparison between BAS and RTM generate................................................25

Figure 11 Engine generate energy flow diagram ............................................................26

Figure 12 Engine generate energy flow schematic ....................................................27

Figure 13 Engine generate mode contour plot ................................................................28

Figure 14 Engine assist energy flow diagram ............................................................29

Figure 15 Engine assist energy flow schematic .............................................................30

Figure 16 Engine assist mode contour plot .....................................................................32

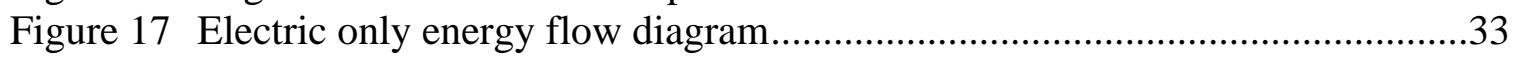

Figure 18 Electric only energy flow schematic...............................................................34

Figure 19 Electric only mode assist efficiency contour plot...............................................35

Figure 20 Regenerative braking energy flow diagram.....................................................36

Figure 21 Regenerative braking energy flow schematic ....................................................38

Figure 22 Conversion efficiency contour plot.....................................................................41

Figure 23 Assist efficiency contour plot based on 34\% conversion efficiency ................43

Figure 24 Assist efficiency contour plot based on 39\% conversion efficiency ................44

Figure 25 Estimated high emissions regions.....................................................................46 
Figure 26 Suggested operational mode areas ..........................................................48

Figure 27 Engine operational areas for Equinox over the UDDS .................................49

Figure 28 Engine operational areas for Equinox $\mathrm{REV}_{\mathrm{LSE}}$ over the UDDS ...................49

\section{Equations}

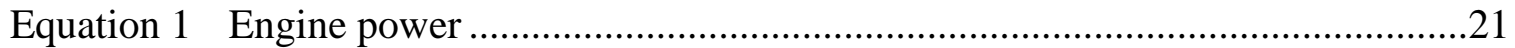

Equation 2 Engine fuel use................................................................................22

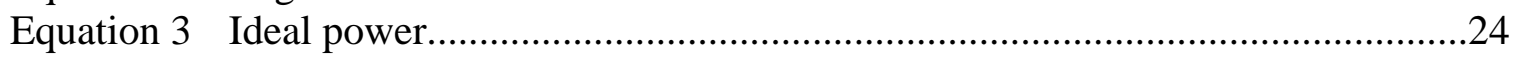

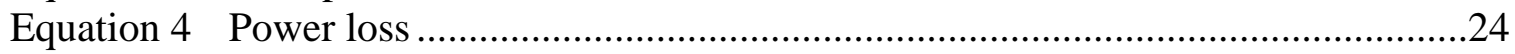

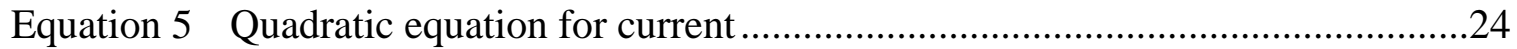

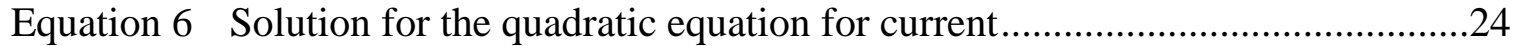

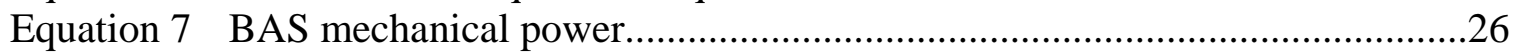

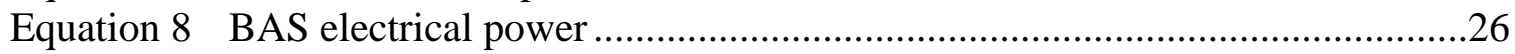

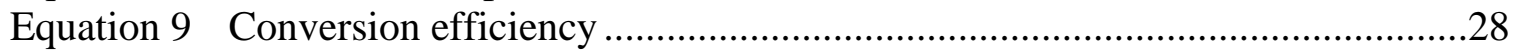

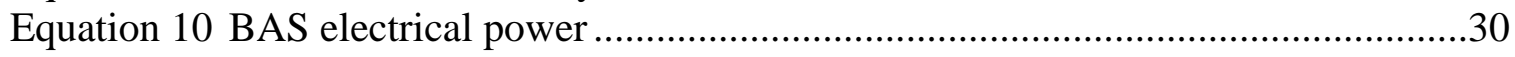

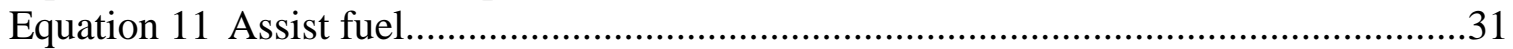

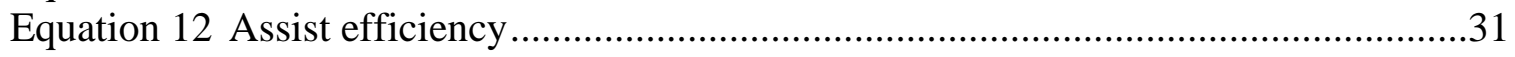

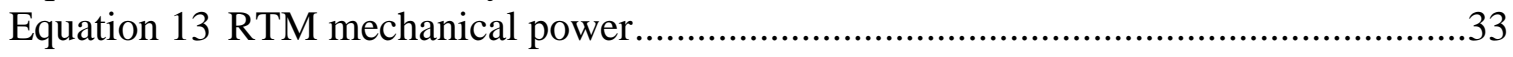

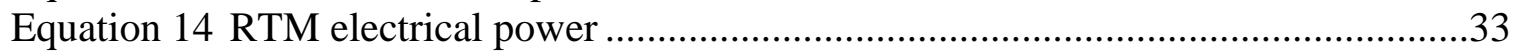




\section{Abbreviations}

$\begin{array}{ll}\Delta & \text { Delta (change) } \\ \text { A } & \text { Amperes } \\ \text { A/C } & \text { Air Conditioning } \\ \text { AC } & \text { Alternating Current } \\ \text { ADVISOR } & \text { Advanced Vehicle SimulatOR } \\ \text { Ah } & \text { Amp hours } \\ \text { ANL } & \text { Argonne National Laboratory } \\ \text { AT PZEV } & \text { Advanced Technology Partial Zero Emissions Vehicle } \\ \text { AVTC } & \text { Advanced Vehicle Technology Competition } \\ \text { BAS } & \text { Belted Alternator Starter } \\ \text { BSFC } & \text { Brake Specific Fuel Consumption } \\ \text { CVT } & \text { Continuously Variable Transmission } \\ \text { DC } & \text { Direct Current } \\ \text { DOE } & \text { U.S. Department of Energy } \\ \text { ECVT } & \text { Electronic Continuously Variable Transmission } \\ \text { ESS } & \text { Energy Storage System } \\ \text { FTP } & \text { Federal Test Procedure } \\ \text { GHG } & \text { GreenHouse Gases } \\ \text { GM } & \text { General Motors corporation } \\ \text { HEV } & \text { Hybrid Electric Vehicle } \\ \text { HEVT } & \text { The Hybrid Electric Vehicle Team of Virginia Tech } \\ \text { hp } & \text { horsepower } \\ \text { hr } & \text { hour } \\ \text { HWFET } & \text { HighWay Fuel Economy Test } \\ \text { kg } & \text { kilograms } \\ \text { km } & \text { kilometer } \\ \text { kW } & \text { kilowatts } \\ \text { lb } & \text { pound } \\ \text { lb-ft } & \text { pound-feet } \\ \text { MG } & \text { Motor Generator } \\ \text { mi } & \text { miles } \\ \text { mpgge } & \text { miles per gallon of gasoline equivalent energy } \\ \text { Nm } & \text { Newton meters } \\ \text { NREL } & \text { National Renewable Energy Laboratory } \\ \text { PNGV } & \text { Partnership for a New Generation of Vehicles } \\ \text { REV } & \text { Renewable Energy Vehicle, the Larsen Special Edition } \\ \text { rpm } & \text { revolutions per minute } \\ \text { RTM } & \text { Rear Traction Motor } \\ \text { s } & \text { seconds } \\ \text { SOC } & \text { State of Charge } \\ \text { SPA } & \text { Split Parallel Architecture } \\ \text { SUV } & \text { Sport Utility Vehicle } \\ & \end{array}$




$\begin{array}{ll}\text { THS II } & \text { Toyota Hybrid System II } \\ \text { TWC } & \text { Three Way Catalyst } \\ \text { UDDS } & \text { Urban Driving Dynamometer Schedule } \\ \text { US06 } & \text { Duty cycle with aggressive highway driving } \\ \text { V } & \text { Volts } \\ \text { VTS } & \text { Vehicle Technical Specifications } \\ \text { W } & \text { Watts }\end{array}$




\section{Introduction}

\subsection{The need for hybrid electric vehicles}

The primary fuel used for transportation in the United States is petroleum, a fossil fuel. Fossil fuels are non-renewable, and they release greenhouse gasses (GHG) and other harmful emissions into the atmosphere when burned. In his remarks to the 2006 Society of Automotive Engineers World Congress, Department of Energy Secretary Samuel Bodman said that the U.S. is “addicted to oil”, importing $60 \%$ of the oil we use, amounting to $\$ 250$ billion for last year alone [1]. To address this issue, hybrid electric vehicles have been introduced to the light-duty consumer vehicle market. These vehicles typically use a smaller engine combined with electric motor(s) and a battery pack to provide good performance and utility while improving vehicle fuel economy by $20 \%$ - 30\%. In the Saturn VUE hybrid paper, it is stated that "General Motors (GM) is pursuing near-term, mid-term, and long-term advanced propulsion technologies with the ultimate goal of removing the automobile from the environmental debate. Hybrid powertrains represent a core mid-term technology, and are already underway in GM's advanced propulsion technology plan” [2]. So hybrid electric vehicles represent a practical solution to reducing the amount of petroleum used for transportation, while further reducing vehicle emissions.

The Hybrid Electric Vehicle Team of Virginia Tech (HEVT) has developed a hybrid electric vehicle for the Advanced Vehicle Technology Competition (AVTC) series entitled "Challenge X: Crossover to Sustainable Mobility”, sponsored by General Motors (GM) and the U.S. Department of Energy (DOE). After a brief introduction to hybrid vehicle technology, the HEVT vehicle design named $\mathrm{REV}_{\mathrm{LSE}}$ (Renewable Energy Vehicle, the Larsen Special Edition) is introduced as the hybrid architecture specifically addressed in this thesis, although this approach to developing a control strategy could be employed for any hybrid vehicle.

\subsection{What constitutes a HEV}

A hybrid electric vehicle achieves higher fuel economy, reduced emissions, and good performance by combining a smaller than normal engine with electric motors and an energy storage system (ESS). The engine is smaller in displacement, or downsized, so that the average loads that the vehicle has to meet during accelerating and highway driving are closer to the engine's higher efficiency operating zones, represented in Figure 1 by higher efficiency percentages. One or two electric motors are used in a variety of ways, depending on how they are connected to the vehicle powertrain. Motors can provide a positive torque to propel the vehicle alone, or assist the engine to provide improved performance. When motors demand a negative torque, they act as generators to recharge the battery. This negative torque can be met through the engine, thus using fuel to recharge the ESS, or the negative torque can be used to help slow down the vehicle, referred to as regenerative braking. Power for the electric motors comes from the ESS, which is most commonly a battery, but can be other methods of energy storage such as ultracapacitors or flywheels. The ESS provides a source of power for the motors, as well as a source to store power the motors generate. Dr. John Miller's book, "Propulsion Systems for Hybrid Vehicles”, is a good resource for more information about hybrid vehicles, 
hybrid vehicle architectures, and component sizing [3]. Dr. Miller also participated as one of the Judges for Challenge X 2006, and he can be seen underneath the Equinox REV LSE in Figure 2.

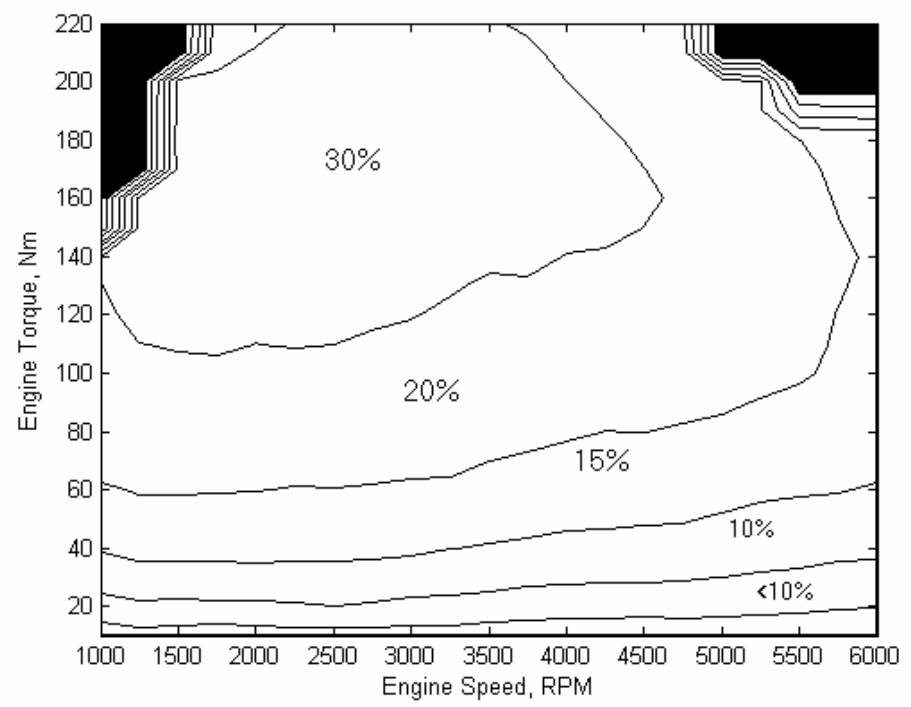

Figure 1. Typical engine efficiency map

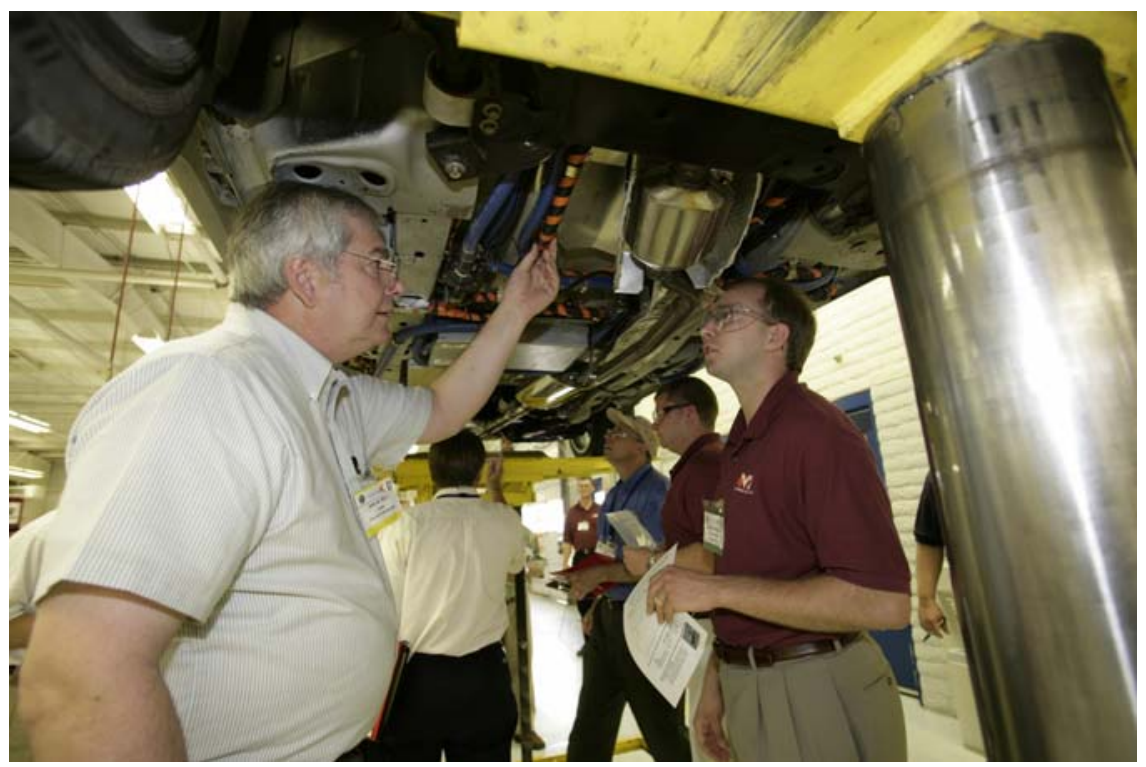

Figure 2. Dr. John Miller (left) inspecting the Equinox $\mathrm{REV}_{\mathrm{LSE}}$ at the 2006 Challenge $\mathrm{X}$ competition. Photo by Roy Feldman

In effect, a hybrid electric vehicle (HEV) uses the electric motors and ESS to average the load on the engine to achieve a more efficient use of fuel. As shown in Figure 1, fuel to the engine is used most efficiently at lower engine speeds ( 2000 RPM) and higher torques (>100 Nm). The black areas at the upper corners of Figure 1 show the "torque envelope" of the engine, where the engine cannot operate because it cannot produce enough torque at those speeds. Peak power demands on the engine, such as a hard acceleration, can be lowered by using the motors to supply some of the additional power required, and discharge the battery. Likewise, for low loads such as maintaining a constant speed, the electric motor can increase the load on the engine by 
acting as a generator to recharge the battery. Another way to increase the average load and decrease fuel use is to shut off the engine when the vehicle load is small. Commonly this is referred to as engine idle stop, but the engine can actually be shut off during braking and sometimes kept off for light accelerations and low steady speeds.

Hybrid vehicles can be "assembled" in different ways, referred to as hybrid architectures. The most common architectures are parallel and series hybrids. Figure 3 shows examples of these with a parallel belted alternator-starter (BAS) hybrid, parallel through-the-road hybrid, and a series hybrid. The different color lines represent energy (or power) transfer between the different powertrain components. A parallel BAS hybrid uses a single motor to provide either positive torque to the engine (or "assist") or negative torque and act as a generator. For either case, the engine needs to be spinning, so it is referred to as a parallel hybrid because the electrical and mechanical paths are in parallel. Similarly, the parallel "through the road" hybrid uses one motor for propulsion assist or to recharge the battery by loading the rear axle with the motor. In contrast, the series hybrid provides power to the wheels by a series path of energy conversion through the engine to the generator, battery, then the rear motor. Note that the series hybrid and through-the-road parallel hybrid can still propel the vehicle without the engine on, sourcing power for the rear motor from the battery. The Split Parallel Architecture (SPA) addressed in this paper combines these three architectures into one with a BAS motor, rear traction motor (RTM), and a transmission (see Figure 6, section 4.1). The "split" designation refers to the two parallel and one series path available to the vehicle.

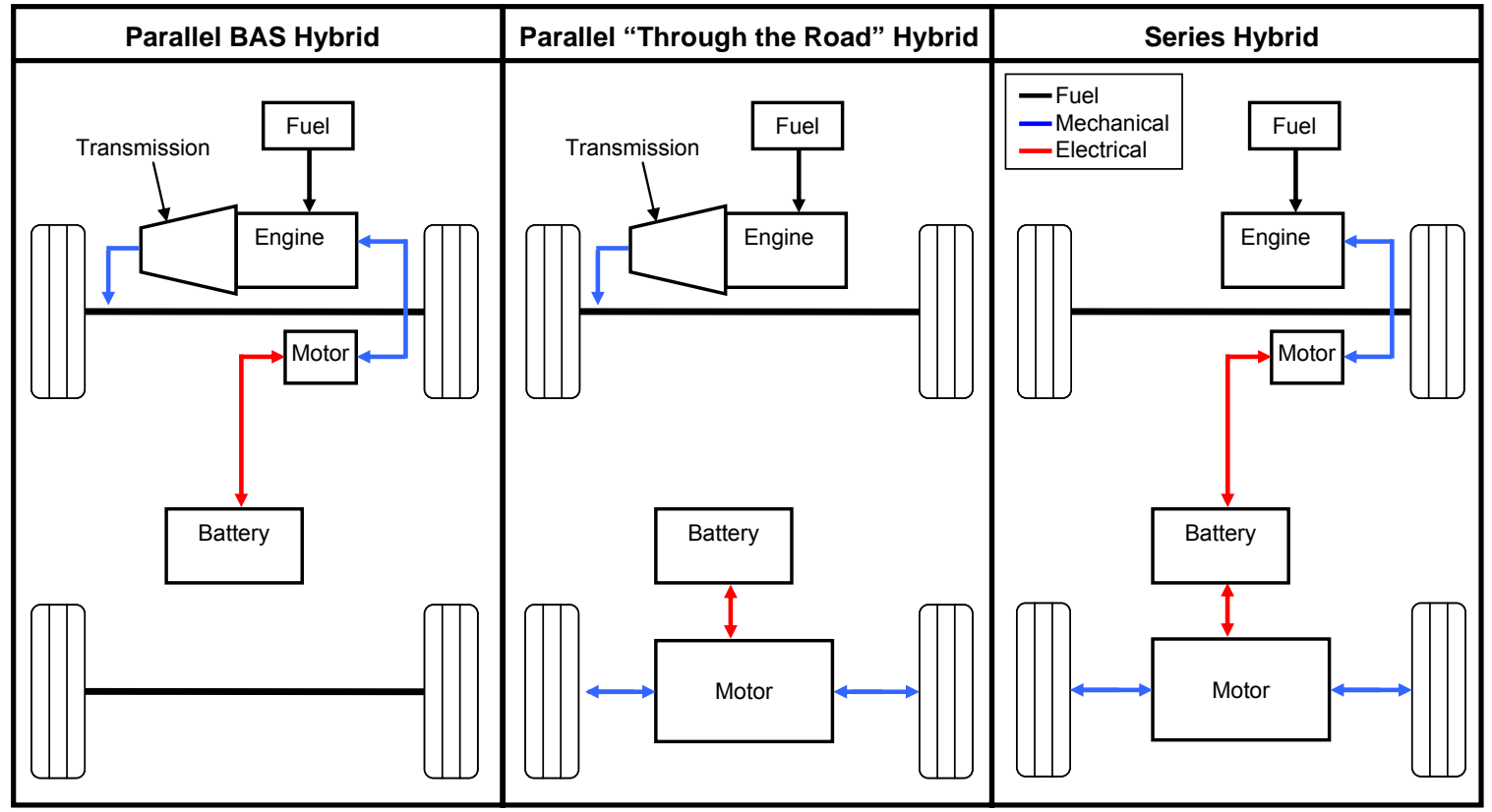

Figure 3. Example hybrid architectures

A HEV should drive and operate like a conventional vehicle, with consumer acceptable performance and driveability. Therefore, all of these different operational modes involving the engine, motors, and battery must be controlled by the vehicle, and respond properly to all driver inputs. This represents a major challenge: how are all these systems controlled to meet the driver demands while working together to achieve higher fuel economy, lower emissions, and good driveability and performance? The answer is through a supervisory control strategy, or 
specifically a hybrid vehicle control strategy. This strategy needs to control the hybrid vehicle components to achieve all of the vehicle requirements using available vehicle signals and data, all while remaining within the operational limits of the individual components.

\subsection{Objectives}

The overall objective of this paper is to define an operating strategy for a SPA HEV by calculating powertrain component losses. The results of these calculations should define how the vehicle can decrease fuel consumption, while maintaining low vehicle emissions. Because of the hybrid system, just operating an engine in its regions of high efficiency does not guarantee efficient vehicle operation. These results will not give the specific powertrain commands necessary to enable complete vehicle operation, and are meant only to define a literal strategy; that is, an understanding as to why the vehicle should operate in a certain way under the given conditions.

Section 2 gives a review of published papers that address the control and control strategies of hybrid electric vehicles. Section 3 details the SPA HEV design developed by HEVT for Challenge X. The control modes of the SPA and how the vehicle control modes are modeled are presented in Section 4. Specific loss calculations for each operational mode are given in Section 5. Section 6 addresses additional considerations for the control model, and Section 7 covers specifically vehicle emissions considerations. Finally, Section 8 presents the overall vehicle control strategy and finally conclusions are stated. 


\section{Review of Literature}

\subsection{Toyota THS II paper}

A paper from the Toyota Motor Corporation [4] covers the overall strategy employed by their Toyota Hybrid System II (THS II), first used on the second generation Prius. Although the Prius hybrid architecture differs from the SPA hybrid architecture, this paper addresses a few important topics. Note that a good portion of this paper covers improvements made to the hardware on the new Prius over the THS I which was not the focus for this review.

2.1.1 Fuel economy - The THS II fuel economy strategy is covered in detail, starting with how the engine operation area affects fuel economy. Since the Prius can use its two motors as an electronic continuously variable transmission (ECVT), it can operate the engine close to its optimal efficiency operating line across the engine map. The SPA uses a conventional transmission, so this type of strategy is not possible. However, under certain operational conditions, the engine does not operate on the optimal efficiency line because the ECVT losses are too great. Instead, the engine operating point is compromised to a lower efficiency instead of going through the ECVT losses. This represents one compromise that the SPA architecture does not have to deal with, despite loosing operation along an optimal efficiency line because of a transmission with finite ratios. The important point is that "the optimal engine operating area does not necessarily provide the optimal vehicle fuel economy” due to losses in the hybrid system. This paper aims to quantify those losses specifically for the SPA hybrid design.

The topic of engine load increasing is addressed specifically. For cold start conditions, when the load on the engine is low, the hybrid system can slightly increase the engine load to the limit of not increasing battery charge losses greatly. This acts to increase engine efficiency during warm up and reducing engine warm-up time, which is important to reduce engine emissions and increase efficiency. Also, the sooner the engine reaches operating temperature, the sooner the engine can be stopped if needed. This same engine loading strategy can be accomplished on the SPA hybrid through the BAS.

Next, for a "relatively large acceleration at low speed" it is simply stated that "THS II controls battery assist, considering engine efficiency, loss of generator revolution, loss of planetary gear revolution, and battery charge/discharge efficiency. As a result, total system efficiency is optimized." This does not provide many specifics about how the hybrid decides to operate. Also, the given accelerations were quite mild, only accelerating from $0-50 \mathrm{kph}(0-31 \mathrm{mph})$ and 0-60 kph (0-37 $\mathrm{mph})$ in about 15 seconds each.

2.1.2 Electrical Accessories - Two short paragraphs cover vehicle accessory efficiency improvements. The DC-DC converter adjusts the $12 \mathrm{~V}$ system operational voltage to prevent excess charge to the $12 \mathrm{~V}$ battery, thus limiting its electrical energy consumption. More important is the implementation of electrically driven air conditioning (A/C), which prevents operation of the engine just to drive the $\mathrm{A} / \mathrm{C}$ compressor. This reduction of low load operation (along with other improvements over the previous model Prius) enabled a $20 \%$ gain in fuel 
economy over a Toyota-specific drive cycle representing city driving. The SPA hybrid uses a similar electric drive A/C system to realize similar benefits in efficiency by avoiding low load engine operation.

2.1.3 Emissions - Vehicle emission strategies are covered, first by stating that the Prius achieves an AT-PZEV (advanced technology - partial zero emissions vehicle) emissions rating in the U.S. with essentially a conventional three way catalyst (TWC) emission control system, improved evaporative emissions system, and engine coolant heat storage system. For a cold start scenario, the engine is operated at a light load and constant throttle, and the hybrid system utilizes motor assist to power the vehicle. The other consideration for emissions is during engine starting and stopping, where the catalyst is "lean", meaning its oxygen storage capacity is saturated. To limit this condition, fuel is cut off to the engine as late as possible, and the air-fuel mixture to the engine is enriched for a short time upon engine restart. The SPA hybrid uses the same type of TWC emission control system and both the cold start and engine restart emissions strategies need to be addressed, but that is out of the scope of this paper. There is no mention of normal operation emissions considerations, which this paper will try to address.

\subsection{Nissan HEV power transfer systems study}

The paper “A Study of the Power Transfer Systems for HEVs” by the Nissan Motor Corporation [5] focuses on quantifying losses in three different types of hybrid systems through the simulation of hybrid power transfer systems. Specifically, motor-generator (MG) operation regions, their losses, and their effect on fuel economy are analyzed. Three different hybrid electric vehicle (HEV) configurations are considered, two parallel and one series, but none of them are a SPA. The model developed includes the vehicle transmission, driveline losses, tires, etc. in addition to the engine and hybrid components. The SPA hybrid calculations in this paper will not calculate losses beyond the powertrain components, as these losses are very similar and necessary for any vehicle.

The analysis that considers the losses in each hybrid system is very relevant to this paper. Three different hybrid systems are compared in four different scenarios, each adding another stage of losses. Electrical losses differentiate the three different hybrid systems the most. Because the series hybrid must use its motor all the time, electrical losses are greatest, compared to the parallel hybrid system which uses its motors less, so electrical losses are at a minimum. Although each system is affected by gear and mechanical transmission losses, these losses are overall not as significant as the electrical losses. In general, Nissan found that the combined losses for these different hybrid systems is anywhere from $22 \%-35 \%$.

\subsection{Saturn VUE hybrid paper}

Two papers from General Motors focus on the Saturn VUE Hybrid. This first paper covers the hybrid architecture, vehicle hardware, and available control modes [2]. The VUE hybrid uses only one motor, a MG belted to the engine, and a 36V nominal battery pack. Although this is not a SPA, the modes available to the VUE shown in Table 1 are very similar to the modes the SPA uses the BAS for. Although the VUE uses a DC-DC converter instead of an alternator, it does have a conventional engine driven air conditioning compressor. The impact on fuel economy for 
running the engine for $\mathrm{A} / \mathrm{C}$ only is addressed by having two $\mathrm{A} / \mathrm{C}$ modes, one that will shut off the engine "ECONO" and another, "Hi-AC" that keeps the A/C on regardless.

Table 1. Saturn VUE Hybrid modes

\begin{tabular}{|l|l|}
\hline 1 & Engine stop-start (Idle Stop) \\
\hline 2 & Early fuel-cut during deceleration with MG torque smoothing \\
\hline 3 & Regenerative braking \\
\hline 4 & Intelligent battery charge-discharge control for 36V battery \\
\hline 5 & Electric power assist \\
\hline 6 & Electrically motored creep \\
\hline
\end{tabular}

Listed in Table 1, the VUE hybrid operates in six different modes to increase vehicle fuel economy: engine idle stop, early fuel-cut during deceleration (with torque smoothing), regenerative braking, intelligent battery charge-discharge, electric power assist, and electrically motored creep. Engine idle stop is simple enough - the engine is stopped and not fueled for idling until there is a driver request to move again, which is signaled by lifting off the brake pedal. Early fuel cut during deceleration saves fuel by essentially stopping engine idle as soon as possible, but the engine stays spinning so that regenerative brake energy can be captured. If the battery state of charge (SOC) is low enough, the MG can be used as a generator to charge the battery and "the hybrid control system selects engine operating conditions where it is most efficient to charge the battery". Similarly, if the battery SOC is high, the hybrid system will select engine operating conditions to discharge the battery. For electric power assist, the MG can be used for a few seconds to improve throttle response during engine restart, and to assist the engine power during “deep accelerator-pedal applications”. This electric assist can be as great as $10 \%$ of the vehicle power, or about $13 \mathrm{~kW}$ (17 hp). Electric assist is also used to provide lowspeed creep to improve driveline smoothness. Most of the above hybrid modes are used for the SPA hybrid as well. Engine idle stop and restart are managed through the BAS, while regenerative braking, creep, and assist come from the RTM instead.

\subsection{Saturn VUE hybrid model paper}

The VUE hybrid control paper [6] begins with a vehicle summary, and moves on to detail the vehicle simulation tool used to predict vehicle fuel economy and performance. The "Simulation Results and Discussions" section covers more of the hybrid system operation, specifically focusing on engine operating points or "zones". Over the FTP composite drive cycle, the engine spent a considerable amount of time at idle stop and at negative torques during regenerative braking events. During propulsion, the engine operation was mostly confined to 40-100 Nm of torque and 1200 to 1600 RPM.

\subsection{NREL HEV control strategy paper}

This National Renewable Energy Laboratory (NREL) paper [7] deals with optimizing a parallel hybrid control strategy for fuel economy and emissions, focusing on the Partnership for a New Generation of Vehicles (PNGV) vehicle platform. The approach to the problem of controlling a hybrid vehicle powertrain is similar to the one in this paper: torque request from the driver can be positive or negative, and this can be met through the engine, electric motors, and brakes. 
However, results for the vehicle control strategy come from a six step process that, summarized: defines the entire operating range, calculates fuel energy used by the engine, calculates effective fuel energy consumed by electromechanical energy conversion, calculates total energy and emissions, normalizes these factors, analyzes them, and selects the best operating point. The operating range of the powertrain is limited by the torques and speeds that the engine and electric motor can operate within, both positive and negative, and considering any gear ratios between the motor and engine. Next, the fuel energy calculations are performed by looking at engine fuel consumption and electric motor effective fuel energy consumption. Relating the amount of energy that the electric motor uses to the equivalent amount of fuel this electrical energy represents is a difficult task. To summarize their method, the equivalent fuel energy is calculated by the requested motor torque and speed, finding the change in battery SOC while accounting for regenerative braking, combining the energy required into a replacement $\Delta \mathrm{SOC}$, and adjusting the equivalent energy by a SOC regulation factor. Engine emissions produced are calculated the same way as engine fuel use, using hot steady state maps. From these calculations, fuel economy or emissions targets can be analyzed by changing weighting factors that determine the overall control strategy. Fuel economy, performance, and emissions results of this control strategy were generated using a PNGV vehicle platform in NREL's ADVISOR (Advanced Vehicle SimulatOR) vehicle modeling software. One interesting conclusion is that "the vehicle control strategy parameters showed little sensitivity to optimization over different cycles".

\subsection{Unified modeling of HEV drivetrains}

This paper [8] intends to document a systematic process to design hybrid vehicle powertrain concepts using existing powertrain components. Starting with an introduction to hybrid vehicles and energy conversion pathways available on vehicles, the paper moves to detail component models of energy converters and energy storage devices that can be used on vehicles. The model used for electrical energy storage is simply a function depending on stored charge and voltage in the case of ultracapacitors, and Peukert relationships for batteries. Stored fuel energy is represented as the product of fuel mass times the fuel's lower heating value (or its potential energy). The component models developed bring a few good points to light. First, the engine model developed uses Willans lines to approximate engine efficiency, which compare accurately to measured engine data for low to medium loads - so an engine is linearly more efficient with increasing load, up to some higher load region where non-linear effects come into play. For electric machines, the same Willans lines can accurately approximate efficiency when compared to measured data. In conclusion, these component models are assembled into a hybrid SUV model and results are presented through simulation.

\subsection{Summary of literature review}

This literature review provides some insight into the hybrid vehicle control papers currently published, but no analysis for the SPA hybrid exists. Also, a direct comparison between conventional engine operation and hybrid modes to document hybrid system losses does not exist. Finally, a more straightforward way of equating stored energy in the battery with fuel energy in the tank is needed. This paper will address these issues, starting with the next section that further describes the Equinox $\mathrm{REV}_{\mathrm{LSE}}$ design and specific components for which this analysis is based on. 


\section{Split Parallel Architecture (SPA)}

From here on, the paper will only deal with a split parallel architecture hybrid - although this approach of calculating individual component losses and establishing a energy stored as an equivalent fuel use could easily be applied to other hybrids. For example, a hybrid with only a BAS motor would have most of these modes available except for the electric only mode, so the calculations in that section would not apply, but the engine generate mode calculations would be the same.

\subsection{Introduction to the Challenge $X$ competition}

The following section summarizes the design process and results for the Equinox $\mathrm{REV}_{\mathrm{LSE}}$. More complete information and analysis are available in HEVT's report from Challenge X 2005,

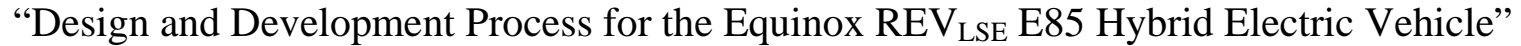
published by SAE [9]. For this paper, a hybrid control strategy will be developed specifically for a split parallel architecture (SPA) HEV. This architecture (depicted latter in Figure 5) represents the HEVT vehicle design for the 2005-2007 Challenge X competition. Challenge X is a student design competition for advanced vehicle technology, representing a "crossover to sustainable mobility”. The goals of the Challenge X competition are to reduce well-to-wheels (WTW) petroleum consumption, increase vehicle fuel economy, and decrease vehicle emissions, all while maintaining the stock vehicle performance, consumer acceptability, and safety. Each team involved designs and modifies a 2005 Chevrolet Equinox to meet these goals.

\subsection{SPA design motivation and process}

In addition to meeting the safety, fuel efficiency, emissions, and performance targets of the Challenge X competition, HEVT's vehicle design focuses on reducing petroleum consumption. With sustainable mobility in mind, fossil fuels like petroleum are non-renewable, and they release greenhouse gasses (GHG) and other harmful emissions into the atmosphere when burned. Petroleum is also an imported resource, so reducing its use has further economic and energy supply security benefits as well.

As part of the Challenge X Vehicle Development Process (XVDP), HEVT's vehicle design process starts with a broad literature review to identify candidate fuels, technologies, and approaches to improving light-duty vehicles. Then, these fuels and technologies are compared to the stock vehicle, establishing what the vehicle design must achieve to meet or improve upon the stock vehicle characteristics. The vehicle design then helps to establish the VTS as guideline metrics which leads to evaluation of general component specifications and vehicle models. Finally, a powertrain/fuel architecture is selected and a vehicle model in PSAT (Powertrain System Analysis Toolkit) [10] is used to develop a design that meets the VTS. This design process establishes the final vehicle design: a Split Parallel Architecture (SPA) hybrid electric vehicle with a 2.0 L inline four cylinder E85 engine that incorporates a belted alternator-starter (BAS) and electric all-wheel drive (AWD). 


\subsection{Baseline vehicle and VTS}

This first step of the design process quantifies the stock vehicle performance and develops a set of specifications that the vehicle design must achieve based on team goals and competitive vehicle analysis. Table 2 contains some general specifications for the stock Chevrolet Equinox.

Table 2. Stock Equinox general specifications

\begin{tabular}{|l|l|}
\hline Equinox Vehicle Specifications \\
\hline Vehicle & 5 passenger SUV \\
\hline Engine & $3.4 \mathrm{~L} \mathrm{~V}-6,185 \mathrm{hp}(138 \mathrm{~kW}), 210 \mathrm{lb} \mathrm{ft}(285 \mathrm{~N} \mathrm{~m})$ \\
\hline Transmission & 5 speed automatic with AWD \\
\hline Curb Weight & $3776 \mathrm{lb}(1713 \mathrm{~kg})$ \\
\hline Emissions & Tier 2 Bin 5 certification \\
\hline
\end{tabular}

Table 3 defines the Vehicle Technical Specifications (VTS) for the vehicle design and compares them to the stock Equinox vehicle technical specifications. The specifications defined in this table represent the initial values used for powertrain design and component selection. Target VTS values for the vehicle design were set to meet competition VTS requirements, except for fuel economy. The stock AWD combined fuel economy represents the 2006 EPA measured, unadjusted fuel economy of $23.7 \mathrm{mpg}$, which proves that the Equinox is already a relatively optimized, efficient conventional vehicle. The HEVT-selected unadjusted combined fuel economy target of 30 mpgge (miles per gallon of gasoline equivalent energy) is $27 \%$ higher than the stock vehicle and represents an aggressive but realistic goal based on the literature review and preliminary vehicle modeling.

HEVT initially defined additional specifications for the vehicle design. To maintain stock launch performance and feel, gradeability from a standstill was kept at the stock value of $>30 \%$, as was IVM-30 mph (48 kph). A continuous (charge-sustaining) top speed of $100 \mathrm{mph}$ (160 $\mathrm{kph}$ ) is very close to the stock value. On the demanding accelerations of a US06 drive cycle, the vehicle design should not have a trace miss greater than $2 \mathrm{mph}$ ( $3 \mathrm{kph}$ ), which is only slightly more than stock. For the consumer, all these criteria translate into a vehicle that has the same performance feel of the stock vehicle, but achieves better fuel economy. Similarly, although the competition specifications demand $2500 \mathrm{lb}(1134 \mathrm{~kg})$ trailering capacity, it was decided to further specify this demand to include a fully loaded vehicle (GVWR plus trailer) traveling at 55 mph (89 kph) climbing a $6 \%$ grade for more than 20 minutes. This specification puts requirements on continuous power demand for the powertrain design, while representing a realworld scenario for many consumers. Finally, the HEVT wanted to quantify its energy, greenhouse gas, and petroleum consumption goals. These numbers are defined as energy consumption over an FTP drive cycle in megajoules per mile (MJ/mi). Note that the petroleumbased well-to-wheels (WTW) energy use reduction of $80 \%$ is the most significant difference between the two vehicles: this is the specification that best differentiates the $\mathrm{REV}_{\mathrm{LSE}}$ from the stock Equinox. 
Table 3. Challenge $X$ competition and team selected vehicle technical specifications for powertrain design and component sizing

\begin{tabular}{|l|l|l|}
\hline VTS Description & $\begin{array}{l}\text { Base } \\
\text { Vehicle }\end{array}$ & HEVT VTS \\
\hline Competition Required & & \\
\hline IVM-60 MPH & $8.9 \mathrm{~s}$ & $<9.0 \mathrm{~s}$ \\
\hline $50-70 \mathrm{MPH}$ & $6.8 \mathrm{~s}$ & $<6.8 \mathrm{~s}$ \\
\hline Vehicle Mass & $<4000 \mathrm{lbs}$ & $<4400 \mathrm{lbs}$ \\
\hline EPA Combined Fuel Economy, Unadjusted & $23.7 \mathrm{mpgge}$ & $>30.0 \mathrm{mpgge}$ \\
\hline Highway Range & $>320 \mathrm{mi}$ & $>200 \mathrm{mi}$ \\
\hline Passenger Capacity & 5 Passengers & 5 Passengers \\
\hline Emissions Cert Level & Tier 2, Bin 5 & Tier 2, Bin 5 \\
\hline Trailering Capacity & $3500 \mathrm{lbs}$ & $2500 \mathrm{lbs}$ \\
\hline Starting Time & $<2.0 \mathrm{~s}$ & $<5.0 \mathrm{~s}$ \\
\hline Additional HEVT Specifications & & \\
\hline FTP PTW Energy Consumption (MJ/mi) & 5.5 & $<4.2$ \\
\hline FTP WTW Petroleum Energy Use (MJ/mi) & 5.5 & $<1.1$ \\
\hline FTP WTW GHG Emissions (g/mi) & 500 & $<375$ \\
\hline Gradeability at 0 MPH & $>30 \%$ & $>30 \%$ \\
\hline IVM-30 MPH & $3.3 \mathrm{~s}$ & $<3.3 \mathrm{~s}$ \\
\hline US06 Drive Cycle Trace Miss & $1.4 \mathrm{MPH}$ & $<2.0 \mathrm{MPH}$ \\
\hline Towing Grade at GVWR with & $>12 \%$ & $>6 \%$ \\
\hline 2500 lb trailer, 55 MPH, 20 min (continuous) & & \\
\hline Air Conditioning Fuel Use & $100 \%$ & $60 \%$ \\
\hline Continuous Top Speed & $109 \mathrm{MPH}$ & $>100 \mathrm{MPH}$ \\
\hline
\end{tabular}

\subsection{Fuel and powertrain selection}

With vehicle specifications set, the selection process starts by evaluating vehicle fuel options. In order to reduce WTW petroleum use by $80 \%$, a vehicle using either RFG or B20 would have to significantly reduce its fuel use beyond the benefits that engine improvements and hybridization can accomplish. This reason eliminated both RFG and B20 fuels from the design process. A small increase in vehicle efficiency would allow E85 to meet the $80 \%$ reduction target, and hydrogen could also achieve this goal using an internal combustion engine (ICE) or a fuel cell. An ICE hybrid vehicle of any configuration could use either E85 or hydrogen, but for a fuel cell vehicle, a series hybrid is the only configuration considered. The different ICE hybrid architectures evaluated for the design include series, power split, and parallel. HEVT has past experience building ICE series hybrid vehicles, and based on this experience and drawbacks of a series hybrid documented in the literature review (weight, energy storage requirements and highway efficiency), the series architecture is eliminated. Power split hybrid vehicles possess many favorable characteristics; however, the complicated power split transmission and simultaneous dual motor operation requires sophisticated control systems and intricate custom fabrication. A parallel hybrid architecture allows for easier integration of the electric motors and more flexible packaging with most of the benefits from a power split hybrid configuration. With 
these considerations in mind, a parallel ICE hybrid vehicle configuration is selected for evaluation, in combination with a hydrogen powered series hybrid fuel cell vehicle (HFCV).

\subsection{Component sizing and selection}

This section compares the two remaining candidate vehicle designs based on performance, HEVT's experience, and component size, mass, and availability. Based on a road load analysis of the stock Equinox, a minimum fuel converter continuous power capability of $80 \mathrm{~kW}$ (110 hp) can achieve appropriate grade, trailering, and speed requirements defined by the VTS. This power requirement is used to size powertrain components in this step of the design downselection process.

To meet the performance demands, a HFCV requires both a large fuel cell system $(80 \mathrm{~kW})$ and electric traction drive $(130 \mathrm{~kW})$. Additionally, the vehicle would need a high voltage power converter, gaseous hydrogen storage tanks, and an energy storage system (ESS) with a large capacity. Although HEVT has experience with fuel cell systems and gaseous hydrogen storage, the availability of these components is the limiting factor. Also, while a HFCV model investigated in PSAT delivered excellent fuel economy (> 50 mpgge); this vehicle design can not meet some of the VTS such as range and acceleration time. There are also significant component packaging and vehicle mass challenges. Based on these considerations, the HFCV design option has to be eliminated.

A parallel hybrid vehicle eases some of the packaging problems because it can use a conventional ICE and transmission to provide most of the tractive power, therefore using a smaller electric motor and ESS. However, the problem of storing enough gaseous hydrogen to meet the range VTS can not be solved with components available to HEVT, as shown in Figure 4. This established our final powertrain selection as an E85-fueled parallel hybrid vehicle.

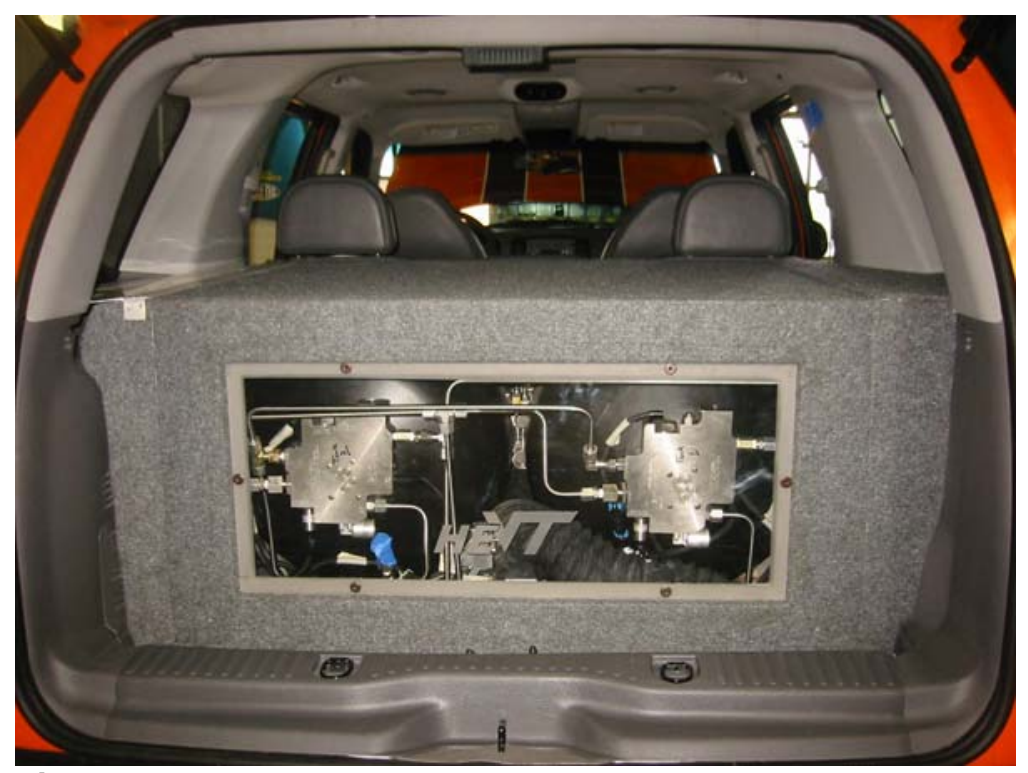

Figure 4. Two $350 \mathrm{MPa}(5000 \mathrm{psi}), 135 \mathrm{~L}$ (35 gal) hydrogen tanks occupy all of the $3^{\text {rd }}$ row seat/cargo space in a 2002 Ford Explorer and store about the same amount of energy as 3 gallons of gasoline 


\subsection{Finalized component selection}

Finally, math models and vehicle simulation techniques establish the details of the vehicle design. A parallel configuration of a large (60 kW peak) rear traction motor (RTM) powering the rear wheels and a small (15 kW peak) motor attached to the engine crank as a belted alternator-starter (BAS) is chosen for packaging, availability, and operational reasons. This design was also compared to pre- and post- transmission parallel architectures through vehicle simulation in PSAT.

In order to achieve more efficient engine operation, the design requires a downsized engine, capable of at least $80 \mathrm{~kW}(110 \mathrm{hp})$ of continuous power output. A turbocharged engine will further increase engine efficiency by providing larger regions of high efficiency compared to a naturally aspirated engine. Additionally, a late-model engine and engine controller can achieve low emissions in order to meet increasingly strict vehicle emissions standards. Since HEVT wanted to start testing of the engine in the Spring of 2005, only small displacement turbocharged engines available in the North American market are considered. These criteria left two candidate engines: the Volkswagen $1.8 \mathrm{~L}$ turbo and Saab $2.0 \mathrm{~L}$ turbo, which are compared in Table 4. Although the VW engine has a higher power output, the torque output of the Saab engine is significantly higher. Fuel economy is evaluated based on vehicles that use these engines, and considering the heavier weight of the Passat, both engines achieve similar economy ratings.

Table 4. Small displacement turbocharged engine comparison

\begin{tabular}{|l|l|l|l|l|}
\hline Vehicle & Engine & Output & Weight & $\begin{array}{l}\text { Fuel Economy } \\
\text { (mpg) }\end{array}$ \\
\hline $\begin{array}{l}\text { VW } \\
\text { Passat }\end{array}$ & $\begin{array}{l}\text { 1.8L, 20V } \\
\text { I-4, turbo }\end{array}$ & $134 \mathrm{~kW}, 225 \mathrm{Nm}$ & $1584 \mathrm{~kg}$ & $\begin{array}{l}\text { City- 21 } \\
\text { Hwy- 30 }\end{array}$ \\
\hline $\begin{array}{l}\text { Saab } \\
9-3\end{array}$ & $\begin{array}{l}\text { 2.0L, 16V } \\
\text { I-4, turbo }\end{array}$ & $129 \mathrm{~kW}, 265 \mathrm{Nm}$ & $1490 \mathrm{~kg}$ & $\begin{array}{l}\text { City- 23 } \\
\text { Hwy- 34 }\end{array}$ \\
\hline
\end{tabular}

For 2005, Saab developed a 9-5 BioPower flexible fuel vehicle (FFV) that utilizes a 2.0 L lowpressure turbocharged engine. When running on E85, the engine achieves a $22 \mathrm{~kW}$ and $40 \mathrm{Nm}$ gain compared to same engine operating on gasoline [11]. Although not currently available in North America, this is the engine selected for the vehicle design. In order to prepare and test an engine for Spring 2005, a 2001 Saab 2.0 L high-pressure turbocharged gasoline engine was obtained in December 2004 and installed on HEVT's engine dynamometer. Working through the team's GM mentor, HEVT has since received and successfully implemented the BioPower $2.0 \mathrm{~L}$ engine.

The RTM is specified as a $30 \mathrm{~kW}$ continuous, $60 \mathrm{~kW}$ peak AC induction motor. This motor should be a small and weight-conscious machine meant for automotive use, and designed to operate on a high voltage (300 V) bus. The Ballard A312V67MS (Ranger EV) and Ballard IPT are the two candidate motor systems available to HEVT that meet these specifications. Past experience with the Ranger EV drive along with availability of the system led the team to select this motor. The Ranger EV meets the performance specification with $32 \mathrm{~kW}$ continuous, $67 \mathrm{~kW}$ peak power output with $325 \mathrm{~V}$ nominal DC input. The peak power output is also a function of 
what the battery can provide, which is specified as $70 \mathrm{~kW}$. This motor system is currently operational through CAN communication on the Equinox REV $\mathrm{LSE}_{\text {. }}$

The BAS needs to be a small and lightweight motor that can be belted to the engine. In order to have a continuous power of $8-10 \mathrm{~kW}$, this will have to be a high speed motor (12k rpm) and must be on the same high voltage bus as the RTM. This high speed capability paired with a 2:1 belt drive ratio in relation to the engine crank rotational speed will give the motor enough torque to enable engine stop/start. Availability of a motor system with these specifications is limited, and one of the only drives HEVT has found so far is the MES 150-125W water-cooled ac induction system. This motor has an $8 \mathrm{~kW}$ continuous power rating, 12k rpm maximum speed, and weighs $32 \mathrm{~kg}$ with its power inverter.

The ESS selected meets the sizing requirement for capacity and voltage. The higher voltage output better matches the VTS and HV system design with the RTM peak power current capability, allowing for more peak electric assist. Also, using a higher bus voltage reduces the amount of current drawn by high voltage components, thus decreasing losses in the entire high voltage system, including the pack itself. Furthermore, this system offers a low-resistance battery pack which helps to increase the vehicle's fuel economy by reducing transport losses into and out of the ESS. More importantly, its integrated state of charge (SOC), voltage, current, and temperature monitoring allows improved control over the hybrid system as a whole.

Table 5 summarizes the major components that comprise the Equinox $\mathrm{REV}_{\mathrm{LSE}}$ design, which is a split parallel architecture (SPA) hybrid. The Cobasys NiMHax 336-70 battery pack is sized to provide peak power, and the capacity is an appropriate compromise between performance, weight, and efficiency. The RTM is also sized primarily to provide stock acceleration times, and its integrated gear reduction allows for a vehicle top speed of over $100 \mathrm{mph}(160 \mathrm{kph})$. Tire rolling resistance is lowered from the stock value of 0.009 to 0.007 due to the use of low rolling resistance tires in the vehicle design. The use of electric air conditioning, power steering, and a DC/DC converter eliminate the mechanical engine accessory load and provide a means to better manage electric accessory loads on the vehicle to further improve fuel efficiency. 
Table 5. Equinox $\mathrm{REV}_{\mathrm{LSE}}$ design summary

\begin{tabular}{|l|l|l|}
\hline Architecture & \multicolumn{2}{|l|}{ Split Parallel Architecture Hybrid with Electric AWD (Figure 1) } \\
\hline Fuel & E85, FFV capable, Hydrogen for APU \\
\hline Components & Size & Type \\
\hline Engine & $130 \mathrm{~kW}$ peak & Saab FFV E85 SI I4 DOHC 16 V Turbocharged 2.0 L \\
\hline $\begin{array}{l}\text { Emission } \\
\text { Control }\end{array}$ & - & E85 3 way catalyst, cold start strategy TBD \\
\hline Transmission & - & Saab 5 speed manual \\
\hline $\begin{array}{l}\text { Belted } \\
\text { Starter } \\
\text { Alternator }\end{array}$ & $8 \mathrm{~kW}$ cont. & MES 150-125W AC induction \\
\hline $\begin{array}{l}\text { Rear } \\
\text { Traction } \\
\text { Motor }\end{array}$ & $32 \mathrm{~kW}$ cont. & Ballard EV Ranger AC induction transaxle \\
\hline $\begin{array}{l}\text { Energy } \\
\text { Storage }\end{array}$ & $336 \mathrm{~V}, 8$ Ah & Cobasys NiMHax 336-70, 70 kW peak output \\
\hline Tires & $235-710 \mathrm{R} 460 \mathrm{~A}$ & Michelin PAX run-flat system, low rolling resistance \\
\hline 12 V Supply & $1 \mathrm{~kW}$ cont. & High voltage DC/DC, optional Ballard Nexa FC system \\
\hline A/C System & $10 \mathrm{~kW}$ & HV electric drive, high efficiency, variable speed \\
\hline Controls & $\begin{array}{l}\text { HEV mode select with energy management, component communication and data } \\
\text { acquisition }\end{array}$ \\
\hline
\end{tabular}

\subsection{SPA hybrid vehicle design considerations}

The split parallel architecture concept is given in Figure 5, and turns out to be similar to GM's Precept $80 \mathrm{mpg}$ PNGV concept sedan [12], but with the front and rear axle functions swapped. Using a small BAS on the engine allows a standard FWD transmission and engine coupling to be used on the front axle. Integrating an electric transaxle on the rear axle makes use of available space and provides a high power motor for efficiency, performance, and AWD capability. This hybrid architecture has two parallel paths (hence the split designation): one directly from the BAS to the engine, the other "through the road" from the engine and the rear drive motor. This two-motor configuration also has an additional series path that can use the engine and BAS to charge the battery and/or provide power directly to the rear traction drive. This two-motor design improves on a pure "through-the-road" parallel design by providing an efficient, direct series path (BAS) for battery charge control. Thus, this design provides some of the benefits and flexibility of a power-split architecture (Prius and Escape HEV) but using many conventional, available components in a simpler mechanical layout. A turbocharged engine also increases efficiency somewhat like an over-expanded Atkinson cycle engine. 


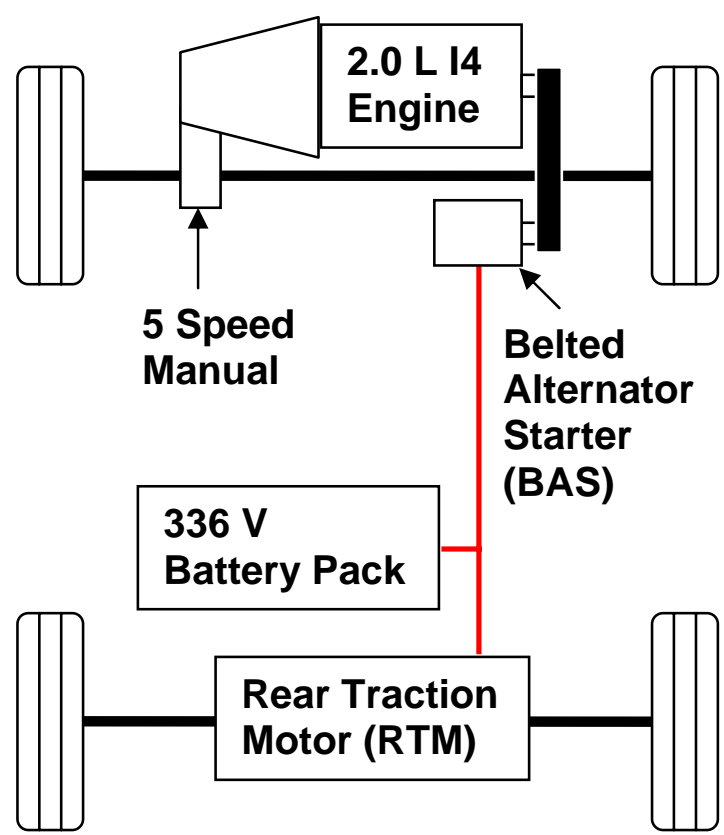

Figure 5. E85 Split Parallel Architecture (SPA) hybrid with BAS and electric AWD

The BAS is sized to provide peak torque for engine starting and continuous rating to apply a minimum torque load on the engine at low speeds $(1000 \mathrm{rpm})$ for efficient idle charging. The BAS can also provide transient torque smoothing as well as power boosting for the engine. The belt drive allows for a lighter high-speed motor with speed reduction to the engine, and simplifies mechanical integration compared to an engine flywheel location. The RTM provides a higher electric power fraction than can be achieved with the BAS alone, with relatively simple mechanical integration and AWD. While the SPA has many of the advantages of the power-split hybrid architecture, it lacks the continuously variable transmission function to control engine speed. However, the SPA design also lacks the complexity of a custom planetary gear set transmission and its control, and does not require that torque and power be absorbed by the generator/BAS to transmit engine torque to the road.

In summary, this section detailed how the SPA architecture was developed and specified the components used in the REV $\mathrm{LSE}_{\mathrm{HEV}} \mathrm{HE}$. Simple vehicle models show that this vehicle can meet the VTS for vehicle performance, emissions, and fuel economy. However, a detailed loss analysis should provide a way to determine a control strategy to meet the VTS. The next section describes the available control modes for the REV $\mathrm{LSE}_{\text {and }}$ ants some parameters for the control strategy analysis. 


\section{Relationship between Control Model and Vehicle}

To develop a control model and strategy for the SPA hybrid vehicle, some assumptions and simplifications must be defined so that conclusions from the model are evident. These include setting some operational parameters, defining operational modes, and drawing reasonable assumptions based on normal vehicle operation.

\subsection{Energy paths and hybrid modes}

The SPA hybrid and its available operational modes are given in Figure 6 and Table 6 . Figure 6 serves to generally describe the different energy paths that are available on the SPA hybrid. A conventional vehicle would simply convert the fuel energy (black line) to mechanical energy with the engine, and send that energy (blue line) to the wheels. With two electric motors, the SPA can also send energy to the battery or provide energy for propulsion from the battery. Arrows in both directions means that energy can travel in either direction, which is true for only the electric motors and battery. In Figure 6, the BAS has an $8 \mathrm{~kW}$ continuous power capability, and the RTM can provide about $52 \mathrm{~kW}$ peak, instead of the previously stated $60 \mathrm{~kW}$, due to voltage limits on the battery. Table 6 further details hybrid operation by describing individual hybrid modes available to the SPA, which are listed below.

4.1.1 Engine only - As mentioned previously, this control mode can be used for most normal driving conditions. However, without the BAS load on the engine, any electrical accessories will lower the ESS SOC. This is desirable if the SOC is too high, or if the controller needs to calibrate the SOC measurement with a given load.

4.1.2 Engine generate - During relatively normal driving conditions, the vehicle operates in this generate mode or the engine only mode for the majority of the time. Since the engine is the primary fuel converter on the vehicle, the direct fuel to engine to wheels path is the most efficient energy path available on the vehicle. The BAS load on the engine is primarily due to electrical accessories, but should also include battery state-of-charge (SOC) control of the ESS.

4.1.3 Engine assist - Adding torque from the BAS, RTM, or both to the engine torque output boosts vehicle performance in this mode. Depending on driver pedal position, change in pedal position, vehicle speed, and corresponding powertrain limits, the amount of electric assist varies. However, to maintain the driveability of the vehicle the total powertrain torque output should not vary significantly during normal driving. A higher electric fraction of peak torque can prevent high load and high speed engine operation, giving the vehicle higher fuel efficiency. Also, avoiding engine operation at especially high or transient loads where many engine fuel maps have increased fueling rates or "fuel enrichment" zones can increase fuel economy and decrease emissions.

4.1.4 Electric only - This mode is the only "engine off” propulsion (positive torque request) mode. RTM torque is positive because this mode can allow the driver to propel the vehicle at low speed using just the RTM power. This mode increases vehicle fuel economy by not 
operating the engine during a low-load situation. For cold-start emissions, the engine should not be shut down before the engine coolant and exhaust catalyst have reached their operational temperatures, because a cold engine or catalyst leads to higher vehicle emissions. Also, the engine or catalyst should not be allowed to cool down below a reasonable operational temperature during this mode either. If the driver torque request is high enough, the engine should start and provide the additional requested torque to meet vehicle load requirements.

4.1.5 Regenerative braking - The vehicle is in this mode whenever the brake pedal is depressed. Negative torque from the motors means that they could both send current back to the ESS, within SOC limits and power limitations on the drive motor. This can increase vehicle fuel economy because this "recaptured" energy can be used later for vehicle propulsion, or to run vehicle accessories, rather than being dissipated as heat through conventional friction brakes. Cutting fuel to the engine during deceleration can also improve fuel economy, but driveability and emissions are concerns.

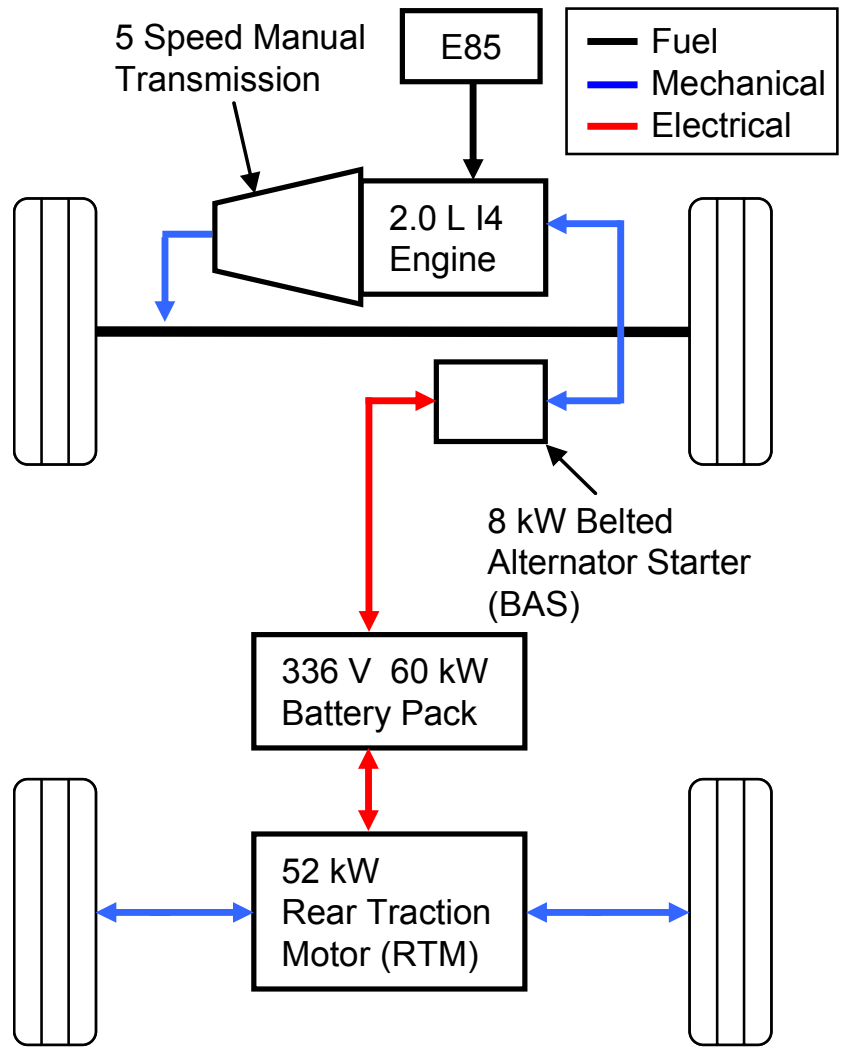

Figure 6. SPA with fuel, electrical, and mechanical energy paths designated between systems 
Table 6. Available modes of operation for propulsion components of the SPA

\begin{tabular}{|l|c||c|c|}
\hline Mode & $\begin{array}{c}\text { Engine } \\
\text { torque }\end{array}$ & $\begin{array}{c}\text { BAS } \\
\text { torque }\end{array}$ & $\begin{array}{c}\text { RTM } \\
\text { torque }\end{array}$ \\
\hline Engine Only & + & 0 & 0 \\
\hline Engine Idle Stop & 0 & 0 & 0 \\
\hline Engine Generate & + & - & 0 \\
\hline Engine Assist & + & $+/ 0$ & + \\
\hline Electric Only & 0 & 0 & + \\
\hline Regen Braking & $-/ 0$ & $-/ 0$ & - \\
\hline
\end{tabular}

\subsection{Meeting driver torque request}

With the mentioned control modes available, the control strategy must decide which mode is best to meet driver demand. The driver can request either a positive or negative torque from the vehicle, using the accelerator and brake pedals respectively. This analysis only considers meeting driver demand for static operation points, and does not address any transient loading conditions or mode transitions. However, this approach should deliver reasonable drivability regardless of driver torque demand because it aims to meet the driver torque request all the time, and has proven sufficient during testing of the Equinox REV $\mathrm{LSE}_{\text {. }}$

4.2.1 Negative torque request - Negative torque is straightforward on a conventional vehicle, where the friction brakes supply deceleration relative to hydraulic pressure in the brake system controlled by brake pedal position. On the SPA, the negative torque request can be met with the fiction brakes alone, or with either electric motor, or a combination of the two. Deciding the amount of negative torque supplied by the motors is up to the control strategy that will be developed later in this paper, however it is important to note that the brake system on a vehicle is a critical safety system, and any approach to interrupt the fail-safe hydraulic system is not permissible.

4.2.2 Positive torque request - Positive torque request is managed through the accelerator pedal on a conventional vehicle; a higher torque demand from the driver increases the torque output from the engine. For the SPA, positive torque can be provided by the engine or either electric motor. Depending on how high the torque request is, it could be met entirely by the RTM or a combination of the motor and engine. So deciding how to meet driver positive torque demand must also come from the control strategy.

\subsection{Initial conditions and assumptions}

To start the development of a control strategy for the SPA, some initial conditions and assumptions must be made clear. First, the control strategy will not address cold start operation. As mentioned in the literature review, cold start emissions are high for SI engines like the E85 engine used in the SPA hybrid. With that issue in mind, a separate control strategy should be developed specifically for cold start conditions and then integrated with the normal operation control strategy. Second, this analysis will only consider positive torque requests to the 
powertrain that are within the power and speed limitations of the individual components. Since regenerative braking captures energy, if the powertrain can request a higher negative torque then it should do that to increase the charge on the battery and further reduce fuel use. The contributions and any effects that regenerative braking has on these control strategy calculations will be discussed further in a later section. Third, this analysis will not cover transmission, driveline, or tire losses. Because of the SPA, all of the powertrian components propulsion power must go through a similar gear reduction, CV joints, and tires. These losses are approximately equal for the front and rear axles, so they are left out of the analysis. Including them would simply require another step in the calculations to determine how much of the power actually gets to the road. This analysis is more focused on which powertrain component, or what combination of components, is the most efficient for a specific torque request.

The initial conditions assumed are that the vehicle is in a normal operational state. This includes that all of the powertrain components are operating correctly within their individual temperature and speed limits. Torque limits for these components are defined and adhered to in the calculations. The battery has some reasonable SOC between $20-80 \%$, a range that the battery would not normally be operated outside of. Also notable is that vehicle operation is considered as charge sustaining, where the battery will supply and absorb some power over a drive cycle, but finishes with a SOC close to its initial SOC. That also means that all energy in the battery originated as fuel energy and was converted through the engine and one of the motors to electrical energy. This is how energy stored in the battery can be considered as fuel energy. Vehicle speed is important for the calculations, but initially some individual component rotational speeds will be chosen for clarity.

\subsection{Specific component and vehicle considerations}

The calculations for this model are based on the vehicle platform and components of the Equinox $\mathrm{REV}_{\mathrm{LSE}}$ described in section 3 that represent a SPA hybrid electric vehicle. Despite this, the same calculations used in this model to determine a control strategy can be applied to any hybrid vehicle, given an appropriate knowledge of component efficiencies and engine emissions. Also, improving the individual components, such as a more efficient engine, does not change how the calculations are performed, but the results will be different. Other improvements to the vehicle outside of the powertrain components like weight reduction or reducing aerodynamic drag will help to decrease fuel consumption and will not change the results at all; the vehicle will simply use less fuel due to lower loads at the same speeds.

Now that the boundaries of the vehicle model are set, the specific calculations can begin. The next section steps through each available hybrid mode and describes how the losses in the hybrid system can be calculated. For hybrid modes, a comparison to the engine only case provides a way to evaluate the hybrid system efficiency. 


\section{Hybrid Mode Loss Calculations}

\subsection{Engine only mode}

This mode represents a simple operational mode where the engine is the only powertrain component powering the vehicle, depicted in Figure 7. E85 fuel is directly converted to mechanical power that goes through the transmission to move the vehicle. This energy path is the most direct for fuel energy to take, and therefore can be very efficient, depending on engine efficiency at certain torques and speeds. Because the E85 fuel is the primary energy source for the vehicle, following its use will be the basis for this model, as well as equating electrical energy in terms of fuel, since all electrical energy onboard the vehicle came from fuel at some point.

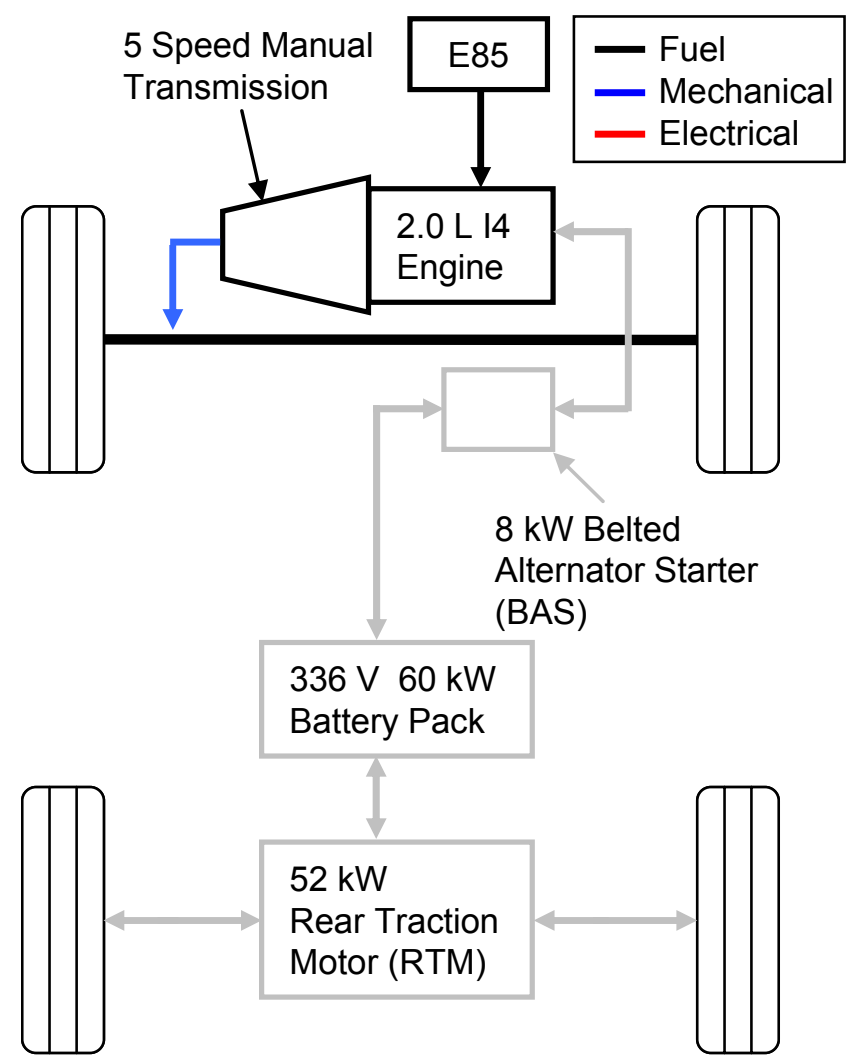

Figure 7. Engine only mode energy flow diagram

5.1.1 Calculating fuel use - Given a torque request from the driver, it will take a certain amount of fuel to make that torque at a given vehicle speed. The amount of fuel required to make that torque depends on the engine's efficiency at that torque and speed. So, given required torque in Nm (Eng_trq), speed in rpm (Eng_spd), and efficiency of the engine at that operating point (Eng_eff) the fuel use is calculated as follows

$$
E n g_{-} p w r_{-} \text {out }=E_{-} g_{-} s p d *\left(\frac{\pi}{30}\right) * E n g_{-} \text {trq }
$$

And 


$$
\text { Eng_fuel_use }=\frac{E n g_{-} p w r_{-} \text {out }}{\text { Eng_eff }}
$$

For example, if the required engine torque was $80 \mathrm{Nm}$ at $2000 \mathrm{rpm}$, and the engine efficiency was $27.8 \%$, the required engine power would be

And

$$
\text { Eng } \text { _p }_{\text {p }} \text { out }=2000 *\left(\frac{\pi}{30}\right) * 80=16.8 \mathrm{~kW}
$$

$$
\text { Eng_fuel_use }=\frac{16.8 \mathrm{~kW}}{0.278}=60.3 \mathrm{~kW}
$$

Figure 8 is a simple schematic representation for this calculation. Since engine power output and fuel power input have been calculated, engine power loss is simply the difference of the two.

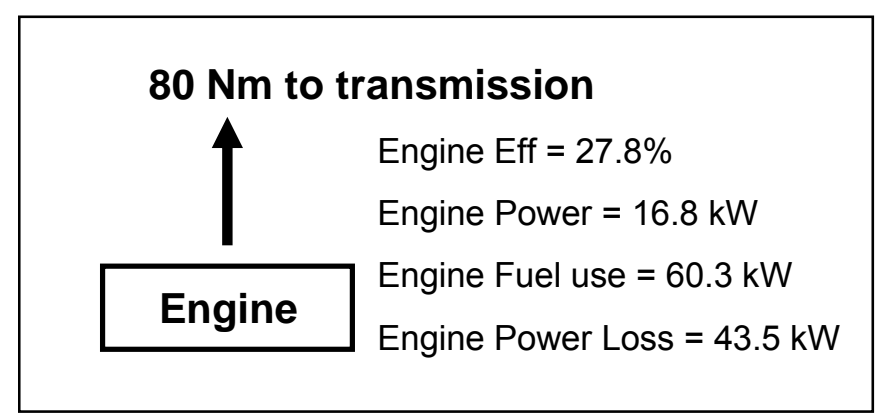

Figure 8. Engine only mode energy flow schematic

Figure 9 below is a torque and speed map of engine efficiency for the Saab engine used in the $\mathrm{REV}_{\text {LSE }}$. Not surprisingly, this efficiency map is similar to Figure 1 in the introduction, as these engine characteristics are similar across many internal combustion engines. The engine is least efficient at low torques, and gets somewhat less efficient with higher speeds. Highest engine efficiency comes at reasonably low speeds and higher torques, around the center of the $30 \%$ efficiency zone shown in dark red. 


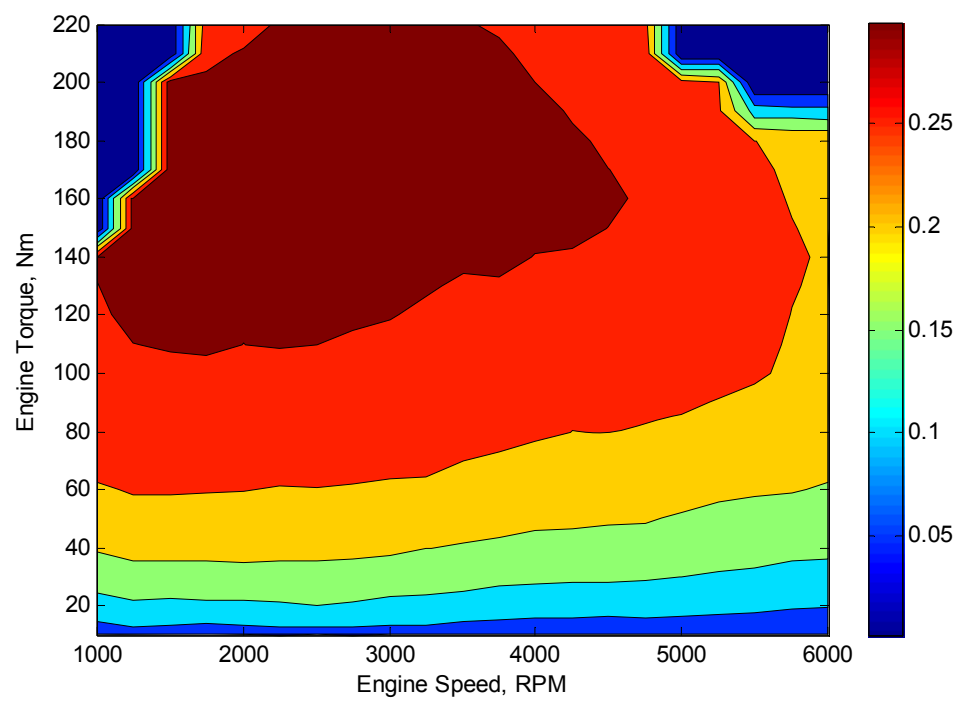

Figure 9. Engine efficiency as a function of torque and speed

\subsection{Energy storage considerations and battery model}

The purpose of an energy storage system on a hybrid electric vehicle is to provide a way to average the vehicle loads on the engine. When the vehicle load is high, such as for a quick acceleration, the battery can provide power to the electric motors and therefore reduce the load on the engine at that time, or provide additional torque if the engine is already operating at maximum torque. At low vehicle loads like constant speed, the engine can use the electric motor as a generator and charge the battery, increasing the engine load. Additionally, most battery systems can provide enough power to run accessory loads such as A/C and $12 \mathrm{~V}$ loads through electrical accessories so the engine can be stopped completely instead of idling. This further increases the average load on the engine by reducing low load operation conditions and duration.

Specifically, the energy storage system used for this model is the previously mentioned Cobasys

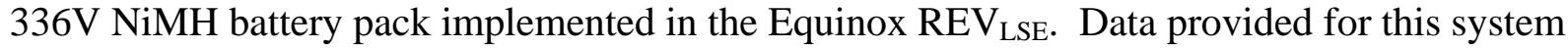
shows that charge and discharge resistances vary little with SOC, and only slightly more with temperature. Between 80 and 30 percent SOC at a normal operating temperature of $35^{\circ} \mathrm{C}$, the battery charge and discharge resistances of 0.38 and 0.44 ohms respectively vary less than $10 \%$. For this reason, a simple model based on these two resistances should be able to achieve a high degree of accuracy in predicting losses internal to the battery pack. Logged vehicle data supports the operational assumptions of battery operational temperature, which typically ranges between 30 and $40{ }^{\circ} \mathrm{C}$, and SOC, which is limited by the vehicle controller to always be greater than 30 and less than 80 . An open circuit voltage of $364 \mathrm{~V}$ is based on measurements at $60 \% \mathrm{SOC}$ and the normal operating temperature of 35 degrees ${ }^{\circ} \mathrm{C}$.

5.2.1 Calculating battery losses - With charge and discharge resistances known, battery losses are calculated as $\mathrm{I}^{2} \mathrm{R}$ losses, where I is battery current and $\mathrm{R}$ is the charge or discharge resistance. For this model, the power going into or coming out of the battery is also known. To use this equation, the current going into or coming from the battery needs to be calculated first, 
using the open circuit voltage of the battery $(V o c)$, power $(P)$, and resistance $(R)$. The equation to find the current $(I)$ is based on two power equations

$$
P_{\text {ideal }}=I * \text { Voc }
$$

And

$$
P_{\text {loss }}=I^{2} * R
$$

Combined gives

$$
P=I * V o c-I^{2} * R
$$

Which can be rearranged into a quadratic equation to solve for current

$$
R * I^{2}-V_{O C} * I+P=0
$$

Giving the solution

$$
I=\frac{V o c-\sqrt{V o c^{2}-4 R P}}{2 R}
$$

Notice that equation 6 represents the proper root for this quadratic equation, which was found and verified by known data. Now that the current is known, the amount of power lost is calculated by equation 4 . This internal power loss applies to power coming into the battery by subtracting the loss, and power coming from the battery by adding the loss term to the required battery power output. Note that equation 6 can give a negative current if the power into the pack is negative, which represents charging the battery. The power loss is still positive for this charging case. An example calculation is given in the next section.

5.2.2 Accounting for stored energy - A few simple definitions can be used to clarify the energy conversion processes that can happen on the vehicle. Fuel conversion represents the conversion of fuel energy to mechanical energy, which happens exclusively at the engine. Electrical conversion takes place when mechanical energy is converted to electrical energy through either electric motor on the vehicle. This electric energy is then stored in the battery. Mechanical conversion is simply the opposite of electrical conversion - converting electrical energy back to mechanical energy. The energy storage system is the reason why mechanical and electrical conversion makes sense; it provides a way to store energy and use it later. Since the electrical energy stored in the battery comes from fuel energy converted to electricity through the engine and one of the motors (fuel conversion and electrical conversion), any energy stored in the battery has already "paid" the associated fuel conversion and electrical conversion efficiency penalties. So any torque request where going through the mechanical conversion is more efficient than the direct fuel conversion is of interest. Similarly, any torque request that increases the electrical conversion efficiency should be noted.

\subsection{Engine generate}

The engine generate mode represents electrical conversion of mechanical energy from the engine through the BAS motor. This energy path represents fuel conversion at the engine, electrical 
conversion through the BAS, and energy storage. The same electrical conversion path can happen through the RTM, with the engine's mechanical output going through the transmission, to the front wheels, through the road, and to the rear wheels before being converted to electrical energy at the rear motor. These two paths are compared in Figure 10. However, with additional losses in the transmission, tire and road (rolling resistance), and gear reduction in the RTM, the "through the road" path using the RTM is too inefficient to be considered. Figure 11 is the energy flow diagram for the engine generate mode.

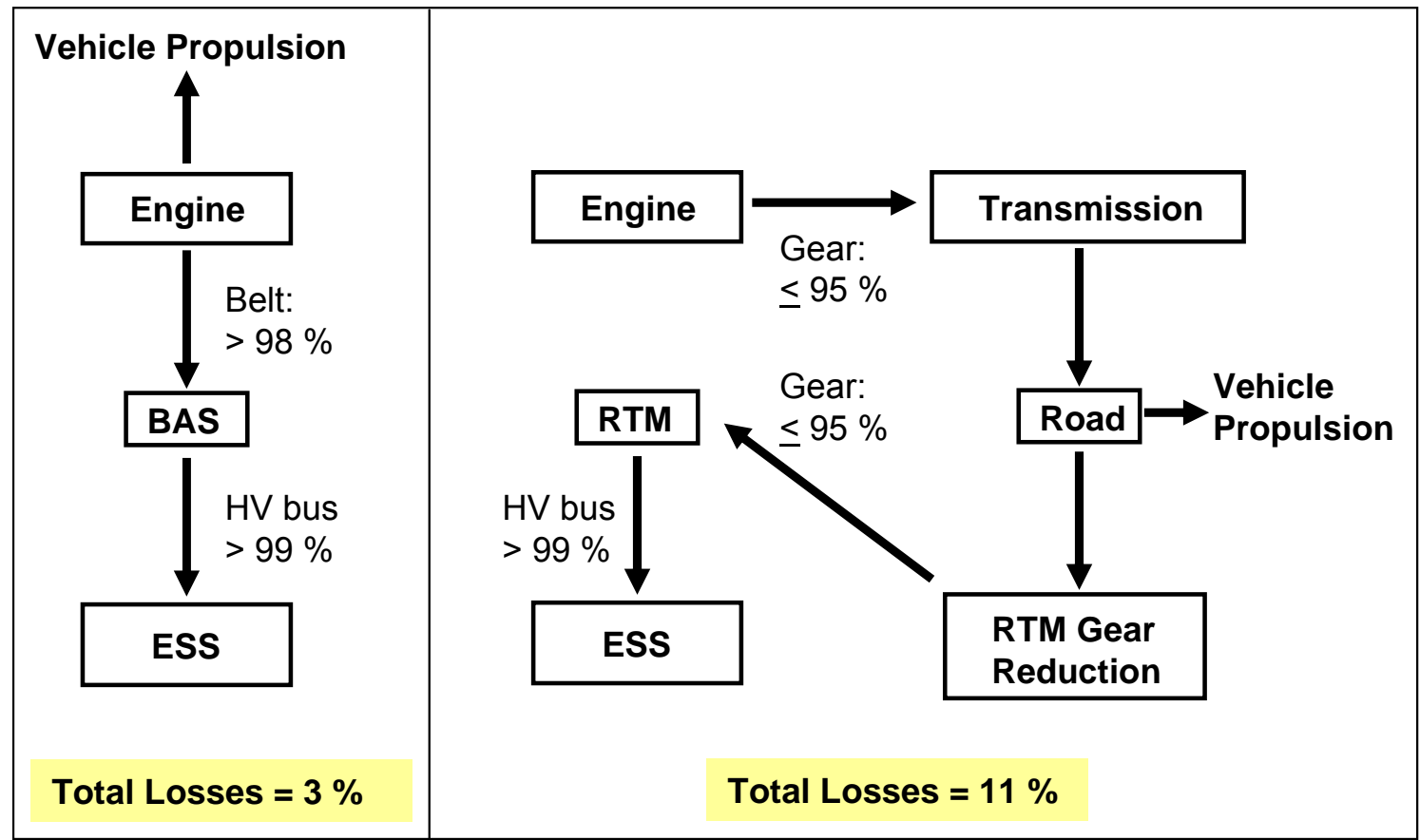

Figure 10. Comparison between BAS generate and RTM generate modes detailing system losses 


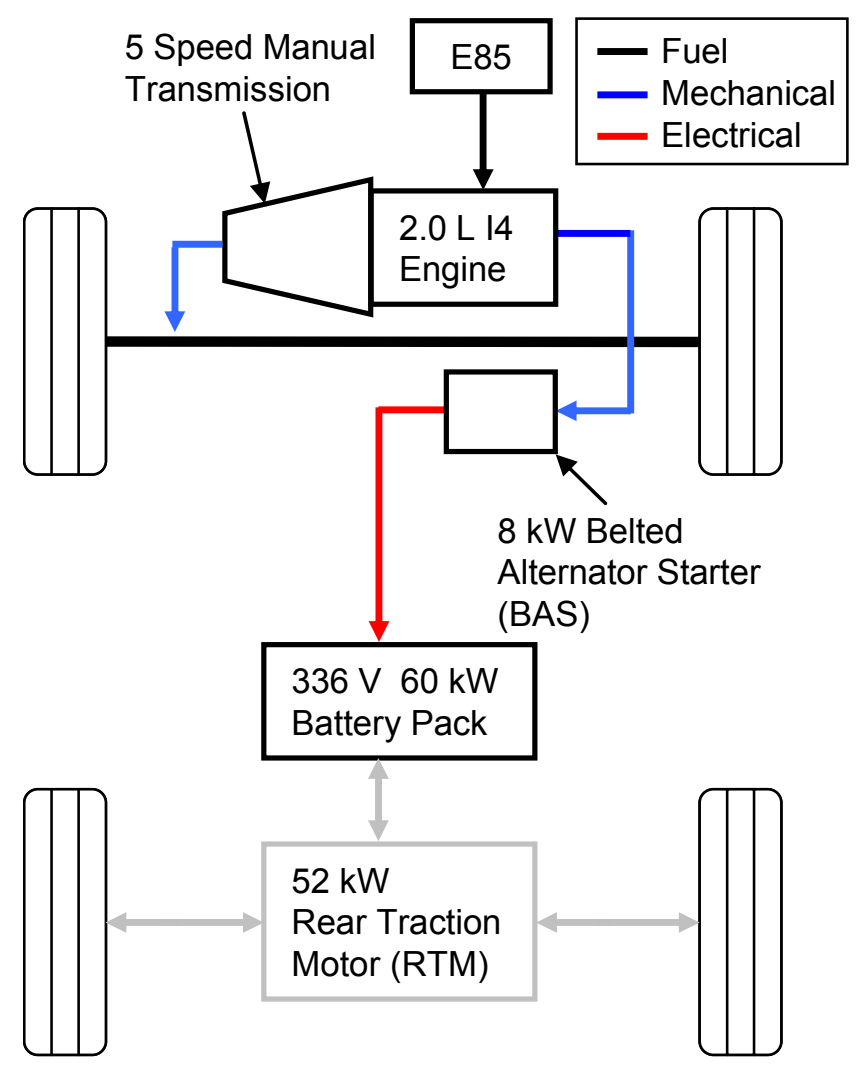

Figure 11. Engine generate mode energy flow diagram

5.3.1 Calculating generate losses - The first step in calculating the losses in the engine generate mode is to calculate engine fuel use at the required torque and speed using equations 1 and 2. Then, the calculations for the BAS efficiency can be carried out in a similar manner. Given requested torque in Nm (BAS_trq) which is negative for the generate case, speed in rpm (Eng_spd), belt drive ratio (BAS_ratio), and efficiency of the motor at that operating point (BAS_eff) the power loss is calculated below. Since the BAS is converting mechanical power into electrical power, the power loss affects the electrical power output.

And

$$
B A S_{-} \text {mech_pwr }=E n g_{-} s p d * B A S_{-} r a t i o *\left(\frac{\pi}{30}\right) * B A S_{-} \text {trq }
$$

$$
B A S_{-} e l e c \_p w r=B A S_{-} m e c h_{-} p w r * B A S_{-} e f f
$$

For example, the net torque to the transmission and speed is the same as the previous engine only mode example. This time, with the BAS requesting $20 \mathrm{Nm}$, the additional torque load on the engine is $40 \mathrm{Nm}$. So the total load on the engine becomes $120 \mathrm{Nm}$ and the engine efficiency increases. At the same engine speed, the BAS speed is doubled. The calculations are as follows

$$
\begin{gathered}
\text { Eng_pwr_out }=2000 *\left(\frac{\pi}{30}\right) * 120=25.1 \mathrm{~kW} \\
\text { Eng_fuel_use }=\frac{25.1 \mathrm{~kW}}{0.307}=81.9 \mathrm{~kW}
\end{gathered}
$$




$$
\begin{gathered}
B A S_{-} \text {mech_pwr }=2000 * 2 *\left(\frac{\pi}{30}\right) *-20=-8.38 \mathrm{~kW} \\
\text { BAS_elec_pwr }=-8.38 * 0.899=-7.53 \mathrm{~kW}
\end{gathered}
$$

Now that the electrical output of the BAS at this torque and speed is known, the amount of power that is stored in the battery can be calculated

$$
\begin{gathered}
I=\frac{364-\sqrt{364^{2}-4 * 0.378 *-7500}}{2 * 0.378}=-20.2 \mathrm{~A} \\
P_{\text {loss }}=(-20.2)^{2} * 0.378=154 \mathrm{~W} \\
P_{\text {stored }}=-7.53+0.154=-7.38 \mathrm{~kW} \\
\text { ESS_eff }=\frac{-7.38}{-7.53}=98.0 \%
\end{gathered}
$$

Figure 12 is a simple schematic representation for this calculation. Since BAS mechanical power input and electrical power output have been calculated, BAS power loss is simply the difference of the two.

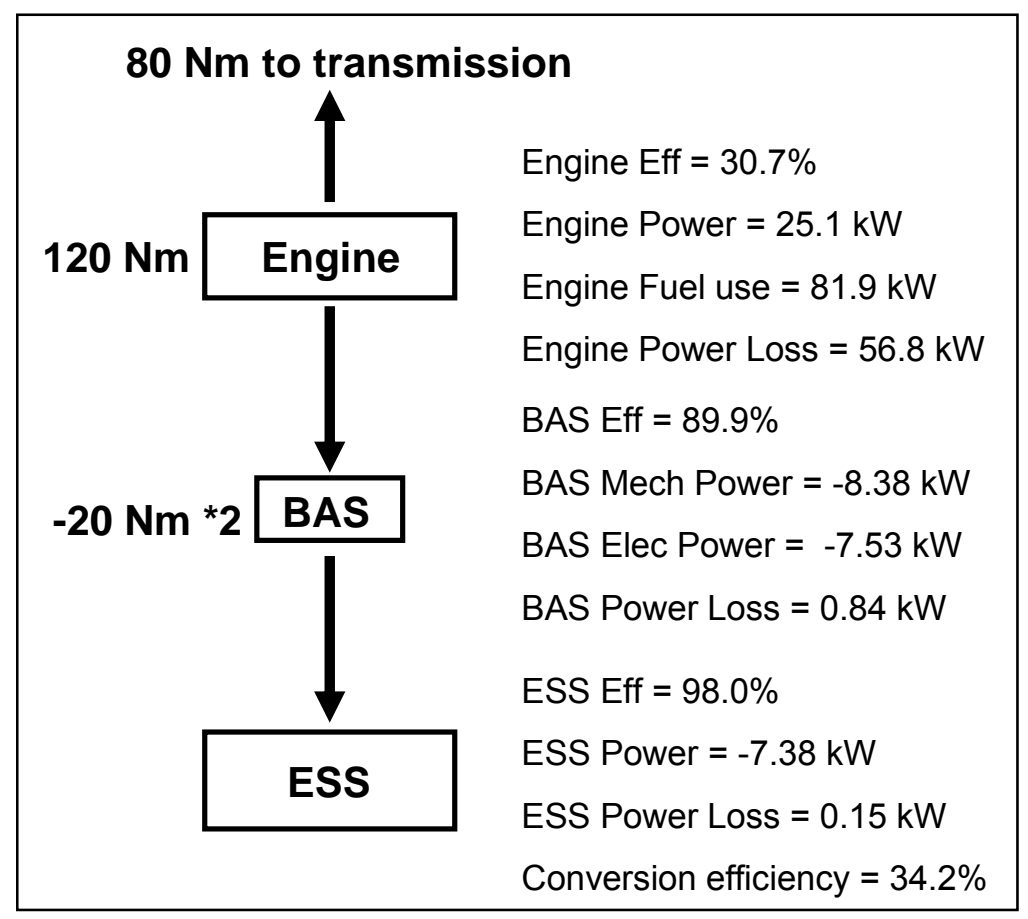

Figure 12. Engine generate mode energy flow schematic

5.3.2 Calculating conversion efficiency - The last value in Figure 12, the "conversion efficiency" represents a comparison between the engine only mode and the engine generate mode. Notice that both cases give the same output to the transmission to meet driver demand, but the engine generate case provides an additional load to the engine with the BAS. This has the effect of raising engine efficiency, and storing some power in the battery. So the conversion efficiency represents the increase in fuel over the engine only mode that it took to store a certain 
amount of power in the battery. The conversion efficiency (Conversion_eff) is therefore calculated as

$$
\text { Conversion_eff }=\frac{\text { ESS Power Stored }}{\Delta \text { Engine Fuel }}=\frac{P_{\text {stored }}}{\text { Engine Only Fuel }- \text { Engine Generate Fuel }}
$$

To compare the two example calculations given for engine only and engine generate modes

$$
\text { Conversion_eff }=\frac{-7.38}{60.3-81.9}=34.2 \%
$$

The engine generate mode has the capability to increase the load on the engine beyond what the driver demands, and increasing the load on the engine effectively moves the engine operation to a more efficient range. Considering a constant $-20 \mathrm{Nm}$ torque increase on the engine through the BAS, Figure 13 is a plot of the change in engine efficiency from the engine only case. The largest gains in engine efficiency can be made at low loads and lower speeds, where engine efficiency is lowest. Table 7 is a small "map" of conversion efficiencies calculated for some speeds and torques. Because of the BAS belt ratio of 2:1, the engine speed noted in the table is half of the BAS speed. The torque values along the side of Table 7 represent the net torque output to the transmission for a BAS torque load of $-10 \mathrm{Nm}$.

Both the BAS and ESS component efficiencies affect the conversion efficiency by generating losses and reducing the amount of power stored in the battery. So one way to evaluate the impact of the hybrid components would be to neglect the component losses and calculate an "ideal" conversion efficiency by adding the BAS and ESS losses to the final amount of stored energy. For the example case given in Figure 12, the result would be a conversion efficiency of about $39 \%$ instead of $34 \%$, so about a $10 \%$ of the fuel energy from the engine is lost through the conversion process.

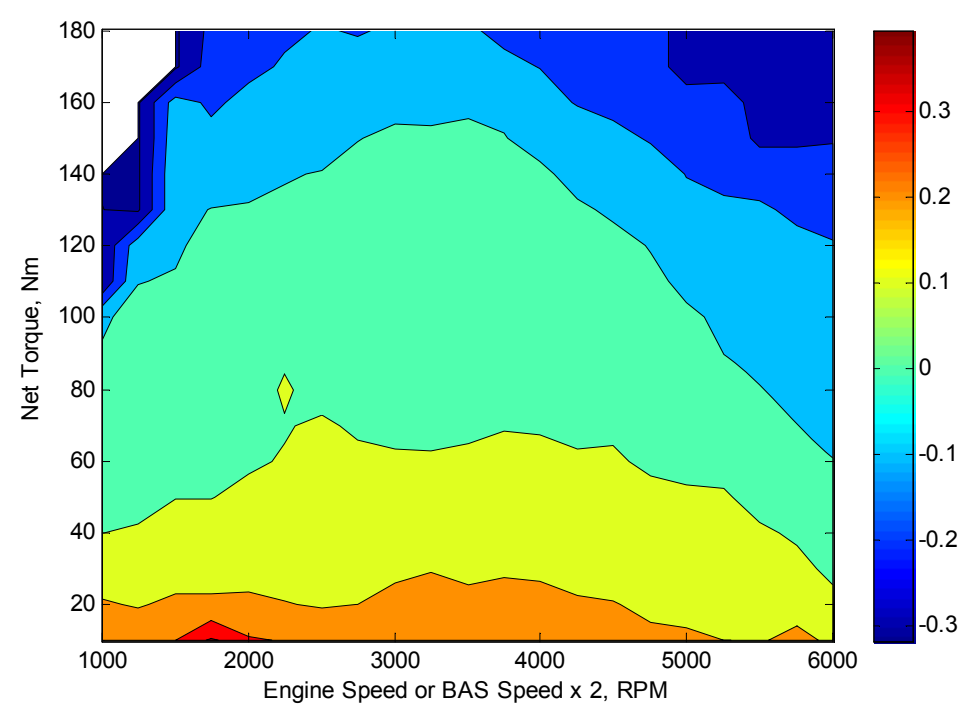

Figure 13. Engine generate mode contour plot which represents a change in engine efficiency over engine only operation 
Table 7. Conversion efficiencies for some engine and BAS speeds and net output torques, with BAS torque equal to $-10 \mathrm{Nm}$

\begin{tabular}{|r|r|r|r|r|r|}
\hline \multirow{2}{*}{$\begin{array}{l}\text { Net } \\
\text { Torque (Nm) }\end{array}$} & \multicolumn{5}{|c|}{ Engine Speed (rpm) and BAS speed/2 (rpm) } \\
\cline { 2 - 6 } & 1000 & 1500 & 2000 & 2500 & 3000 \\
\hline 10 & $40.4 \%$ & $39.5 \%$ & $48.7 \%$ & $40.6 \%$ & $37.4 \%$ \\
\hline 20 & $34.9 \%$ & $38.7 \%$ & $38.9 \%$ & $34.0 \%$ & $39.8 \%$ \\
\hline 30 & $33.3 \%$ & $35.3 \%$ & $31.8 \%$ & $35.2 \%$ & $34.8 \%$ \\
\hline 40 & $31.6 \%$ & $32.2 \%$ & $33.2 \%$ & $32.7 \%$ & $33.4 \%$ \\
\hline 50 & $31.1 \%$ & $32.0 \%$ & $36.1 \%$ & $32.4 \%$ & $36.3 \%$ \\
\hline 60 & $27.8 \%$ & $32.0 \%$ & $35.0 \%$ & $35.7 \%$ & $37.9 \%$ \\
\hline 70 & $28.1 \%$ & $33.8 \%$ & $32.2 \%$ & $39.1 \%$ & $34.4 \%$ \\
\hline 80 & $33.1 \%$ & $31.9 \%$ & $32.4 \%$ & $36.1 \%$ & $32.2 \%$ \\
\hline 90 & $28.7 \%$ & $31.7 \%$ & $34.1 \%$ & $34.3 \%$ & $33.6 \%$ \\
\hline 100 & $24.6 \%$ & $35.6 \%$ & $34.8 \%$ & $32.9 \%$ & $35.5 \%$ \\
\hline
\end{tabular}

\subsection{Engine assist}

This mode represents mechanical conversion of electrical energy from the battery through the BAS motor and/or RTM, as shown in Figure 14. This energy path represents sourcing power from the battery, electrical to mechanical power conversion through either motor, and power assist to the vehicle, reducing the engine load. The calculations will be for assist with the BAS motor, and a discussion of those results will follow.

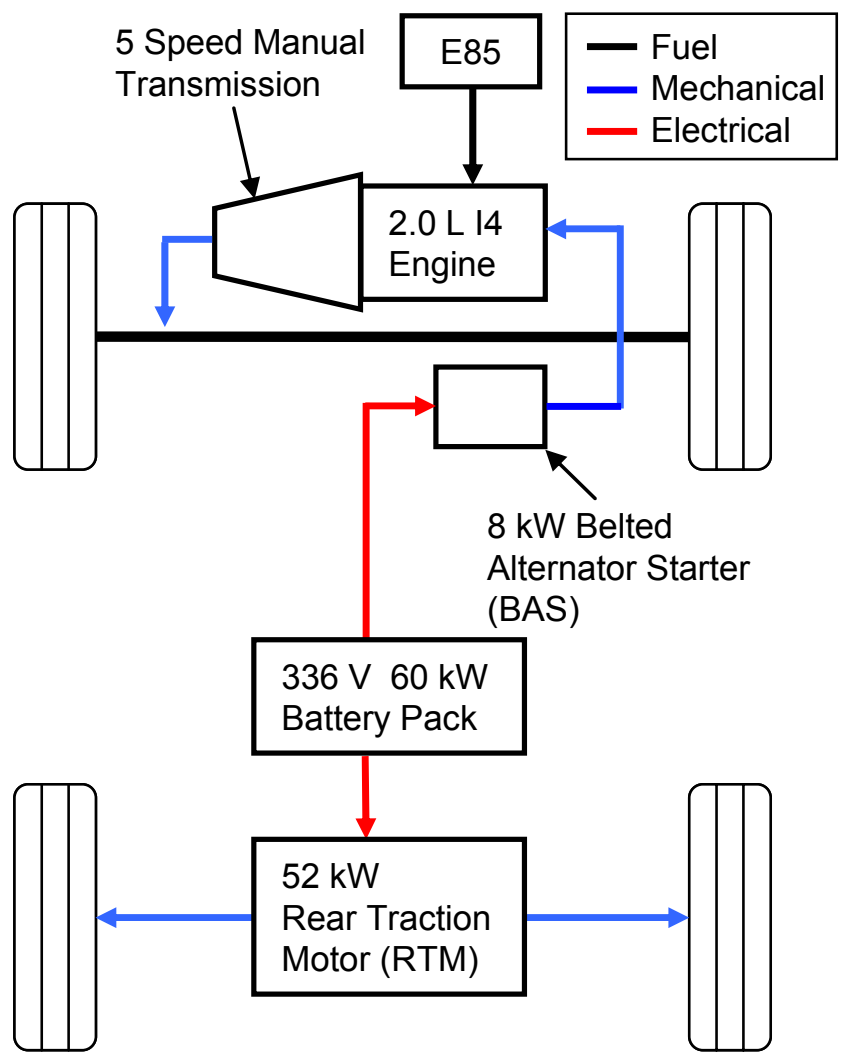

Figure 14. Engine assist mode energy flow diagram 
5.4.1 Calculating assist losses - The first step in calculating the losses in the engine assist mode is to calculate engine fuel use at the required torque and speed using equations 1 and 2. Then, the calculations for the BAS efficiency can be carried out in a similar manner. Given requested torque in $\mathrm{Nm}$ (BAS_trq) which is positive for engine assist, speed in rpm (Eng_spd), belt drive ratio (BAS_ratio), and efficiency of the motor at that operating point (BAS_eff) the power loss is calculated below. Since the BAS is converting electrical power into mechanical power, the power loss affects the mechanical power output.

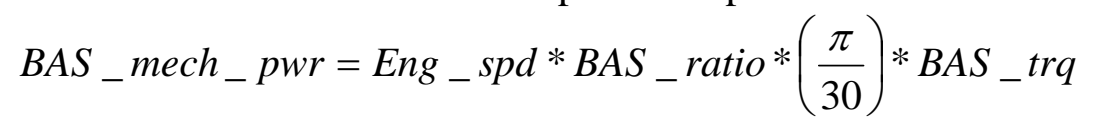

And

$$
B A S_{-} e l e c_{-} p w r=\frac{B A S_{-} \text {mech_pwr }}{B A S_{-} e f f}
$$

For example, the engine torque and speed is the same as the previous engine only mode example. This time, with the BAS assisting by $20 \mathrm{Nm}$, the torque load on the engine is reduced by $40 \mathrm{Nm}$ to $40 \mathrm{Nm}$ total, down from $80 \mathrm{Nm}$ in the engine only mode. So the total load on the engine becomes $40 \mathrm{Nm}$ and the engine efficiency decreases. The calculations are as follows

$$
\begin{gathered}
\text { Eng_pwr_out }=2000 *\left(\frac{\pi}{30}\right) * 40=8.38 \mathrm{~kW} \\
\text { Eng_fuel_use }=\frac{8.38 \mathrm{~kW}}{0.214}=39.1 \mathrm{~kW} \\
B A S_{-} \text {mech_pwr }=2000 * 2 *\left(\frac{\pi}{30}\right) * 20=8.38 \mathrm{~kW} \\
\text { BAS_elec_pwr }=\frac{8.38}{0.899}=9.31 \mathrm{~kW}
\end{gathered}
$$

Now that the required electrical input of the BAS at this torque and speed is known, the amount of power that must be sourced from the battery can be calculated. Note that for these calculations the discharge resistance and efficiency definition of the battery should be used.

$$
\begin{gathered}
I=\frac{364-\sqrt{364^{2}-4 * 0.435 * 9310}}{2 * 0.435}=26.4 \mathrm{~A} \\
P_{\text {loss }}=(26.4)^{2} * 0.435=303 \mathrm{~W} \\
P_{\text {out }}=9.31+0.303=9.61 \mathrm{~kW} \\
\text { ESS_eff }=\frac{9.31}{9.61}=96.8 \%
\end{gathered}
$$

Figure 15 is a simple schematic representation for this calculation. Since BAS mechanical power output and electrical power input have been calculated, BAS power loss is simply the difference of the two. 


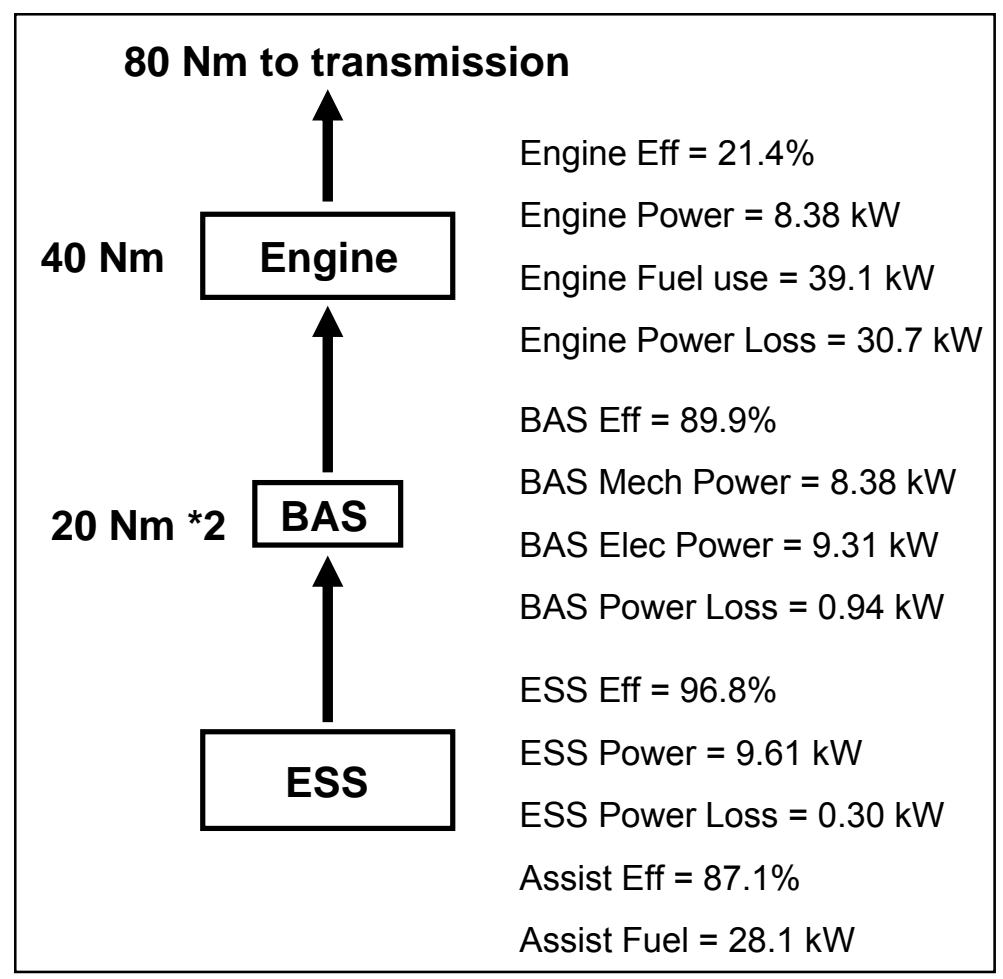

Figure 15. Engine assist mode energy flow schematic

5.4.2 Calculating assist fuel and efficiency - Assist fuel is the equivalent amount of fuel that was originally put into the battery through the engine generate case required to assist the engine. That is, starting with fuel going to the engine, through the BAS to the battery and back out again, it represents the amount of "fuel" the battery has to supply to the BAS to assist. Assist fuel is calculated using the equation

$$
\text { Assist_fuel }=\frac{P_{\text {out }}}{\text { Conversion_eff }}=\frac{9.61}{0.342}=28.1 \mathrm{~kW}
$$

This represents the equivalent amount of fuel power required to assist the engine with the BAS at this torque and speed. If a different operational point is used to calculate the conversion efficiency, then this number will change. Next, the assist efficiency represents how efficient the engine assist path is in comparison to the engine only path.

$$
\text { Assist_eff }=\frac{\text { Engine only fuel }}{\text { Assist_fuel }+ \text { Engine assist fuel }}=\frac{60.3}{28.1+39.1}=87.1 \%
$$

So, an assist efficiency of $100 \%$ would mean that the hybrid system assisting the engine is just as efficient as the engine meeting a higher load by itself. In this particular case, it took more power to generate, store, and provide power back to the engine through the hybrid system than simply using more fuel directly with the engine. This is because assisting the engine effectively lowers engine efficiency for this combination of torque and speed. Also, although the BAS motor and battery are reasonably efficient, assisting with the hybrid system means paying those power 
losses twice: once to store the power in the battery, and once to use the battery to power the BAS motor.

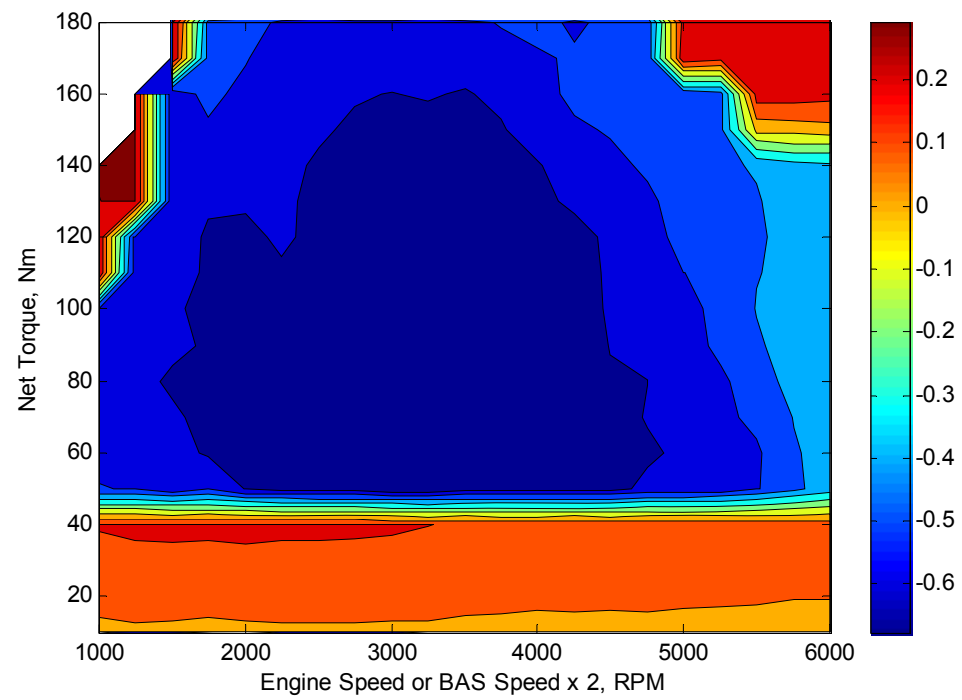

Figure 16. Engine assist mode contour plot which represents a change in engine efficiency over engine only operation

Figure 16 represents a contour plot of the difference between engine assist efficiency with a 20 $\mathrm{Nm}$ BAS torque and engine only efficiency. Because the BAS torque is $20 \mathrm{Nm}$, the plot doesn't change until $40 \mathrm{Nm}$ torque. For all torques within the engine's operating range above $40 \mathrm{Nm}$, the efficiency decreases due to the assist. Although this case was calculated using the BAS motor, the RTM would have the same effect of lowering the torque load on the engine, thus lowering its efficiency.

For maximum vehicle performance, instead of normal part load operation, the BAS motor and RTM should provide assist. In this case the driver isn't requesting a set amount of torque, but a "best effort" from the vehicle powertrain. To achieve the best possible performance, the engine should be assisted by the motors regardless of vehicle fuel efficiency.

\subsection{Electric only}

This mode uses the RTM to meet the driver torque request instead of the engine, as shown in Figure 17. This energy path represents sourcing power from the battery and electrical to mechanical power conversion through the RTM to power the vehicle. 


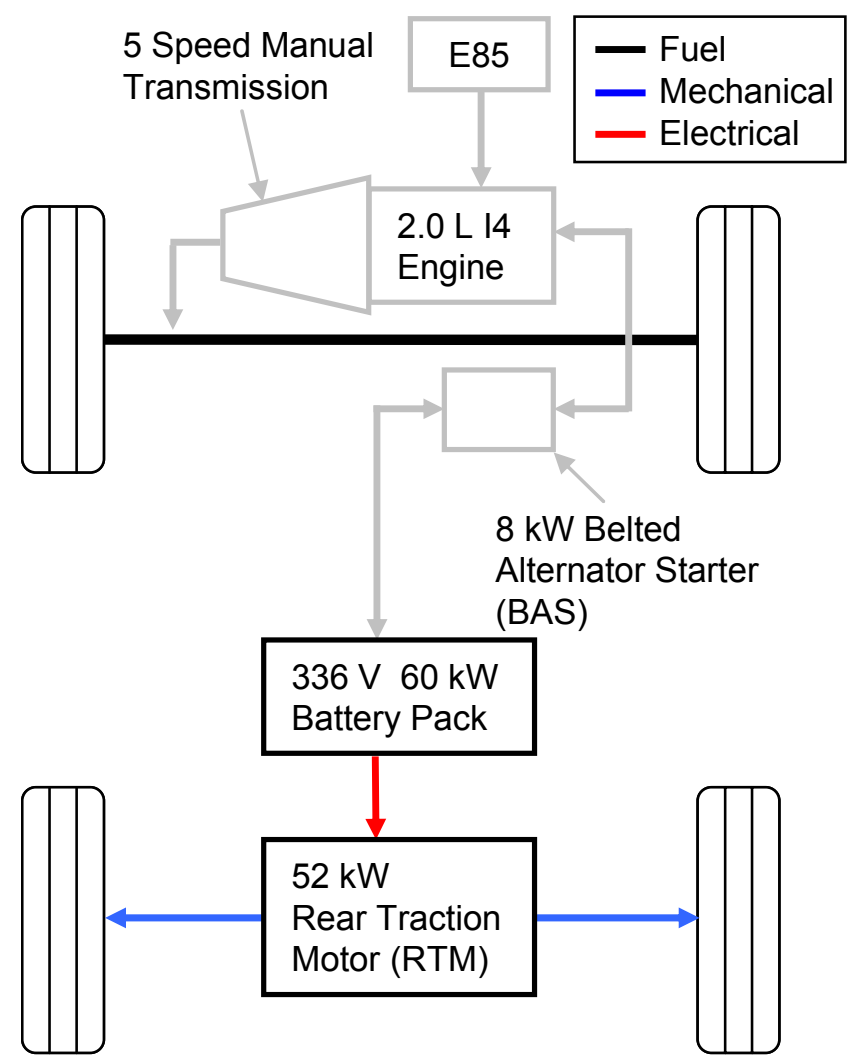

Figure 17. Electric only mode energy flow diagram

5.5.1 Calculating RTM losses - The losses in the electric only mode are due to the RTM and associated battery losses. As a comparison, engine fuel use at the required torque and speed is also calculated using equations 1 and 2. Then, the calculations for the RTM efficiency can be carried out in a similar manner. Given requested torque in Nm (RTM_trq) which is positive for torque assist, speed in rpm (RTM_spd), and efficiency of the motor at that operating point (RTM_eff) the power loss is calculated below. Since the RTM is converting electrical power into mechanical power, the power loss affects the mechanical power output.

$$
R T M_{-} \text {mech_pwr }=R T M_{-} s p d *\left(\frac{\pi}{30}\right) * R T M_{-} \text {trq }
$$

And

$$
R T M_{-} e l e c_{-} p w r=\frac{R T M_{-} \text {mech }_{-} p w r}{R T M_{-} e f f}
$$

As an example, torque is $20 \mathrm{Nm}$ and speed is $2000 \mathrm{RPM}$ for both the engine and RTM. Since this is electric only mode, the engine calculations are done only for comparison. The calculations are as follows

$$
\begin{gathered}
\text { Eng_pwr_out }=2000 *\left(\frac{\pi}{30}\right) * 20=4.19 \mathrm{~kW} \\
\text { Eng_fuel_use }=\frac{4.19 \mathrm{~kW}}{0.141}=29.7 \mathrm{~kW}
\end{gathered}
$$




$$
\begin{gathered}
R T M_{-} \text {mech_pwr }=2000 *\left(\frac{\pi}{30}\right) * 20=4.19 \mathrm{~kW} \\
R T M_{-} \text {elec_pwr }=\frac{4.19}{0.797}=5.26 \mathrm{~kW}
\end{gathered}
$$

Now that the required electrical input of the RTM at this torque and speed is known, the amount of power that must be sourced from the battery can be calculated. Note that for these calculations the discharge resistance and efficiency definition of the battery should be used.

$$
\begin{gathered}
I=\frac{364-\sqrt{364^{2}-4 * 0.435 * 5260}}{2 * 0.435}=14.7 \mathrm{~A} \\
P_{\text {loss }}=(14.7)^{2} * 0.435=94.0 \mathrm{~W} \\
P_{\text {out }}=5.26+0.094=5.35 \mathrm{~kW} \\
\text { ESS_eff }=\frac{5.26}{5.35}=98.3 \%
\end{gathered}
$$

Figure 18 is a simple schematic representation for this calculation. Since RTM mechanical power output and electrical power input have been calculated, RTM power loss is simply the difference of the two.

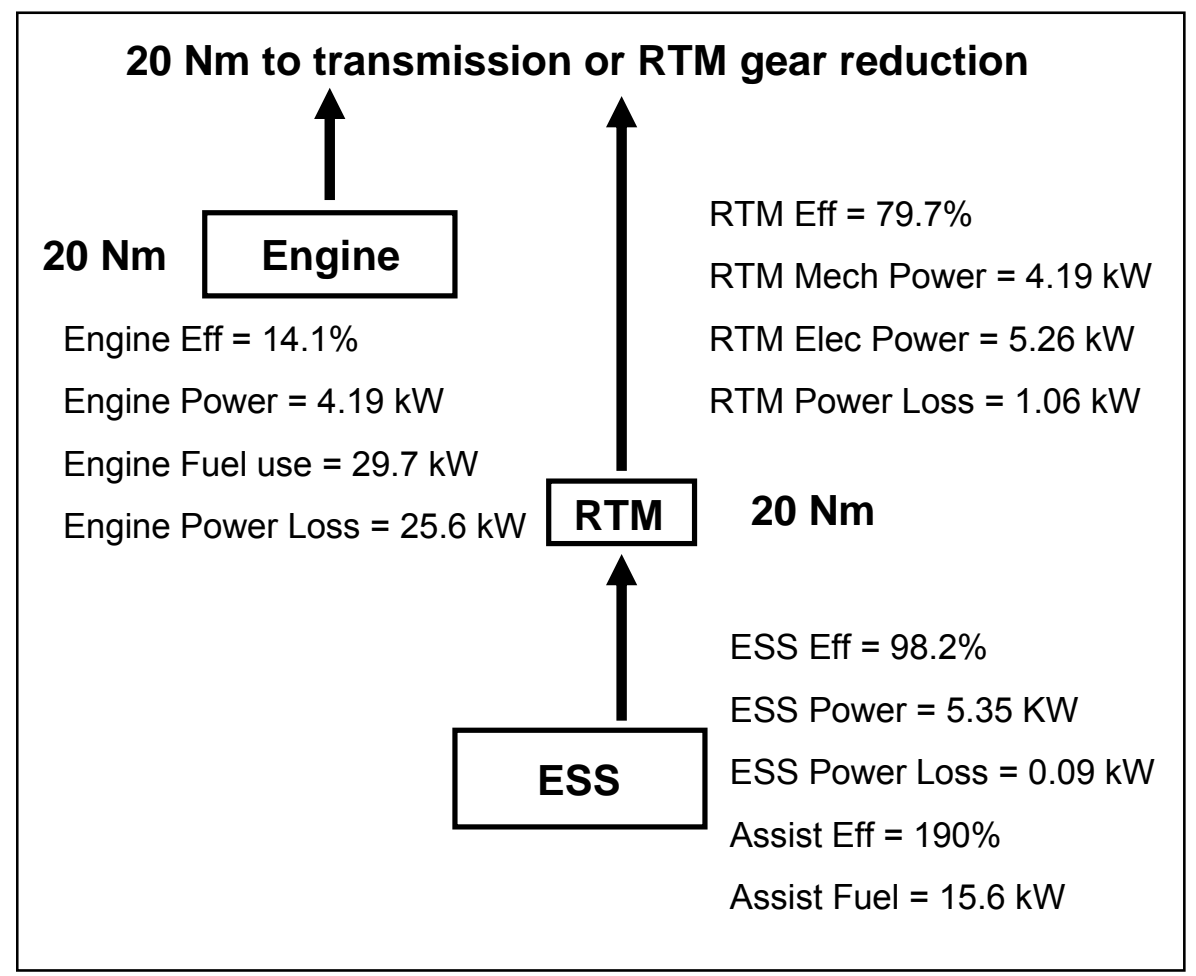

Figure 18. Electric only mode energy flow schematic compared to the engine only mode

5.5.2 Calculating assist fuel and efficiency - Assist fuel is the equivalent amount of fuel that was originally put into the battery through the engine generate case required to assist the 
engine. The conversion efficiency of 0.342 used in this calculation is for the torque and speed example calculations given previously. For electric only mode the engine is not being assisted and the RTM is meeting the driver demand, however, the assist fuel is calculated in the same way using equation 11.

$$
\text { Assist_fuel }=\frac{P_{\text {out }}}{\text { Conversion_eff }}=\frac{5.35}{0.342}=15.6 \mathrm{~kW}
$$

This represents the equivalent amount of fuel power required to meet the driver demand with the RTM at this torque and speed. If a different operational point is used to calculate the conversion efficiency, then this number will change. Next, the assist efficiency represents how efficient the electric only path is in comparison to the engine only path.

$$
\text { Assist_eff }=\frac{\text { Engine only fuel }}{\text { Assist_fuel }+ \text { Engine assist fuel }}=\frac{29.7}{15.6+0}=190 \%
$$

Again, an assist efficiency of $100 \%$ in this case would mean that the RTM was just as efficient as the engine in meeting the driver demand. But with an assist efficiency of over $100 \%$ for this torque and speed, the RTM was much more efficient in powering the vehicle at this low power level, despite the losses in the hybrid system. Essentially, the engine efficiency was lower than the roundtrip losses in the hybrid system, given that the energy stored in the battery was generated at a high enough conversion efficiency.

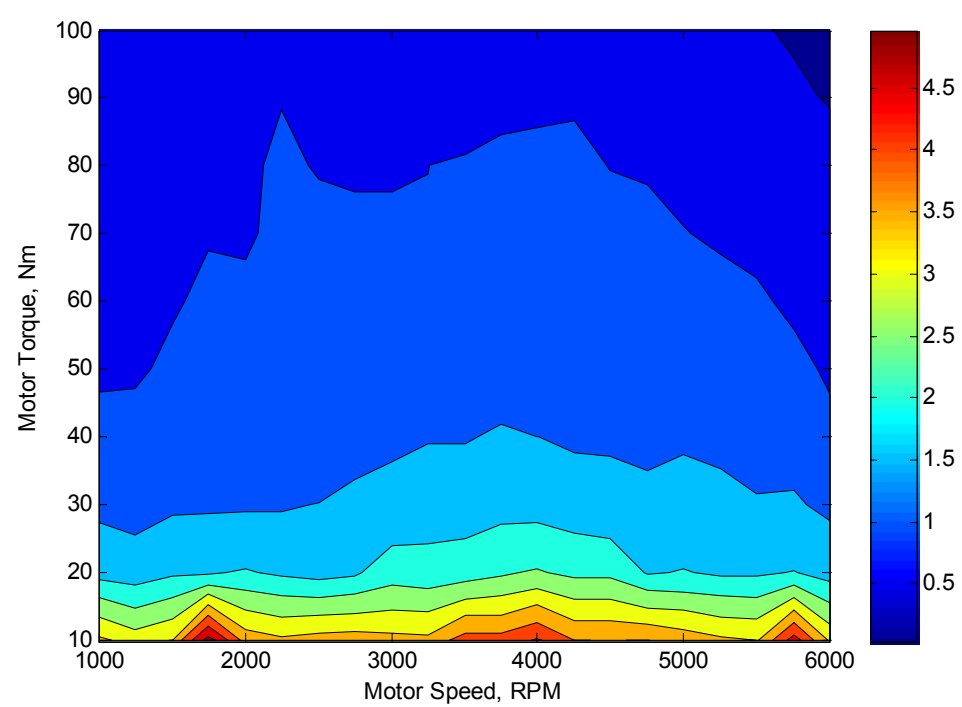

Figure 19. Electric only mode assist efficiencies for a range of torques and speeds

Figure 19 represents a contour plot of the assist efficiencies for the electric only mode. At low loads, the RTM can be as much as 4 times more efficient at providing power to the vehicle than the engine, even when taking into account that the engine had to burn fuel at some efficiency to get energy into the battery for the RTM to use. When the contour is equal to 1, the RTM is 
equally as efficient as the engine only case. Thus, using exclusively the RTM to power the vehicle at very low loads is a benefit that the hybrid strategy should try to utilize.

\subsection{Regenerative braking}

This section will address what effects regenerative braking have on the calculations performed for the control strategy model. Regenerative braking is an interesting case because it literally represents "free" energy. It is "free" because the vehicle must accelerate to a given speed to meet driver demand, and the vehicle must stop when a negative torque is requested by the driver. Regenerative braking simply uses the RTM as a generator to assist the slowing of the vehicle by applying a negative torque and charging the battery, as represented in Figure 20. So there is no fuel contribution to regenerative braking, it is just extra energy that is added to the battery. The issue is that regenerative braking is drive cycle dependant, and therefore cannot be completely controlled by the control strategy. The vehicle controller, however, does mix regenerative brake energy from the RTM with the vehicle friction brakes for safety and when the SOC of the battery is too high and should not accept a higher charge. The BAS motor could be used for regenerative braking as well, but for higher fuel efficiency the engine should be shut off during braking, and then the BAS speed would be zero.

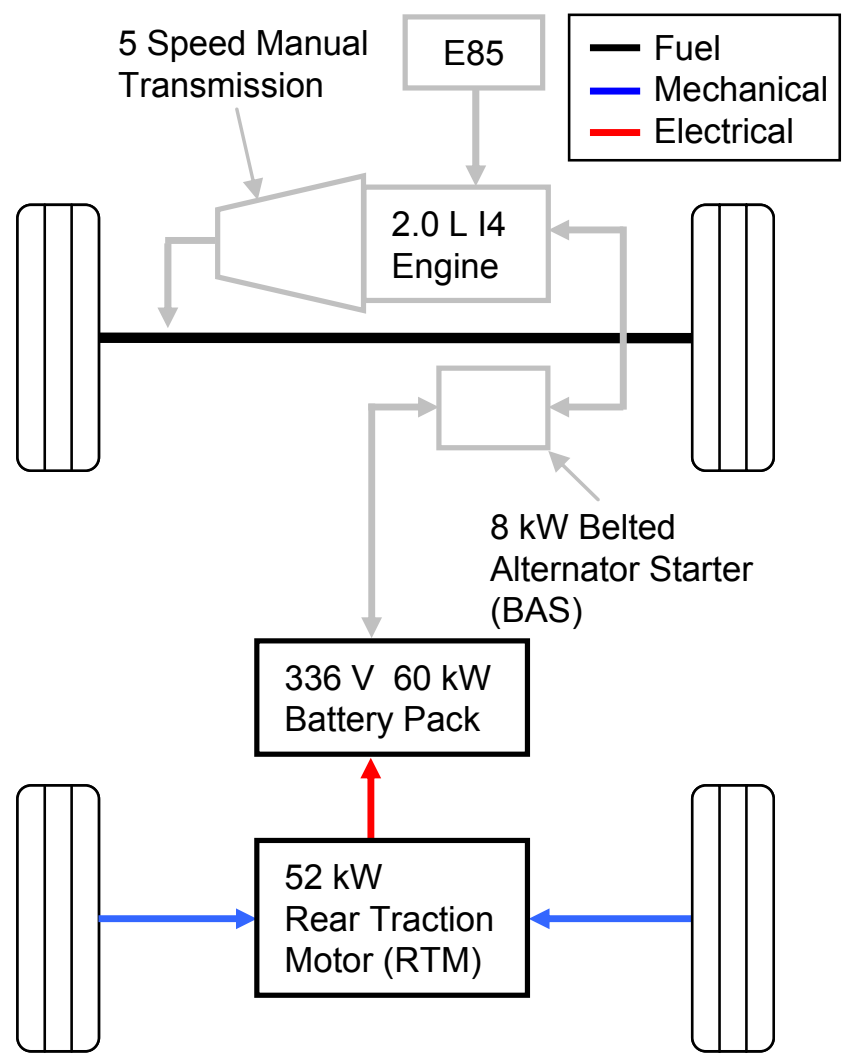

Figure 20. Regenerative braking mode energy flow diagram

5.6.1 Calculating regenerative braking losses - The losses for regenerative braking come from the RTM converting mechanical power to electrical power and then losses in the battery from storing that power. Given requested torque in Nm (RTM_trq) which is negative for 
regenerative braking, speed in rpm (RTM_spd), and efficiency of the motor at that operating point (RTM_eff) the power loss is calculated below.

$$
R T M_{-} \text {mech_pwr }=R T M_{-} s p d *\left(\frac{\pi}{30}\right) * R T M_{-} t r q
$$

And

$$
R T M_{-} e l e c_{-} p w r=R T M_{-} m e c h_{-} p w r * R T M_{-} e f f
$$

As an example, the requested torque is $-20 \mathrm{Nm}$ and speed is $2000 \mathrm{RPM}$.

$$
\begin{gathered}
R T M_{-} \text {mech_p }_{-} w r=2000 *\left(\frac{\pi}{30}\right) *-20=-4.19 \mathrm{~kW} \\
R T M_{\text {_elec_p }} \mathrm{pwr}=-4.19 * 0.797=-3.34 \mathrm{~kW}
\end{gathered}
$$

Now that the electrical output of the RTM at this torque and speed is known, the amount of power that is actually stored in the battery can be calculated. Note that for these calculations the charge resistance and efficiency definition of the battery should be used.

$$
\begin{gathered}
I=\frac{364-\sqrt{364^{2}-4 * 0.378 *-3340}}{2 * 0.378}=-9.09 \mathrm{~A} \\
P_{\text {loss }}=(-9.09)^{2} * 0.378=31.2 \mathrm{~W} \\
P_{\text {stored }}=-3.34+0.031=-3.31 \mathrm{~kW} \\
\text { ESS_eff }=\frac{-3.31}{-3.34}=99.1 \%
\end{gathered}
$$

Figure 21 is a simple schematic representation for this calculation. Since RTM mechanical power output and electrical power input have been calculated, RTM power loss is simply the difference of the two. 


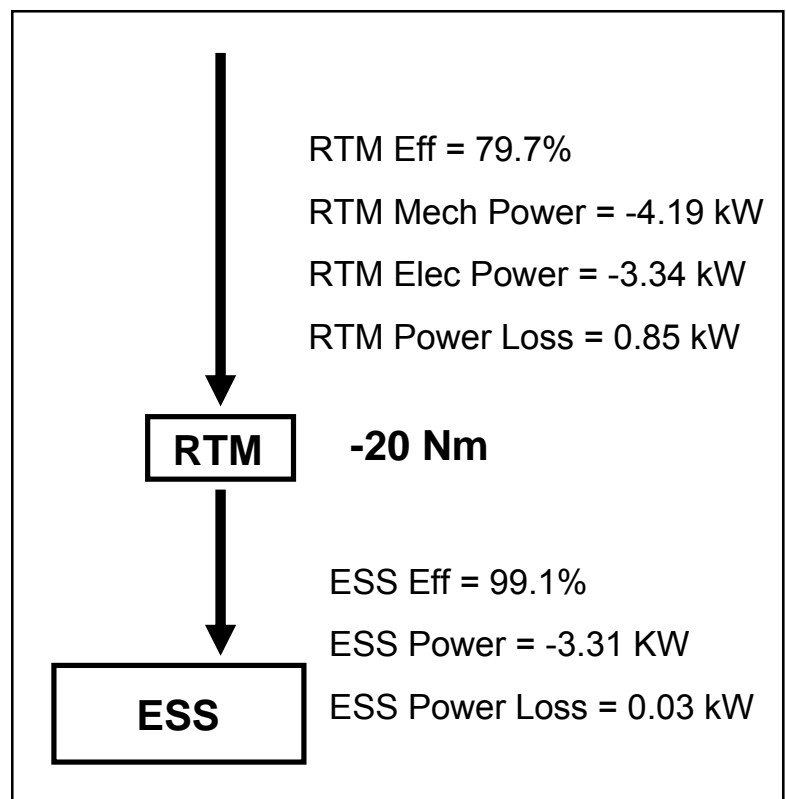

Figure 21. Regenerative braking energy flow schematic

Without knowing how much regenerative braking energy reaches the battery, it is difficult to calculate the effects this captured energy has on the control strategy. Mathematically, more energy stored in the battery from regenerative braking has the affect of inflating the overall conversion efficiency of the system, because for the same amount of engine fuel more energy is reaching the battery. This would make the hybrid system appear more efficient, because it takes less fuel for the same amount of stored power. An attempt at estimating an overall conversion efficiency including regenerative braking contributions will be made later in this paper.

This section presents the loss calculations specific to each hybrid mode. With the model developed to this far, a few straightforward considerations will help to further define a control strategy for the vehicle. 


\section{Practical Considerations for Analysis}

Now that the loss calculations for each mode are documented, they need to be applied to form an overall control strategy for the SPA HEV. Normal engine operation areas, in the form of torques and speeds, are defined to simplify the analysis and eventually calculate the average conversion efficiency. This allows for direct fuel energy to stored energy comparison, which enables further specification of other control mode operational areas.

\subsection{Defining the areas of normal engine operation}

To focus the development of a control strategy, the areas of normal engine operation need to be defined, similar to the approach used in the Saturn VUE Hybrid model paper [2]. Normal engine operation is determined by the operational torques and speeds that the engine would experience over most drive cycles. This includes urban driving, highway driving, and mixed cycles. Appendix A contains engine operational points for a number of drive cycles including the UDDS, HWFET, US06, and other test cycles which vehicle data was available for. The data for the UDDS, HWFET, and US06 drive cycles came from a vehicle model of the Equinox REV $_{\mathrm{LSE}}$ developed in PSAT. All of these drive cycles represent different types of driving under normal, hot start conditions. Two of the drive cycles from vehicle data (sections A.4 and A.6) include best effort accelerations from zero speed to above $100 \mathrm{kph}$ (60 mph). The z-axis on the three dimensional contour plots represents time of operation in seconds. Note that negative engine torques are not included in these plots, for two reasons. First, the vehicle is capable of turning the engine off to avoid idle time, even while capturing regenerative braking, so the engine should not show significant operational time at negative torques. Second, the purpose of this data is to define where the engine normally operates during vehicle propulsion (when driver torque demand is greater than zero) not during deceleration or idle. Table 8 also weighs into this analysis. Given a small set of reasonable constant speeds, and vehicle parameters for the Equinox $\mathrm{REV}_{\mathrm{LSE}}$, engine torque and speed can be calculated with simple road load calculations. Some speeds might be encountered in different gears, and some of those combinations are also included in this table. 
Table 8. Engine torques and speeds for the Equinox REV $_{\mathrm{LSE}}$ given a constant speed and transmission gear

\begin{tabular}{|r|r|r|r|r|r|r|}
\hline $\begin{array}{r}\text { Vehicle } \\
\text { Speed (mph) }\end{array}$ & \multicolumn{1}{l|l|l}{$\begin{array}{l}\text { Gear } \\
20\end{array}$} & $\begin{array}{l}\text { Engine } \\
\text { RPM }\end{array}$ & $\begin{array}{l}\text { Engine } \\
\text { Power (kW) }\end{array}$ & $\begin{array}{l}\text { Engine } \\
\text { Torque (Nm) }\end{array}$ & $\begin{array}{l}\text { RTM } \\
\text { RPM } \\
230\end{array}$ & $\begin{array}{l}\text { RTM } \\
\text { Torque (Nm) }\end{array}$ \\
\hline 25 & 4 & 1160 & 3.5 & 24 & 3737 & 6.4 \\
\hline 30 & 4 & 1390 & 4 & 28 & 4488 & 8.5 \\
\hline 30 & 5 & 1040 & 4 & 38 & 4488 & 8.5 \\
\hline 35 & 4 & 1630 & 5.5 & 33 & 5233 & 10 \\
\hline 35 & 5 & 1210 & 6 & 44 & 5233 & 10 \\
\hline 40 & 5 & 1380 & 7 & 52 & 5980 & 11 \\
\hline 45 & 5 & 1550 & 10 & 59 & 6727 & 14 \\
\hline 50 & 5 & 1720 & 12.5 & 68 & 7475 & 16 \\
\hline 55 & 5 & 1900 & 15.5 & 78 & 8223 & 18 \\
\hline 60 & 5 & 2070 & 19 & 89 & 8970 & 20 \\
\hline
\end{tabular}

After studying this data, an engine speed range of 0-3000 RPM and 0-maxiumum engine torque over that range was determined as the normal operating zone of the engine. The maximum engine torque or "torque envelope" varies with speed, and is best illustrated in the engine efficiency map of Figure 9, generally going from a minimum of $140 \mathrm{Nm}$ at $1000 \mathrm{RPM}$ to a maximum of $220 \mathrm{Nm}$ at $1750 \mathrm{RPM}$.

\subsection{Calculation of average conversion efficiency}

Although the conversion efficiency of fuel to stored energy can be calculated for any torque and speed combination, without a prior knowledge of the drive cycle the effective conversion efficiency is unknown. To make control strategy decisions, a conversion efficiency that is representative of what the vehicle could achieve over a normal drive cycle is needed. Since normal engine operating areas are now established, an average conversion efficiency over these operational points can be calculated.

Table 9 is generated through a short computational program that calculates the conversion efficiency for each operational point. The torque load that the BAS places on the engine is varied for each point from $5 \mathrm{Nm}$ to the BAS maximum of $25 \mathrm{Nm}$, not exceeding $8 \mathrm{~kW}$ of power. Highlighted boxes in the table represent conversion efficiencies that are higher with a high BAS torque load of $10 \mathrm{Nm}$ or above. A torque request of above $10 \mathrm{Nm}$ on the BAS represents a significant load on the engine, and therefore would store more power in the ESS. In general, the torque load of the BAS is not a large factor in the conversion efficiency. The two values of 2.70 and 0.65 for $10 \mathrm{Nm}$ output torque are correct. At this low load, increasing the load on the engine effectively doubles its efficiency, so the extra fuel used to energy stored ratio becomes quite large. Realistically, a load this low on the engine would not happen often, and when it did the duration of operating at this point would not be significant. Figure 22 is a contour plot of these conversion efficiencies mapped against engine speed and net torque output to the transmission, and shows that the majority of them are above $30 \%$. The average of these efficiencies is 0.338 , so $34 \%$ will represent the average conversion efficiency for the remainder of the calculations used to determine a hybrid strategy. Note again that the conversion efficiency does not represent 
a direct fuel to energy conversion, but the "marginal" efficiency represented by the increase of fuel needed above the engine only mode to store energy in the battery.

Table 9. Conversion efficiencies for specified net torque output and speed values. Highlighted boxes represent efficiencies where the BAS torque is higher than $10 \mathrm{Nm}$.

\begin{tabular}{|r|r|r|r|r|r|r|r|r|r|}
\hline Combined & \multicolumn{8}{|c|}{ Engine Speed (rpm) and BAS speed/2 (rpm) } \\
\cline { 2 - 10 } Torque (Nm) & 1000 & 1250 & 1500 & 1750 & 2000 & 2250 & 2500 & 2750 & 3000 \\
\hline 10 & 0.46 & 0.39 & 0.40 & 2.70 & 0.49 & 0.42 & 0.65 & 0.47 & 0.37 \\
\hline 20 & 0.35 & 0.35 & 0.39 & 0.40 & 0.47 & 0.40 & 0.34 & 0.35 & 0.42 \\
\hline 30 & 0.34 & 0.34 & 0.39 & 0.37 & 0.34 & 0.33 & 0.40 & 0.38 & 0.37 \\
\hline 40 & 0.32 & 0.36 & 0.33 & 0.38 & 0.35 & 0.36 & 0.33 & 0.35 & 0.33 \\
\hline 50 & 0.31 & 0.31 & 0.34 & 0.34 & 0.36 & 0.34 & 0.36 & 0.33 & 0.36 \\
\hline 60 & 0.31 & 0.32 & 0.33 & 0.35 & 0.36 & 0.37 & 0.36 & 0.36 & 0.38 \\
\hline 70 & 0.31 & 0.32 & 0.34 & 0.35 & 0.34 & 0.34 & 0.42 & 0.37 & 0.37 \\
\hline 80 & 0.33 & 0.32 & 0.34 & 0.34 & 0.34 & 0.36 & 0.36 & 0.37 & 0.32 \\
\hline 90 & 0.34 & 0.33 & 0.34 & 0.34 & 0.37 & 0.39 & 0.36 & 0.32 & 0.34 \\
\hline 100 & 0.28 & 0.35 & 0.36 & 0.34 & 0.39 & 0.42 & 0.34 & 0.33 & 0.36 \\
\hline 110 & 0.28 & 0.35 & 0.36 & 0.35 & 0.40 & 0.43 & 0.35 & 0.35 & 0.36 \\
\hline 120 & 0.30 & 0.28 & 0.29 & 0.35 & 0.42 & 0.32 & 0.35 & 0.36 & 0.33 \\
\hline 130 & 0.29 & 0.28 & 0.29 & 0.35 & 0.42 & 0.33 & 0.35 & 0.36 & 0.34 \\
\hline 140 & & 0.25 & 0.29 & 0.33 & 0.30 & 0.33 & 0.33 & 0.33 & 0.35 \\
\hline 150 & & 0.24 & 0.29 & 0.32 & 0.29 & 0.32 & 0.32 & 0.33 & 0.35 \\
\hline 160 & & & 0.28 & 0.25 & 0.28 & 0.29 & 0.30 & 0.32 & 0.35 \\
\hline 170 & & & 0.28 & 0.24 & 0.27 & 0.29 & 0.30 & 0.32 & 0.35 \\
\hline 180 & & & 0.22 & 0.18 & 0.22 & 0.23 & 0.27 & 0.27 & 0.25 \\
\hline 190 & & & 0.22 & 0.17 & 0.21 & 0.22 & 0.26 & 0.26 & 0.25 \\
\hline 200 & & & &
\end{tabular}

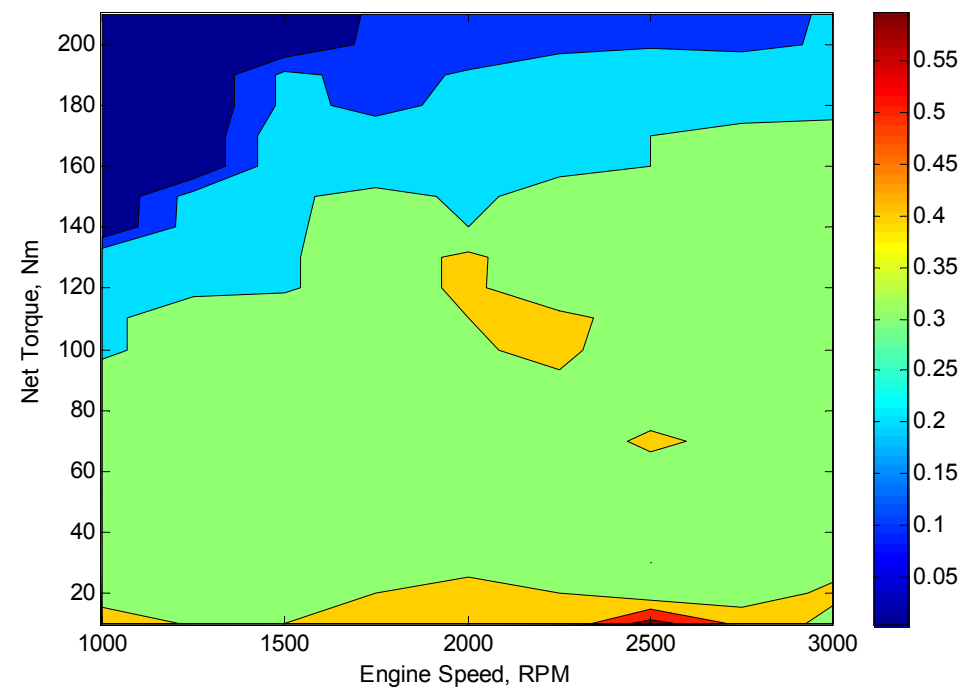

Figure 22. Conversion efficiency contour plot based on the numbers in Table 9 


\subsection{Regenerative braking contributions to conversion efficiency}

Regenerative braking will have the affect of increasing the conversion efficiency of the hybrid system. Since regenerative braking requires no fuel energy, as discussed in section 5.6.1, there will be more energy stored in the battery than equivalent to the amount of fuel required by the conversion efficiency. However, the amount of energy produced by regenerative braking will vary greatly with the drive cycle and individual driver, as fast stops leave a smaller window of opportunity for regenerative braking, so less energy is captured. So, the affect of regenerative braking on conversion efficiency will be measured by estimating the greatest amount of regenerative braking energy that could be captured over a reasonable drive cycle and comparing that case to a drive cycle without any regenerative braking at all.

The drive cycle used for this case is the UDDS drive cycle, which represents city "stop and go" driving conditions, as shown in Appendix A.1. Over the UDDS drive cycle, the REV $V_{\text {LSE }}$ hybrid vehicle model required $3407 \mathrm{~kJ}$ of energy, or about $2.5 \mathrm{~kW}$ (3.5 hp) to keep the high voltage battery charged, including the electric accessory loads. This does not have to be a constant power, but it is evaluated this way for simplicity. To meet that energy requirement at an average conversion efficiency of 34\% it would take about $10 \mathrm{MJ}$ of fuel energy. Now consider that over the UDDS drive cycle, which includes a lot of opportunities for regenerative braking, the RTM was able to provide $407 \mathrm{~kJ}$ of energy to the battery. That decreased the amount of fuel that the BAS needed to provide through the engine generate mode, and with the same $34 \%$ conversion efficiency required only 8.8 MJ of fuel energy. Using equation 9, the conversion efficiency equals the stored energy over the fuel used, and the regenerative braking energy contribution increases the conversion efficiency to $39 \%$. Table 10 summarizes these results.

Table 10. Tabulated calculations for the effects of regenerative braking on conversion efficiency over the UDDS

\begin{tabular}{|l|rl|}
\hline Total stored energy needed for UDDS & 3407 & $\mathrm{~kJ}$ \\
\hline BAS generate fuel energy needed @ 34\% & 10021 & $\mathrm{~kJ}$ \\
\hline Regenerative braking energy contribution & 407 & $\mathrm{~kJ}$ \\
\hline BAS generate fuel energy needed w/regen & 8824 & $\mathrm{~kJ}$ \\
\hline Apparent conversion efficiency w/regen & $39 \%$ & \\
\hline
\end{tabular}

\subsection{Impact of average conversion efficiency on assist efficiency}

As covered in section 5.5.2, the assist efficiency is the ratio of engine only fuel compared to stored energy required to meet driver demand through the RTM. When this ratio is above one, then it is more efficient to use stored energy to power the vehicle, despite the losses in generating, storing, and converting the energy through the hybrid system. Now that an average conversion efficiency is established, the torque and speed regions of favorable electric only operation can be defined. Table 11 represents assist efficiencies calculated using the average conversion efficiency of $34 \%$ for the shown torques and speeds of the RTM compared to engine only operation at these points. The highlighted cells show when the assist efficiency is above one and electric only mode is preferred. Figure 23 is the same table of assist efficiencies shown as contours of efficiency. Both Table 11 and Figure 23 are cut off at $140 \mathrm{Nm}$ because the assist efficiency only continues to go down with higher torques, so the smaller range of torques gives better resolution. These are tables of assist efficiency compared to engine only efficiency at the 
same torques and speeds. Refer to Table 8 for an idea of what motor rotor speeds and torques the vehicle would require at different vehicle speeds.

Table 11. Table of assist efficiencies with an average conversion efficiency of $34 \%$

\begin{tabular}{|r|r|r|r|r|r|r|r|r|r|}
\hline \multirow{2}{*}{ Torque (Nm) } & \multicolumn{7}{|c|}{ RTM Speed (rpm) or Engine Speed (rpm) } \\
\cline { 2 - 11 } & 1000 & 1250 & 1500 & 1750 & 2000 & 2250 & 2500 & 2750 & 3000 \\
\hline 10 & 3.29 & 3.01 & 3.14 & 3.64 & 3.32 & 3.23 & 3.33 & 3.33 & 3.42 \\
\hline 20 & 1.85 & 1.76 & 1.83 & 1.86 & 1.89 & 1.89 & 1.84 & 1.92 & 2.08 \\
\hline 30 & 1.42 & 1.36 & 1.41 & 1.42 & 1.42 & 1.45 & 1.50 & 1.53 & 1.57 \\
\hline 40 & 1.20 & 1.18 & 1.19 & 1.22 & 1.24 & 1.28 & 1.27 & 1.29 & 1.33 \\
\hline 50 & 1.08 & 1.05 & 1.08 & 1.09 & 1.13 & 1.14 & 1.16 & 1.16 & 1.21 \\
\hline 60 & 1.00 & 1.00 & 1.01 & 1.03 & 1.04 & 1.07 & 1.07 & 1.09 & 1.11 \\
\hline 70 & 0.94 & 0.94 & 0.95 & 0.97 & 0.98 & 1.00 & 1.02 & 1.02 & 1.03 \\
\hline 80 & 0.91 & 0.90 & 0.91 & 0.92 & 0.93 & 0.95 & 0.95 & 0.96 & 0.97 \\
\hline 90 & 0.87 & 0.87 & 0.87 & 0.88 & 0.89 & 0.90 & 0.90 & 0.90 & 0.92 \\
\hline 100 & 0.84 & 0.84 & 0.84 & 0.84 & 0.86 & 0.87 & 0.86 & 0.87 & 0.89 \\
\hline 110 & 0.82 & 0.81 & 0.81 & 0.82 & 0.83 & 0.82 & 0.83 & 0.84 & 0.84 \\
\hline 120 & 0.81 & 0.78 & 0.78 & 0.79 & 0.79 & 0.78 & 0.80 & 0.80 & 0.80 \\
\hline 130 & 0.78 & 0.76 & 0.76 & 0.76 & 0.76 & 0.76 & 0.77 & 0.77 & 0.77 \\
\hline 140 & 0.76 & 0.74 & 0.74 & 0.73 & 0.72 & 0.74 & 0.73 & 0.73 & 0.73 \\
\hline
\end{tabular}

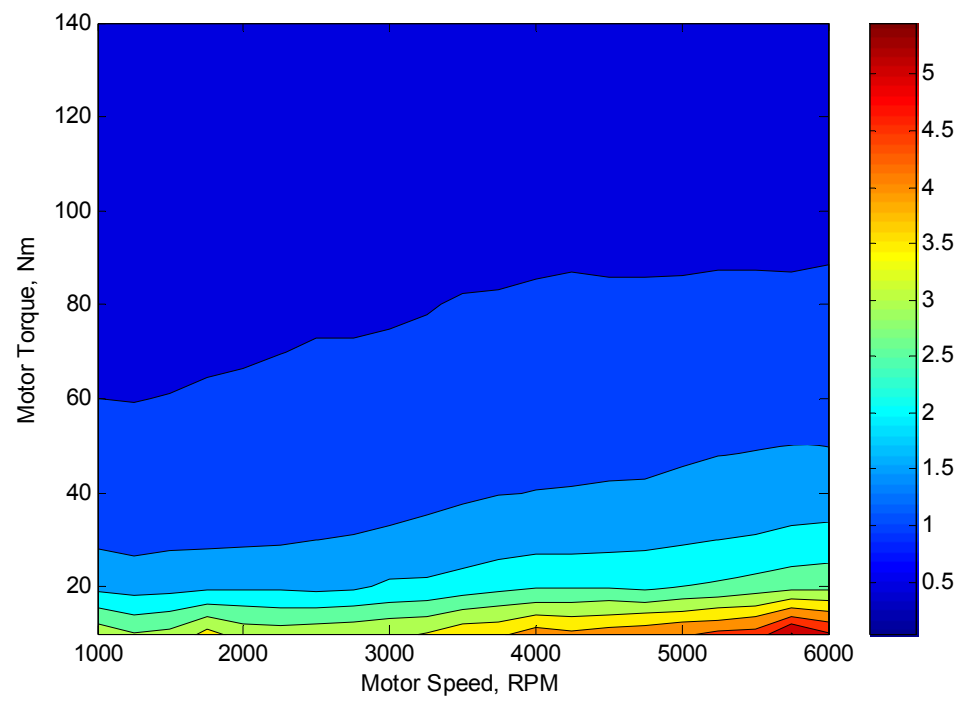

Figure 23. Electric only (assist) efficiency contour plot based on the numbers in Table 11, and a constant average conversion efficiency of $34 \%$

Increasing the conversion efficiency to 39\% accounts for a large amount of regenerative braking, specifically the amount of braking observed over the UDDS. Table 12 and Figure 24 represent the same assist efficiency calculations performed above, but with a conversion efficiency 5\% higher. This higher conversion efficiency allows the electric only mode to appear more efficient, and therefore be more efficient than the engine only mode at even higher torques than before. 
Table 12. Table of assist efficiencies with a conversion efficiency of 39\%, meant to represent contributions from regenerative braking on the UDDS

\begin{tabular}{|r|r|r|r|r|r|r|r|r|r|}
\hline \multirow{2}{*}{ Torque (Nm) } & \multicolumn{8}{|c|}{ RTM Speed (rpm) or Engine Speed (rpm) } \\
\cline { 2 - 11 } & 1000 & 1250 & 1500 & 1750 & 2000 & 2250 & 2500 & 2750 & 3000 \\
\hline 10 & 3.77 & 3.45 & 3.61 & 4.17 & 3.81 & 3.71 & 3.81 & 3.82 & 3.92 \\
\hline 20 & 2.12 & 2.02 & 2.10 & 2.13 & 2.17 & 2.17 & 2.11 & 2.20 & 2.38 \\
\hline 30 & 1.63 & 1.56 & 1.62 & 1.63 & 1.63 & 1.66 & 1.72 & 1.75 & 1.80 \\
\hline 40 & 1.38 & 1.35 & 1.36 & 1.40 & 1.42 & 1.46 & 1.45 & 1.48 & 1.53 \\
\hline 50 & 1.24 & 1.21 & 1.24 & 1.25 & 1.30 & 1.31 & 1.33 & 1.33 & 1.39 \\
\hline 60 & 1.15 & 1.14 & 1.15 & 1.18 & 1.20 & 1.23 & 1.23 & 1.25 & 1.28 \\
\hline 70 & 1.08 & 1.08 & 1.09 & 1.11 & 1.12 & 1.14 & 1.17 & 1.17 & 1.18 \\
\hline 80 & 1.05 & 1.03 & 1.04 & 1.05 & 1.06 & 1.09 & 1.09 & 1.10 & 1.11 \\
\hline 90 & 1.00 & 1.00 & 0.99 & 1.00 & 1.03 & 1.04 & 1.04 & 1.04 & 1.06 \\
\hline 100 & 0.96 & 0.97 & 0.97 & 0.97 & 0.98 & 1.00 & 0.99 & 1.00 & 1.02 \\
\hline 110 & 0.94 & 0.93 & 0.93 & 0.94 & 0.95 & 0.95 & 0.95 & 0.96 & 0.97 \\
\hline 120 & 0.93 & 0.89 & 0.89 & 0.90 & 0.91 & 0.90 & 0.92 & 0.92 & 0.92 \\
\hline 130 & 0.90 & 0.87 & 0.87 & 0.87 & 0.87 & 0.87 & 0.88 & 0.88 & 0.88 \\
\hline 140 & 0.87 & 0.85 & 0.85 & 0.84 & 0.83 & 0.84 & 0.84 & 0.84 & 0.84 \\
\hline
\end{tabular}

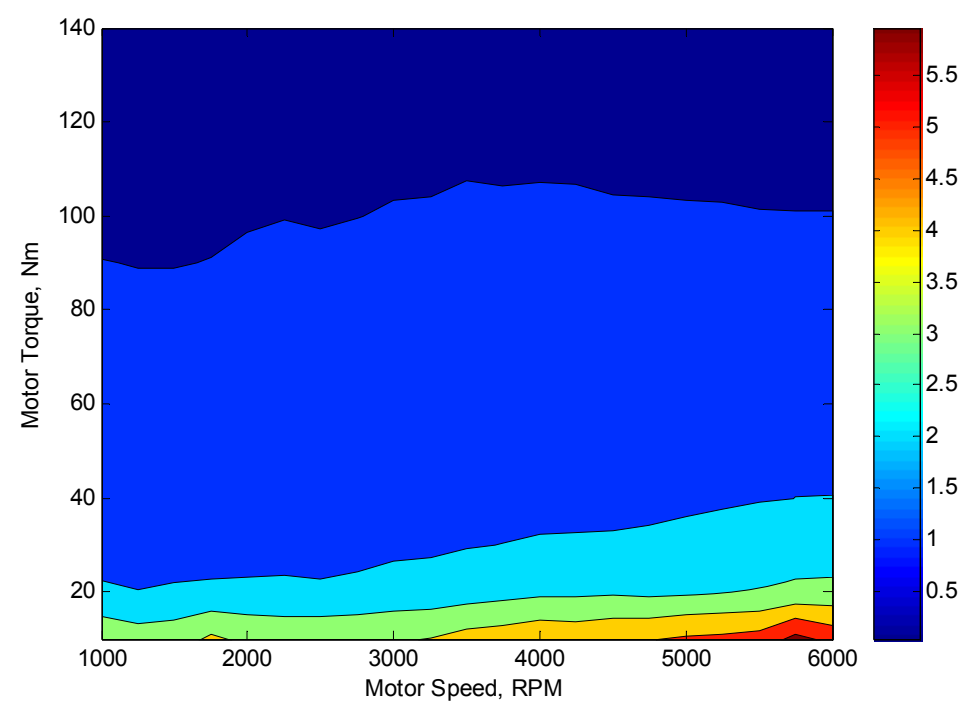

Figure 24. Electric only (assist) efficiency contour plot based on the numbers in Table 12, with a conversion efficiency of $39 \%$ representing regenerative brake energy contributions from the UDDS

This section defines normal engine operational areas, and then used that definition to establish an average conversion efficiency. To account for regenerative brake energy capture, the average conversion efficiency can be increased, depending on the drive cycle. The next section covers how this model can address vehicle emissions in addition to fuel efficiency, which has been the primary focus so far. 


\section{Vehicle Emissions Considerations}

Vehicle emissions are difficult to model, and really a dynamometer test is the only way to accurately measure changes or improvements to vehicle emissions. However, just as fuel economy is important for a vehicle, emissions must also be considered. This section will address what issues are known for vehicle emissions, and how they can be addressed through a control strategy.

\subsection{Cold start emissions}

Cold start emissions are where the majority of emissions are created for a spark ignited engine, so this remains true for the $\mathrm{REV}_{\mathrm{LSE}}$. Based on the literature review, the best strategy to reduce cold start emissions is to control the engine so that it reaches its operational temperature sooner while at reasonably light loads to promote catalyst heating while not letting too many harmful emissions go by. The primary catalyst temperature is the one of most interest, which can take about 30 seconds to reach effective operational ("light off") temperatures depending on engine operation. With the BAS, the control strategy could easily place a load on the engine that is beneficial to increasing the catalyst temperature fast, which would be independent of driver demand. Also, for low to medium torque requests, the RTM could meet driver demand exclusively in electric only mode, and then the BAS would have complete control over the engine load during catalyst warm up. Although the battery cannot store enough energy to drive the vehicle for a long distance, it does have the capacity to meet reasonable driver demands for short periods, like those required for warm up.

\subsection{Engine operation emissions}

Although a three way catalyst (TWC) system is very effective in reducing engine emissions, some consideration should be given to the operational regions of the engine with regards to emissions, just as it has been with fuel economy. Figure 25 is an estimated map of emissions for the Saab Biopower engine, with high NOx areas highlighted in red and dark red, and high CO emissions in blue and medium blue. These emissions regions represent direct engine out emissions, before reaching the catalyst. Measured catalyst out emissions may vary based on catalyst loading. That is, depending on the instantaneous state of the catalyst, certain emissions (like NOx) may or may not "breakthrough" or saturate the catalyst. This is a complex relationship, so only engine out emissions are addressed for this analysis. The two dark blue regions are outside of the engine torque envelope.

Studying this map and comparing to the engine efficiency contour plot (Figure 9), the best area of operation for high efficiency and low emissions is below 2000 RPM, from 100 to $200 \mathrm{Nm}$. The issue is that $200 \mathrm{Nm}$ at $2000 \mathrm{RPM}$ only produces about $41 \mathrm{~kW}$ (55 hp), which is not enough power for some reasonable vehicle accelerations, particularly in a $2000 \mathrm{~kg}$ (4400 lb) SUV. So for higher power, efficiency is best and emissions are lower at higher torques (above $150 \mathrm{Nm}$ ) and speeds up to about $4000 \mathrm{RPM}$. If the engine in the REV $\mathrm{LSE}_{\mathrm{L}}$ was downsized below $2.0 \mathrm{~L}$ to optimize for fuel economy, higher average engine loads could lead to operation in high NOx 
producing areas. Although the $\mathrm{REV}_{\mathrm{LSE}}$ could achieve higher fuel economy with a smaller displacement engine, maintaining a reasonably downsized engine helps to avoid high emissions.

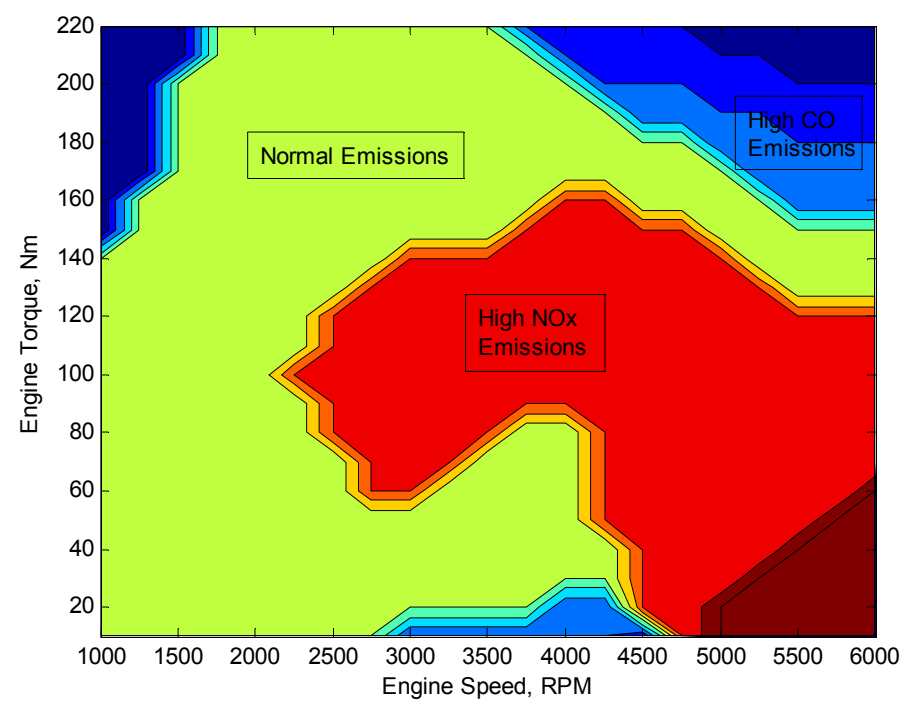

Figure 25. Estimated high emissions regions for the Saab Biopower engine

With vehicle emissions considerations in place, a final overall control strategy should be defined. This overall control strategy should take into account all of the hybrid modes and their associated efficiencies, while weighing the benefits of fuel economy against vehicle emissions and performance. 


\section{Overall Control Strategy}

The overall control strategy for the Equinox $\mathrm{REV}_{\mathrm{LSE}}$, based on the loss calculations explained in this paper, is to increase the average load on the engine while balancing engine generate mode with electric only mode to maintain battery SOC within the desired limits.

\subsection{Control strategy and operational areas}

Increasing the average load on the engine for the SPA HEV is accomplished through three different modes. Engine idle stop decreases the amount of time that the engine is idling, therefore decreasing the amount of time the engine spends at low loads. Idle stop should be used whenever the engine needs to be idled, and this mode can be enabled even while the vehicle is coming to a stop. Engine generate mode increases the engine load while the engine is on by providing an additional load through the BAS to recharge the ESS. The stored power from engine generate mode, and including any power stored through regenerative braking, can be utilized best through the electric only mode. This mode increases the average load on the engine because it provides an efficient way to meet low driver demands without the engine on, and uses stored energy so that the engine load can be increased again for the engine generate mode once the engine is on again. Although the engine assist mode is not considered for efficiency, it is important to assist the engine for vehicle performance. In vehicle testing, a 0-60 mph (0-97 kph) acceleration time of 8.9 seconds (in $110^{\circ} \mathrm{F}$ ambient) was achieved with assist from the RTM, closely matching the stock Equinox performance.

Figure 26 defines what control modes the vehicle should use, based on engine torque and speed, which are a function of driver demand, gear selected, and vehicle speed. These areas are shown as boxes, but the vehicle operation is not this clearly defined by the loss analysis given in this paper; the boxes are simply shown for clarity. At low torques and any speed, the electric only mode can be used with the engine off, provided there is enough stored energy available. The engine generate mode should be used at low to moderate torques and speeds below 3000 RPM. The first tradeoff zone "Tradeoff Zone 1" represents mode selection between the engine generate and electric only modes. Many factors could affect this mode selection, but certainly it will be a function of SOC. The engine only zone is marked primarily by the highest contour of engine efficiency, from $120 \mathrm{Nm}$ to the engine torque envelope and 0-5500 RPM. When the engine is operating in this zone, its efficiency is high enough that the hybrid system should not be used. Tradeoff zone 2 is smaller than zone 1, and represents the transition between generating with the BAS and engine only mode. This mode selection should also consider many factors, including SOC. Engine assist should happen only for peak vehicle performance purposes, right at the engine's torque envelope. Note that the hybrid modes are mostly located outside of the engine's peak efficiency area. Again, the goal of the hybrid system is to increase the average load on the engine, so when there is a high enough load on the engine the hybrid system should not interfere unless necessary. Keeping the engine operation to a full range of torques at low (below 2500 RPM) speeds and then higher (above $120 \mathrm{Nm}$ ) torques should help avoid the high NOx regions illustrated in Figure 25. 


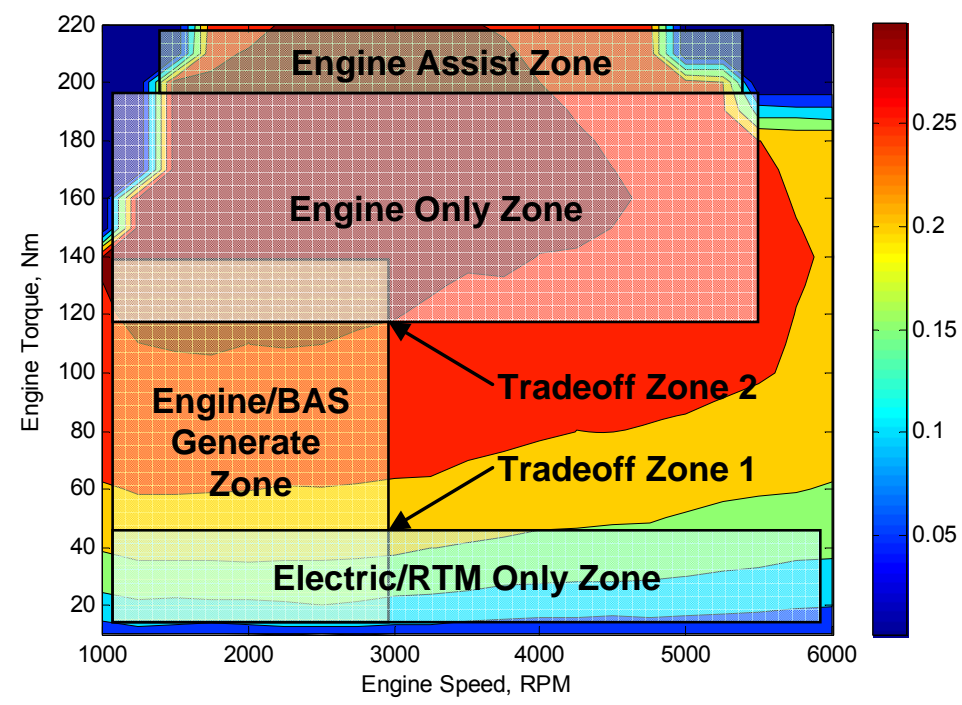

Figure 26. Suggested operational mode areas based on engine torque and speed for the Equinox $\mathrm{REV}_{\mathrm{LSE}}$. The engine efficiency contour plot below shows that this analysis is driven by engine efficiency.

\subsection{Analysis of control strategy over the UDDS}

Using the vehicle simulation software PSAT, a model of the REV $V_{\text {LSE }}$ using the control strategy presented in this section was developed and run over the UDDS (A.1). The stock Equinox was also run over the same drive cycle. The overall result was an increase in fuel economy compared to the stock Equinox, up 3.3 mpgge or about 15\% from 21.3 mpgge to 24.6 mpgge. The main reason for this increase in fuel economy is the increase in torque load on the engine of the $\mathrm{REV}_{\mathrm{LSE}}$. The stock Equinox engine had an average torque load (only considering positive torques) of $46 \mathrm{Nm}$ where the hybrid achieved an average load of $85 \mathrm{Nm}$. Figure 27 is a plot of engine torques and speeds for the stock Equinox over the UDDS, and Figure 28 is the same plot for the $\mathrm{REV}_{\mathrm{LSE}}$. Note how the stock Equinox spends significant time at very low torques due to idling time while running engine accessories, which represent a constant low load on the engine, and the $\mathrm{REV}_{\mathrm{LSE}}$ does not. Also, torques for the drive cycle are generally higher for the SPA $\mathrm{HEV}$ as well.

The fuel economy goal for the $\mathrm{REV}_{\mathrm{LSE}}$ is 30 mpgge, or a $27 \%$ increase in fuel economy over the stock Equinox. Although the results presented here are for a vehicle model and not actual results, more fuel efficiency improvements need to be made to meet the fuel economy goal. These improvements can include better utilization of electric only mode for light engine loads, more time spent with the engine off, and more regenerative brake energy capture. So although this paper presents a successful overall strategy, more work can be done to improve this strategy for the $\mathrm{REV}_{\mathrm{LSE}}$. 


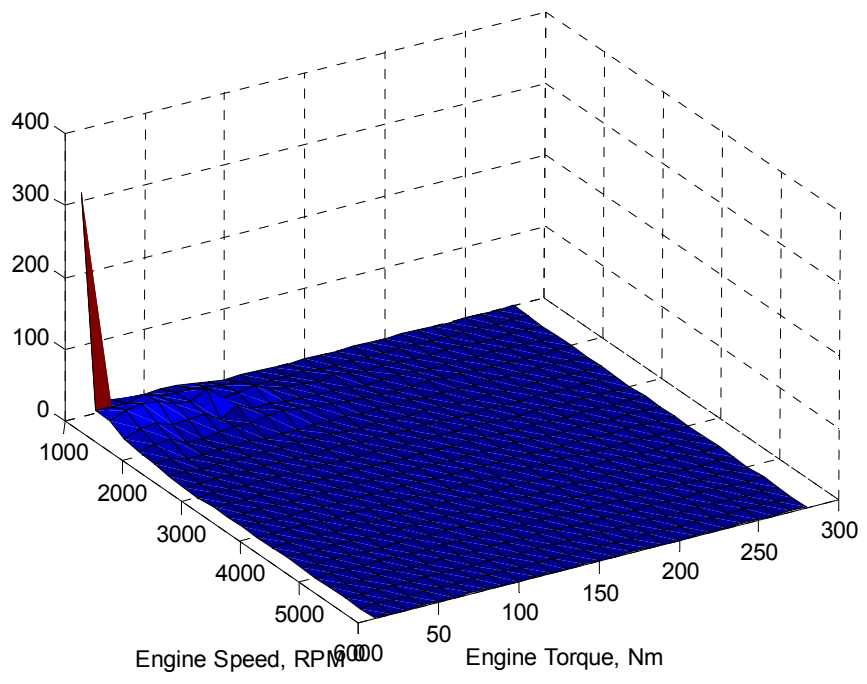

Figure 27. Torque and speed plot of engine operation for the stock Equinox, where the Z-axis represents seconds of operation over the 1372 second UDDS

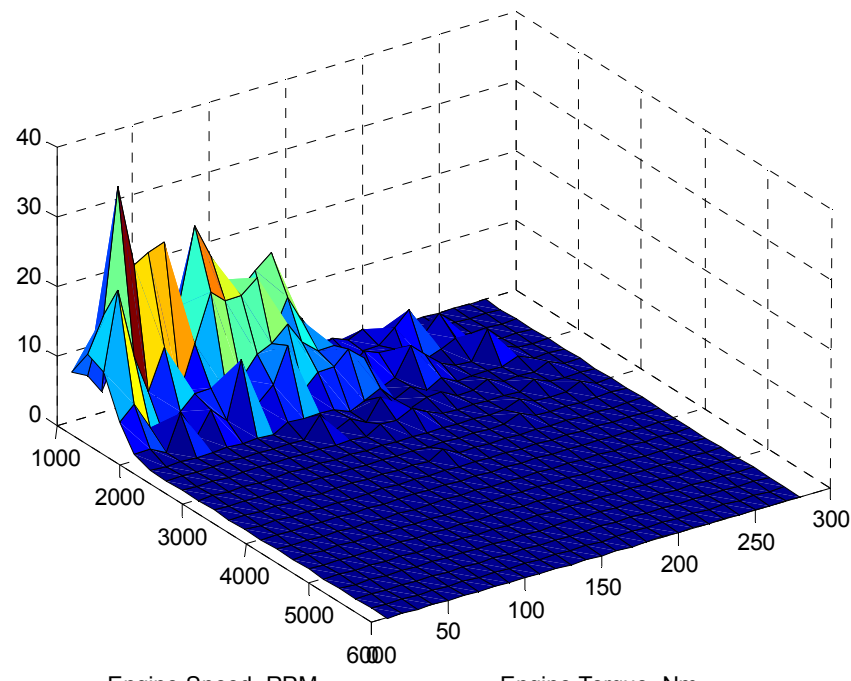

Figure 28. Torque and speed plot of engine operation for the Equinox $\mathrm{REV}_{\mathrm{LSE}}$, where the $\mathrm{Z}$-axis represents seconds of operation over the 1372 second UDDS. Note a lack of low torques and higher torques overall compared to the stock Equinox in Figure 26.

\subsection{Future control strategy development}

Although the calculations and analysis in this paper present an overall control strategy for the SPA HEV, the control strategy can be developed further. Including driveline losses and transmission gear ratios would add further sophistication to this analysis. Vehicle driveability and mode transitions need to be addressed. And now that a fully operational, instrumented test

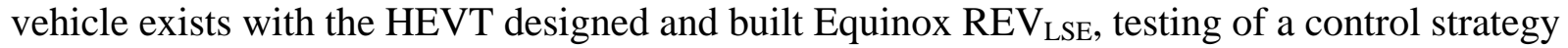
can begin on a real vehicle platform, in parallel with vehicle simulation. 


\section{Conclusion}

This paper presents a control strategy for a SPA HEV through calculating powertrain component losses. The literature review gives a background of hybrid vehicle control publications, and without the SPA HEV addressed or a hybrid analysis based on loss calculations between engine

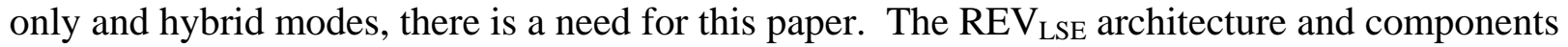
are explained in detail because the analysis presented is tied directly to the efficiencies of the engine, motors, and battery used. Next, the SPA hybrid modes are explained. It is noted that this analysis is based on static operating conditions, and transient or dynamic considerations have not been made. Other assumptions for the calculation model include normal operating conditions for the vehicle powertrain components and that driveline losses are not included. Then the losses for each hybrid mode are calculated, and both the conversion and assist efficiencies are detailed. The conversion efficiency represents the amount of additional fuel required to store a certain amount of energy in the battery, and this marginal efficiency can be higher than peak engine efficiency itself. For the SPA HEV, using the RTM for a generator is not considered due to the additional losses of using the through-the-road generate path, and the potential for driveability issues. The calculation of an average conversion efficiency allows electric only propulsion to be evaluated against the engine, and at low torques the electric motor is more efficient despite the roundtrip losses of the hybrid system and energy storage.

Regenerative braking can contribute a significant amount of energy to the battery, thus offsetting fuel that would have been used to store energy in the battery otherwise.

In summary, the analysis of these calculations provides an operational strategy that ultimately defines how the vehicle should operate, and quantifies why that operation decreases fuel consumption. Because this strategy aims to meet driver demand alone, the strategy would not be affected by different drive cycles. However, a more aggressive drive cycle would use more energy, so fuel economy in miles per gallon would decrease. While decreasing vehicle fuel consumption for a HEV does not depend on the control strategy alone, this strategy does provide a starting point in determining and optimizing fuel efficiency by increasing the average load on the engine through different hybrid operational modes, providing that the losses in the hybrid system are less than those of the engine at the given torque and speed. 


\section{References}

1. U.S. Department of Energy website, "Society of Automotive Engineers World Congress", April 6, 2006, http://www.doe.gov/news/3440.htm

2. Tamai, Goro, et al., "Development of the Hybrid System for the Saturn VUE Hybrid," SAE 2006-01-1502.

3. Miller, John M., "Propulsion Systems for Hybrid Vehicles," London, The Institution of Electrical Engineers, 2004.

4. Muta, Koichiro, et al., "Development of New-Generation Hybrid System THS II - Drastic Improvement of Power Performance and Fuel Economy," SAE 2004-01-0064

5. Hanyu, Tomoyuki, et al., "A Study of the Power Transfer Systems for HEVs," SAE 2006-010668

6. Lo, Chihsiung, et al., "A Simulation Model for the Saturn VUE Green Line Hybrid Vehicle," SAE 2006-01-0441

7. Johnson, Valerie H., et al., "HEV Control Strategy for Real-Time Optimization of Fuel Economy and Emissions," SAE 2000-01-1543

8. Rizzoni, Giorgio, et al., "Unified Modeling of Hybrid Electric Vehicle Drivetrains,"

IEEE/ASME Transactions on Mechatronics, Vol. 4, No. 3, September 1999

9. Boyd, Steven, et al., 2005, "Design and Development Process for the Equinox REV $V_{\text {LSE }}$ E85

Hybrid Electric Vehicle,” SAE paper 2006-01-0514

10. Powertrain Systems Analysis Toolkit (PSAT), http://www.transportation.anl.gov/software/PSAT/index.html

11. Saabnet.com Press, "BioPower Flex-Fuel 9-5,” April 25, 2005, http://www.saabnet.com/tsn/press/041203.html

12. Sloane, Christine S., George M. Claypole, Larry D. Laws, Bruce E. Zemke, "Rationale for Technology Selections in GM's PNGV Precept Concept Car based on Systems Analysis", General Motors Corp., SAE Future Car Congress paper 2000-01-1582 


\section{Appendix A: Engine Operational Points for Drive Cycles}

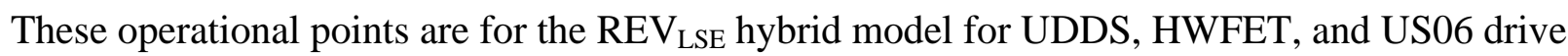
cycles. The on road energy use and test drive operational points are logged from the actual vehicle.

\section{A.1 UDDS}

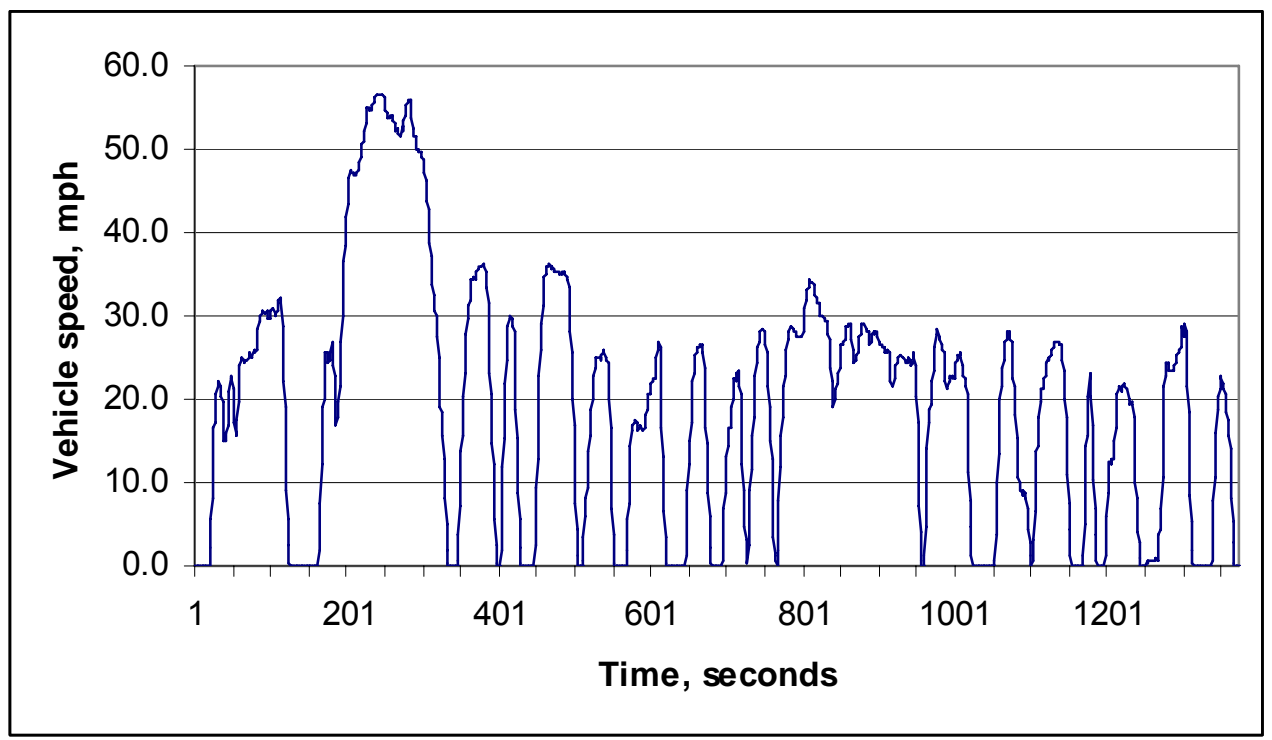



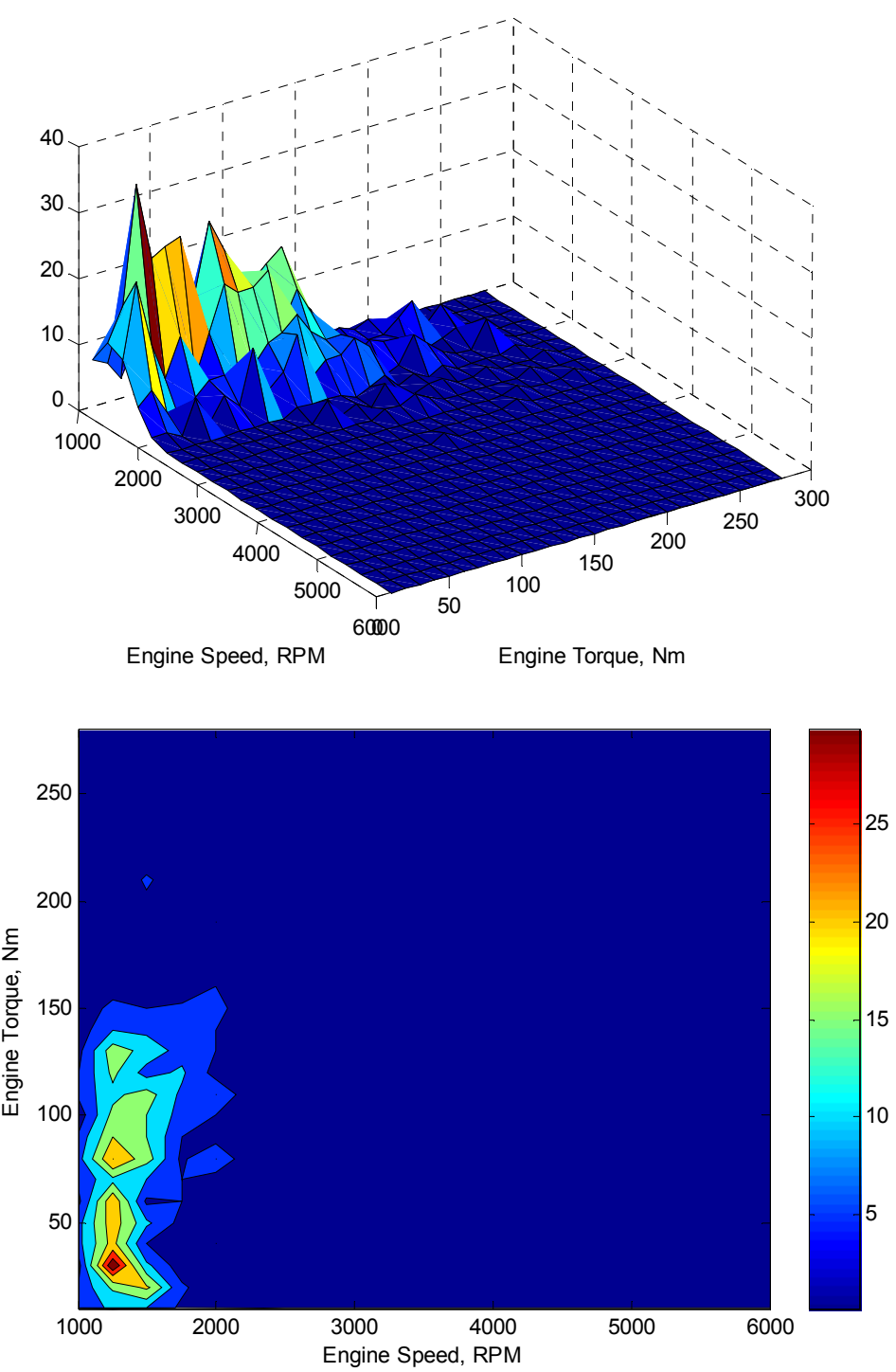


\section{A.2 HWFET}
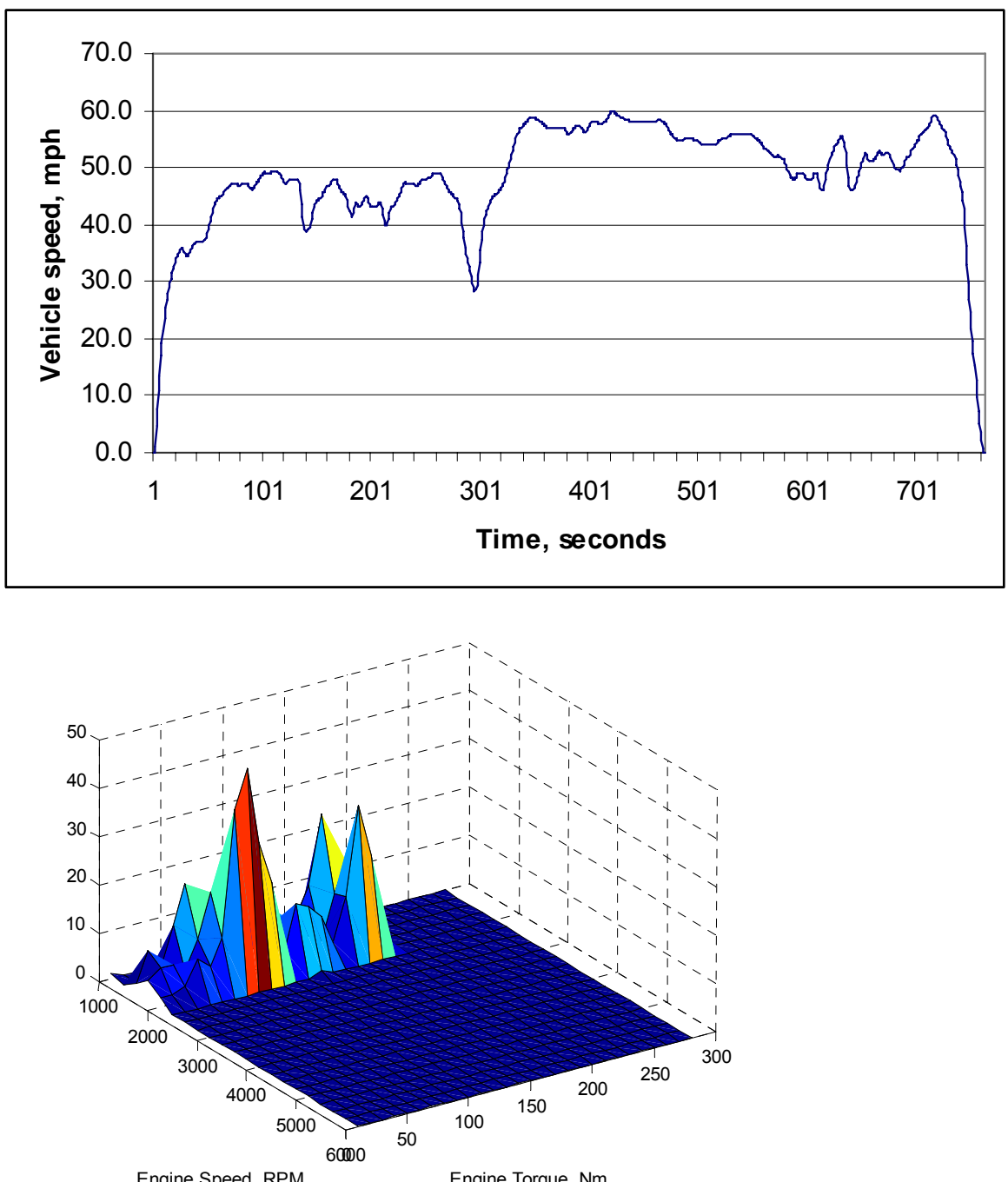

Engine Torque, Nm

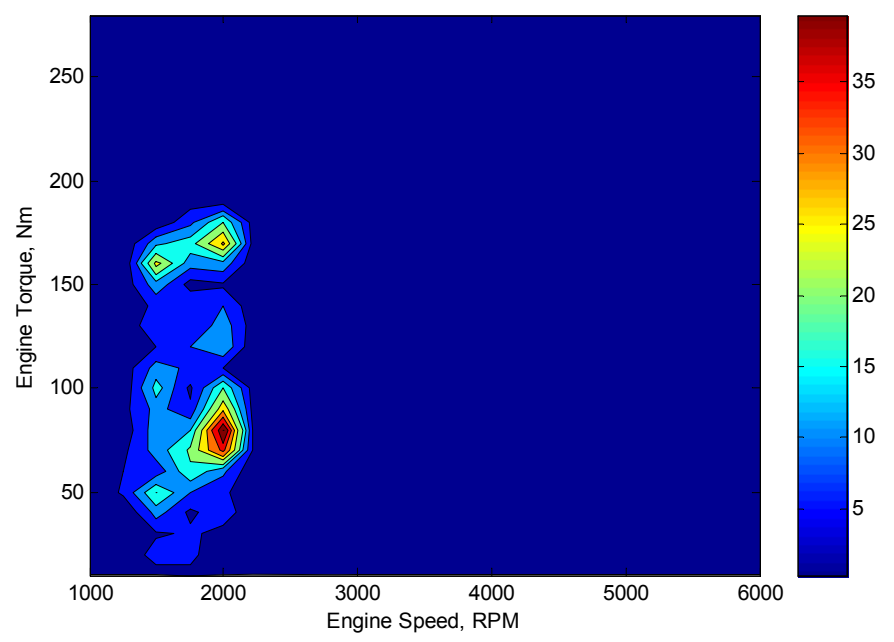




\section{A.3 US06}
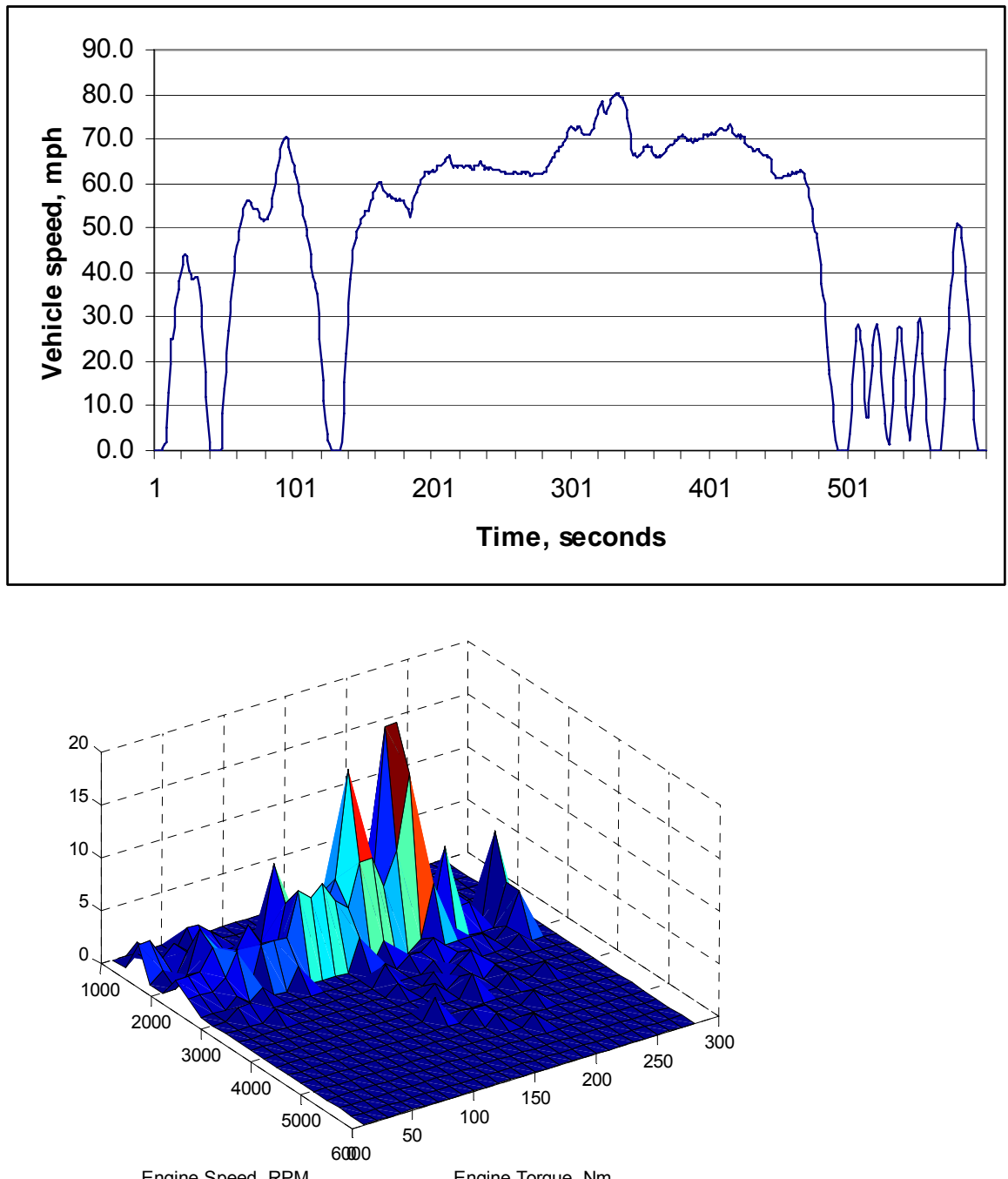

Engine Speed, RPM Engine Torque, Nm

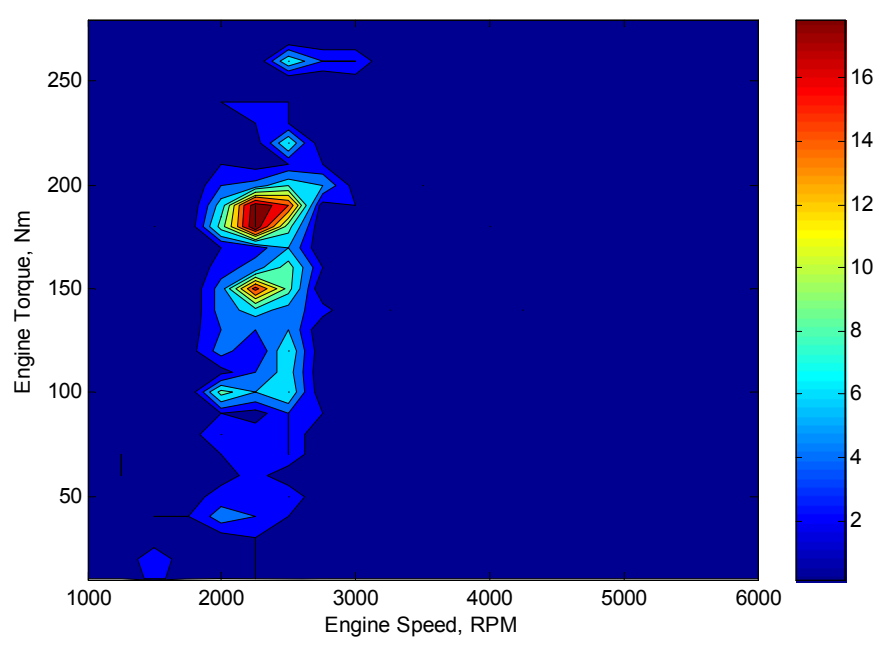




\section{A.4 On road energy use event drive cycle from Challenge X 2006}
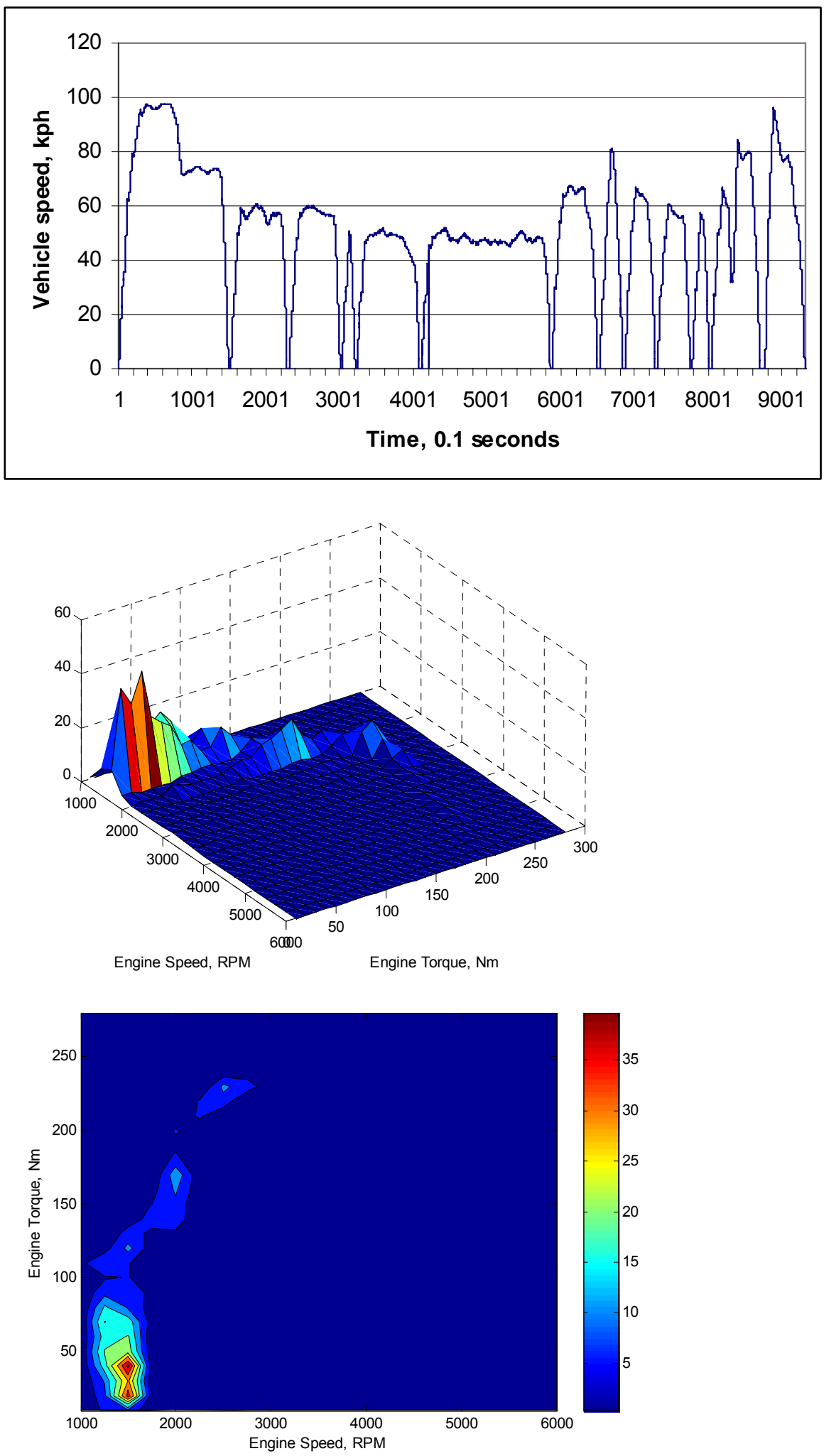
A.5 On road emissions event drive cycle from Challenge $X 2006$
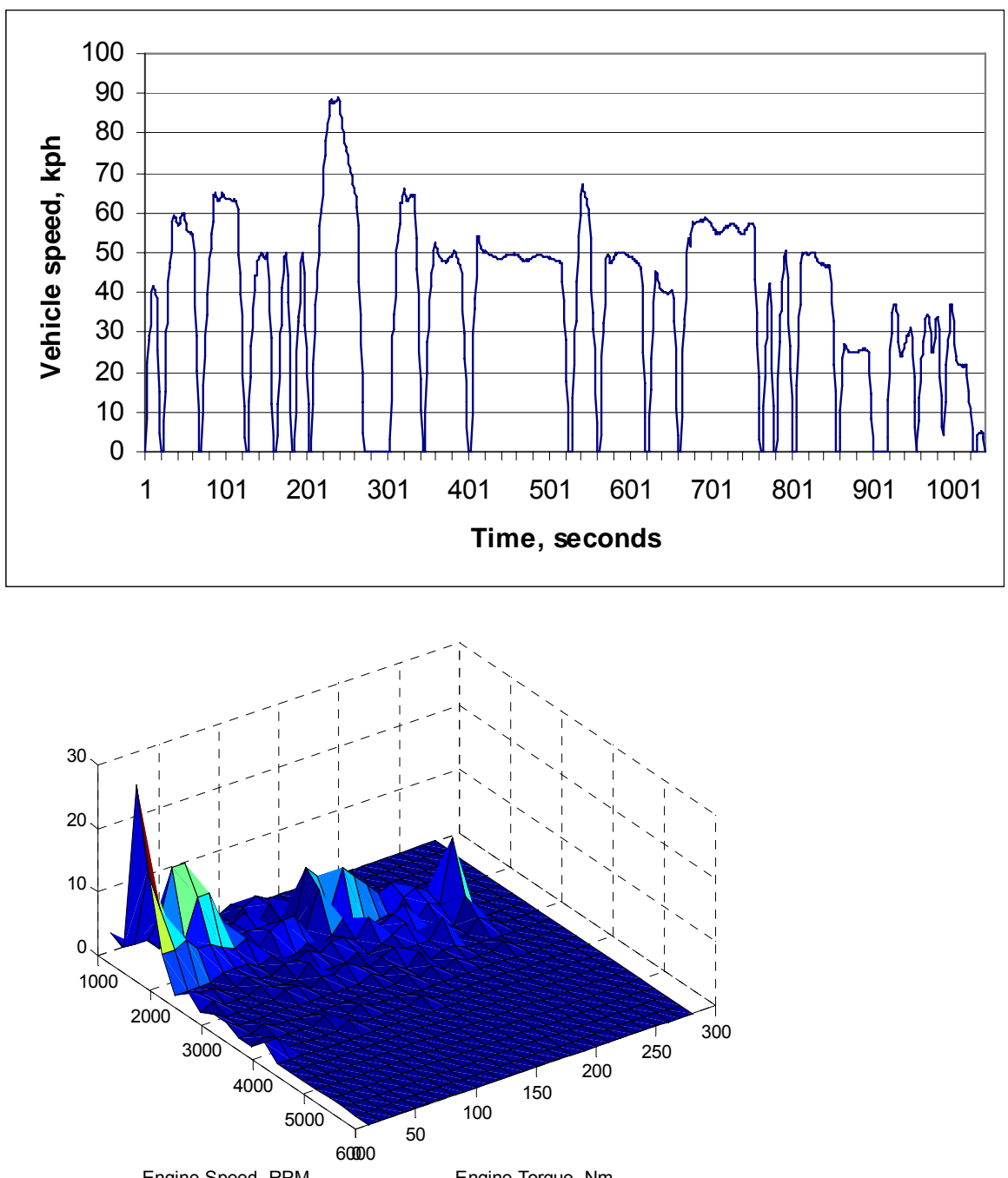

Engine Speed, RPM

Engine Torque, $\mathrm{Nm}$

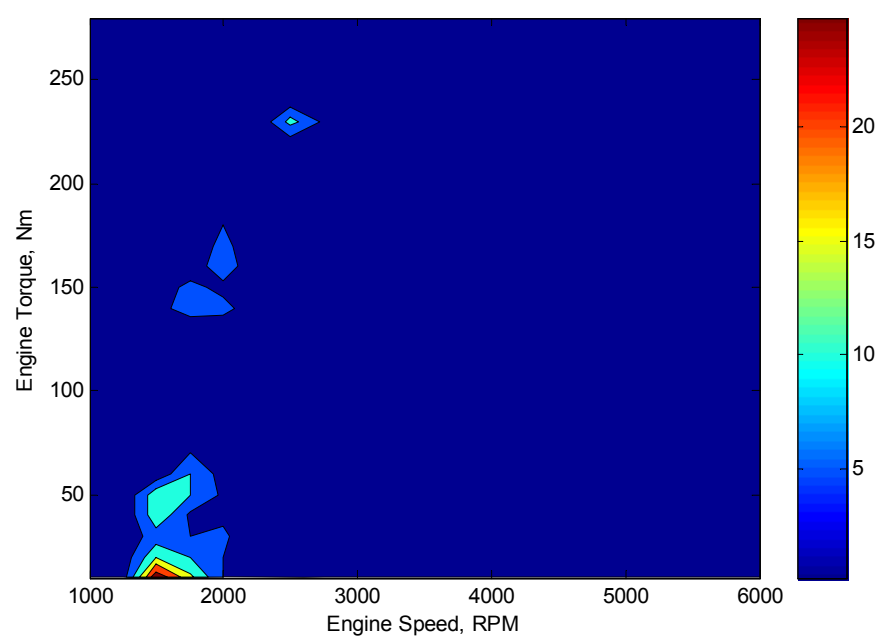




\section{A.6 Vehicle test drive cycle}
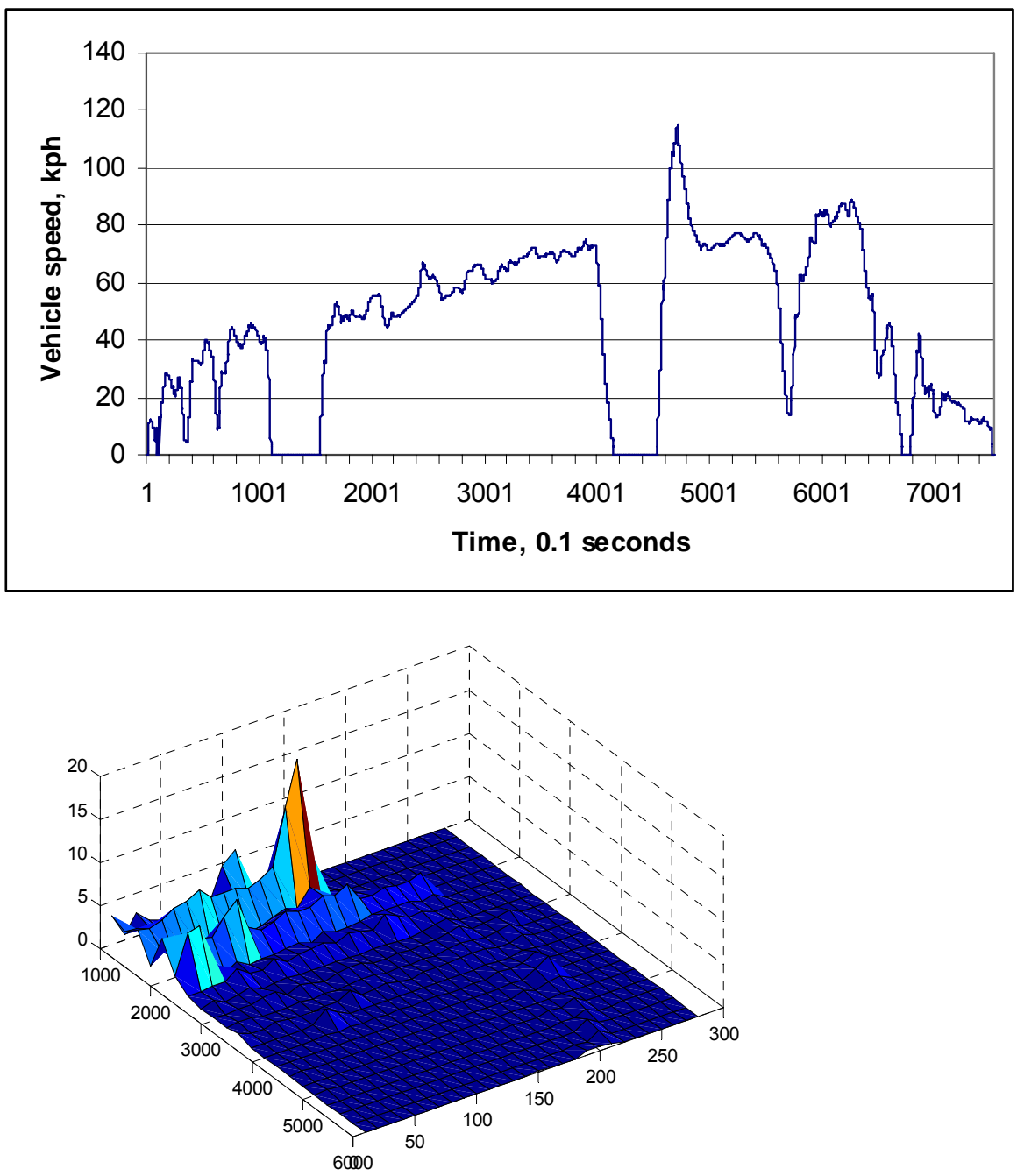

Engine Speed, RPM

Engine Torque, $\mathrm{Nm}$

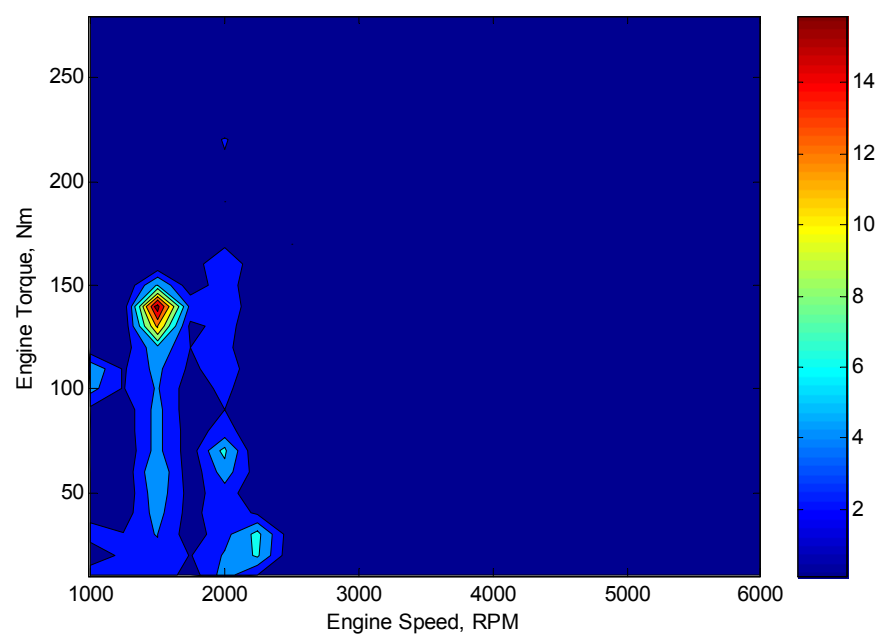




\section{Vita}

\section{Steven Boyd}

Contact:

sb@vt.edu

EDUCATION

M.S. Candidate in Mechanical Engineering, expected completion Dec 2006 GPA 3.3/4.0 Thesis concentrating on hybrid vehicle control system logic

B.S. Mechanical Engineering, May 2004

Virginia Polytechnic Institute and State University (Virginia Tech), Blacksburg, VA

EXPERIENCE Team Leader for Senior Design Team, Hybrid Electric Vehicle Team of Virginia Tech July 2004 - June 2006

- Graduate Teaching assistant for team and overall team leader for 2 years (paid position)

- Led team of 40 students to $1^{\text {st }}$ place overall finish in 2006 Challenge X competition

- Primary author of two technical papers which were judged $1^{\text {st }}$ overall

- Managed vehicle development and design which won lowest emissions and reduced WTW petroleum energy use by $74 \%$

- Also lead team to $4^{\text {th }}$ place overall finish and $2^{\text {nd }}$ best technical reports in cX 2005

\section{HEVT Student Project}

September 1999 - Present

- Extensive electric drive motor system experience

- Hydrogen fuel system design, integration, and testing experience

- High voltage system design and integration experience including vehicle safety systems

Co-op with Philip Morris USA, Richmond, Virginia

August 2001 - December 2002

- Designed three prototype machine systems

- Worked closely with on-site machine shop and parts vendors

- Drafted over 150 CAD drawings

ACTIVITIES \& HONORS

COMPUTER SKILLS
Published SAE paper \#2006-01-0514 "Design and Development Process for the Equinox

REV LSE E85 Hybrid Electric Vehicle", and presented paper at 2006 SAE World Congress

Presented "Design Process, Fuel Selection, and Vehicle Characteristics of the REV LSE E85 Hybrid Electric Vehicle" at 2006 Environment Virginia Conference

Transportation Applied Technology student paper award, Virginia Transportation Research Council (VTRC), September 2005

$\mathrm{CTECH}^{2}$ educational program instructor, July 2005

SAE paper and presentation "Magellan: A Hydrogen Internal Combustion Engine Hybrid Electric Vehicle", SAE World Congress March 2004

Dean's List: Fall 2003, Spring 2004

CAD - Unigraphics, Microstation, and AutoCAD

Matlab - including simulink and stateflow

ADVISOR and PSAT vehicle simulation software

National Instruments LabView 